\title{
Epidemiology of pancreatic cancer : a global approach
}

Citation for published version (APA):

Bosetti, C. (2014). Epidemiology of pancreatic cancer : a global approach. [Doctoral Thesis, Maastricht University]. Datawyse / Universitaire Pers Maastricht. https://doi.org/10.26481/dis.20140903cb

Document status and date:

Published: 01/01/2014

DOI:

10.26481/dis.20140903cb

Document Version:

Publisher's PDF, also known as Version of record

\section{Please check the document version of this publication:}

- A submitted manuscript is the version of the article upon submission and before peer-review. There can be important differences between the submitted version and the official published version of record.

People interested in the research are advised to contact the author for the final version of the publication, or visit the DOI to the publisher's website.

- The final author version and the galley proof are versions of the publication after peer review.

- The final published version features the final layout of the paper including the volume, issue and page numbers.

Link to publication

\footnotetext{
General rights rights.

- You may freely distribute the URL identifying the publication in the public portal. please follow below link for the End User Agreement:

www.umlib.nl/taverne-license

Take down policy

If you believe that this document breaches copyright please contact us at:

repository@maastrichtuniversity.nl

providing details and we will investigate your claim.
}

Copyright and moral rights for the publications made accessible in the public portal are retained by the authors and/or other copyright owners and it is a condition of accessing publications that users recognise and abide by the legal requirements associated with these

- Users may download and print one copy of any publication from the public portal for the purpose of private study or research.

- You may not further distribute the material or use it for any profit-making activity or commercial gain

If the publication is distributed under the terms of Article $25 \mathrm{fa}$ of the Dutch Copyright Act, indicated by the "Taverne" license above, 


\section{EPIDEMIOLOGY OF PANCREATIC CANCER A GLOBAL APPROACH}

Cristina Bosetti 
Epidemiology of Pancreatic Cancer: a Global Approach

Cristina Bosetti

Lay-out: Cristina Bosetti

Printed by: Datawyse - Universitaire Pers Maastricht

\section{ISBN 9789461593535}

(C) Copyright Cristina Bosetti, 2014

All rights reserved. No part of this dissertation may be reproduced or transmitted in any form or by any means, electronic or mechanical, including photocopying, recording or any information storage or retrieval system, without permission in writing from the author, or, when appropriate, from the publishers of the publications. 


\title{
Epidemiology of PANCREatic CANCER: A Global Approach
}

\author{
DISSERTATION \\ to obtain the degree of Doctor at Maastricht University, \\ on the authority of the Rector Magnificus, \\ Prof. dr. L.L.G. Soete, \\ in accordance with the decision of the Board of Deans, \\ to be defended in public on \\ Wednesday September 3 2014, at 12.00 hours \\ by \\ Cristina Bosetti
}

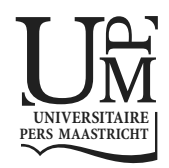




\section{Supervisors}

Prof.dr. M.P.A. Zeegers

Prof.dr. C. La Vecchia (Università degli Studi di Milano, Milan, Italy)

\section{Assessment Committee}

Prof.dr. A.A.M. Masclee (chair)

Prof.dr. P.C. Dagnelie

Prof.dr.ir. E.J.M. Feskens (Wageningen University, The Netherlands)

Prof.dr. T.S. Nawrot (Hasselt University, Belgium)

Prof.dr.ir. P.A. van den Brandt

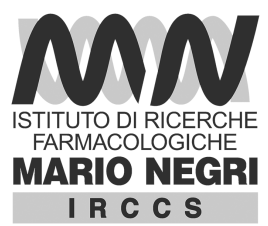

The studies conducted within this dissertation were performed at the Department of Epidemiology, IRCCS - Istituto di Ricerche Farmacologiche "Mario Negri", Milan, Italy in collaboration with the Complex Genetics Department of Genetics \& Cell Biology, Nutrition and Toxicology Research Institute Maastricht (NUTRIM), Maastricht University Medical Centre, Maastricht, the Netherlands. 


\section{Table of contents}

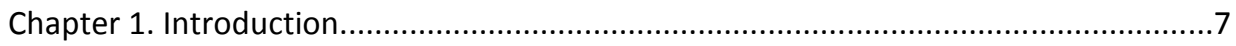

Chapter 2. Pancreatic Cancer: Overview of Descriptive Epidemiology............................15

Chapter 3. The International Pancreatic Cancer Case-Control Consortium..................31

Chapter 3.1. Cigarette Smoking and Pancreatic Cancer: an Analysis from the International Pancreatic Cancer Case-Control Consortium...............................................33

Chapter 3.2. Ulcer, Gastric Surgery and Pancreatic Cancer Risk: an Analysis from the International Pancreatic Cancer Case-Control Consortium...............................................53

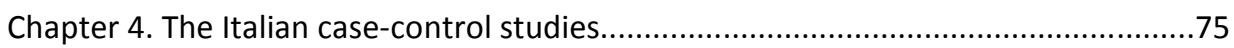

Chapter 4.1. Diabetes Mellitus and Cancer Risk in a Network of Case-Control Studies77

Chapter 4.2. The Role of the Mediterranean Diet on the Risk of Pancreatic Cancer.....95

Chapter 4.3. Nutrient-Based Dietary Patterns and Pancreatic Cancer Risk....................111

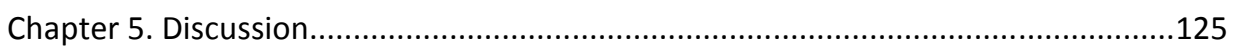

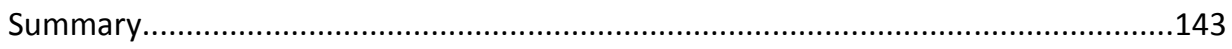

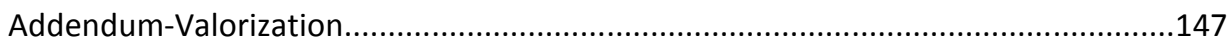

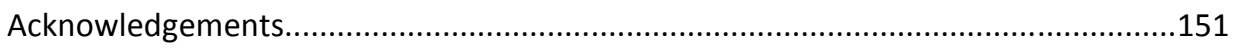

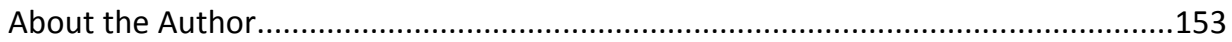



Chapter 1. Introduction 
Pancreatic cancer is the 13th most common cause of cancer and represents the 7th most frequent cause of cancer death worldwide [1, 2]. In Italy, it ranks as the 9th most frequent cancer and the 6th more frequent cause of cancer death, with 10,446 pancreatic cancers and 9684 pancreatic cancer deaths in 2008 [1, 2]. Higher rates have been reported in high-income areas, while rates are intermediate in South and Central America and eastern Asia, and lowest in low-income areas. Men have an approximately 1.5 -fold greater rates than women [3]. Pancreatic cancer is a highly aggressive cancer and its survival has remained very low over the last few decades (5year relative survival $<5 \%)[4,5]$.

Most pancreatic cancers arise from the exocrine pancreas, while endocrine subtypes, such as Islet-cell tumors, sarcomas, and lymphomas, are very uncommon [3]. Approximately $90 \%$ of pancreatic neoplasms are adenocarcinomas, two-thirds of which occur in the head of the organ with the remainder in the body or tail.

Pancreatic cancer is commonly diagnosed through imaging techniques, including, transcutaneous ultrasound, computed tomography (CT), magnetic resonance imaging, and more recently endoscopic ultrasound (EUS) [6, 7]. Biopsies in patients with resectable tumors can be taken during surgery, while for patients who are not suitable candidates for radical surgery, the most common approaches to obtain a tissue are by CT-guided biopsy, endoscopic retrograde cholangiopancreatography, or EUS with fineneedle aspiration. Because the organ is inconveniently located and because of the morbidity associated with biopsy, pancreatic cancer continues to have among the lowest proportion of histologically verified cases among major cancers [3].

Treatment for patients with early stage pancreatic cancer (TNM stage I and stage II) includes radical surgery, i.e., pancreatic resection according to Whipple procedure, distal pancreatectomy, or total pancreatectomy [6]. Only a low proportion of patients (15-20\%), however, present with a locally resectable tumor, while most cases present with unresectable tumors (TNM stage III and IV). Chemotherapy alone (e.g., 5fluorouracil, gemcitabine or combination chemotherapy regimens) or with radiotherapy is suggested in patients with resected pancreatic cancer, although improvement in survival is still very poor [8]. Chemotherapy alone or in combination with radiotherapy might also be used in non resectable tumors to relieve some of the symptoms.

Up to $10 \%$ of pancreatic cancer patients report a family history of the disease [3]. A family history of pancreatic cancer in first-degree relatives is associated to a 2 to 4 -fold excess risk of pancreatic cancer $[9,10]$, the risk increasing with the number of relatives affected. This familial clustering may be due to inherited mutations in specific genes [11], to polymorphic mutations in genes involved in tobacco or alcohol metabolisms, or to shared environment exposures.

Among environmental factors, cigarette smoking is the major established risk factor for pancreatic cancer, although it explains a limited proportion of all cancers only [3, 
12-16]. Most epidemiological studies reported that current cigarette smokers have about a 2-fold increased risk of pancreatic cancer as compared with never smokers. With reference to other types of smoking, cigar smoking has been associated to a 50 $60 \%$ increased risk of pancreatic cancer, while pipe smoking has been associated to a lower excess risk, and no association was found for smokeless tobacco $[13,17]$.

Other recognized risk factors are overweight/obesity [18-21] and diabetes mellitus [2224] - that is a correlate of overweight -, the RR of pancreatic cancer being approximately 1.5 for obese subjects, and between 2 and 3 for diabetics.

Patients with chronic pancreatitis have also been reported to have an increased risk of developing pancreatic cancer $[25,26]$. Other medical conditions, such as gallstones, cholecystectomy, peptic ulcer, and peptic ulcer surgery, have been investigated in relation to pancreatic cancer but results have been inconsistent [26].

Epidemiological studies have extensively analyzed the relation between diet and pancreatic cancer, but no consistent association has been found except for a possible increased risk for low intake of fruit and vegetables and high intake of meat $[21,27]$. Low-to-moderate levels of alcohol consumption are not associated to pancreatic cancer risk, but heavy consumption is associated to an approximate $60 \%$ excess risk $[28,29]$.

\section{Aims of the dissertation}

In order to further address some open issues in the etiology of this neoplasm, within this dissertation I considered various epidemiological aspects of pancreatic cancer, including a descriptive overview of mortality trends in Europe and in selected areas of the world over the last few decades and a further evaluation of selected lifestyle and environmental risk factors for this neoplasm. In particular, the work of the dissertation was focused on the quantification of dose-risk and duration-risk relationships with cigarette smoking, the role of diabetes, with particular reference to time since diagnosis, the association with ulcer and its treatments, and the identification of favorable/unfavorable dietary patterns through the adoption of various methods to combine different foods and nutrients.

\section{World Health Organization data}

Data used for the descriptive analyses of mortality from pancreatic cancer were derived from the online databank of the World Health Organization Statistical Information System (WHOSIS) containing, in a standard format, numbers of deaths by cause, sex, age, calendar year and country from major selected cancer sites and a few other major causes for the European countries and about 30 extra-European countries [30]. The database also comprises estimates of the resident population in the various countries and calendar years, starting from 1950. This data bank is periodically 
updated with the new data for the most recent years, as they become available at WHOSIS.

The databank has long been used by the Department of Epidemiology of the Mario Negri Institute, Milan to monitor cancer mortality in Europe and other selected areas of the world. Within this project, I have collaborated in the development of programs to extract the raw data from the WHO databank, to compute sex-, age-specific rates and age-standardized rates, and to produce tables and graphs.

\section{International Pancreatic Cancer Case Control Consortium (PanC4).}

For the investigation of cigarette smoking and ulcer, I used data from the International Pancreatic Cancer Case Control Consortium (PanC4). The PanC4 is a Consortium of over 12 case-control studies of pancreatic cancer which involves a group of scientists from diverse biomedical disciplines (Epidemiology, Genetics, Biostatistics, Bioinformatics, Molecular Biology, Gastroenterology, Surgery) across the world. It was set up in February 2006 by Dr. Paolo Boffetta (at that time at the International Agency for Research on Cancer, IARC, Lyon, France) with the aim of improving the understanding of the causes of pancreatic cancer through pooled analyses of data from these case-control studies (http://panc4.org/index.htm). The Consortium also includes data from two case-control studies conducted in Italy by the Department of Epidemiology of the Mario Negri Institute, Milan in the late 1980's and late 1990's, respectively.

\section{Italian case-control studies}

For the investigation of diabetes and dietary correlates of pancreatic cancer I used data from the two Italian case-control studies. These studies are part of a network of hospital-based case-control studies conducted in Italy and Switzerland since the early 1980 's by the Department of Epidemiology of the Mario Negri Institute, Milan, to investigate the role of various environmental risk factors for common neoplasms. These studies were conducted in major general and teaching hospitals of the study areas, and included incident, histologically confirmed cancer cases and a group of controls, selected among patients admitted to the same hospitals as cases for a series of acute, non-neoplastic conditions, not related to known risk factors of the cancers under investigation. Similar protocols and questionnaires have been used to assess the role of various lifestyle and environmental exposures. Since the 1990's, a more detailed questionnaire was adopted, including a validated and reproducible food frequency questionnaire to investigate the patients' usual diet. The two case-control studies on pancreatic cancer were conducted in Italy respectively between 1983 and 1992 on 362 incident cases of pancreatic cancer cases and 1,552 controls and between 1992 and 2008 on 326 incident cases and 652 controls. 


\section{Outline of the dissertation}

The global overview of recent trends in pancreatic cancer mortality in Europe and selected other areas of the World is provided in Chapter 2. Although this overview has mainly a descriptive aim, a few general comments and selected relevant references were included in order to assist reading and interpreting such trends in terms of changes in risk factors exposures and in disease treatment over time.

Chapter 3.1 presents the quantification of the role of cigarette smoking on pancreatic cancer and its dos-e and duration-risk relationships within the PanC4 study.

The results of the analyses on the role of ulcer and its treatments on pancreatic cancer within the PanC4 study are given in Chapter 3.2.

The quantification role of diabetes on pancreatic cancer in one of the case-control study conducted in the Italian population is given in Chapter 4.1.

Chapter 4.2 presents the relation between pancreatic cancer and adherence to the Mediterranean diet, measured using a priori defined scores proposed in the literature and adopted in various other epidemiological studies.

The role of combinations of foods and nutrients on pancreatic cancer has also been analyzed in Chapter 4.3 through the identification of a posteriori dietary patterns built on the specific dietary data under consideration.

Chapter 5 summarizes and discusses the results of the overall work done in the dissertation. 


\section{References}

1. Ferlay J, Randi G, Bosetti C et al. Declining mortality from bladder cancer in Europe. BJU Int 2008; 101: 11-19.

2. Ferlay J, Shin HR, Bray F et al. GLOBOCAN 2008, Cancer Incidence and Mortality Worldwide: IARC CancerBase No. 10 [Internet]. Available at: http://globocan.iarc.fr

3. Anderson KE, Mack TM, Silverman DT. Cancer of the pancreas. In Schottenfeld D, Fraumeni JFJr (eds): Cancer Epidemiology and Prevention, Edition 3th. New York: Oxford University Press 2006; 721-762.

4. Karim-Kos HE, de Vries E, Soerjomataram I et al. Recent trends of cancer in Europe: a combined approach of incidence, survival and mortality for 17 cancer sites since the 1990s. Eur J Cancer 2008; 44: 1345-1389.

5. Klint A, Engholm G, Storm HH et al. Trends in survival of patients diagnosed with cancer of the digestive organs in the Nordic countries 1964-2003 followed up to the end of 2006. Acta Oncol 2010; 49: 578-607.

6. Hidalgo M. Pancreatic cancer. N Engl J Med 2010; 362: 1605-1617.

7. Sharma C, Eltawil KM, Renfrew PD et al. Advances in diagnosis, treatment and palliation of pancreatic carcinoma: 1990-2010. World J Gastroenterol 2011; 17: 867-897.

8. Conroy $T$, Desseigne $F$, Ychou $M$ et al. FOLFIRINOX versus gemcitabine for metastatic pancreatic cancer. N Engl J Med 2011; 364: 1817-1825.

9. Hart AR, Kennedy $H$, Harvey I. Pancreatic cancer: a review of the evidence on causation. Clin Gastroenterol Hepatol 2008; 6: 275-282.

10. Permuth-Wey J, Egan KM. Family history is a significant risk factor for pancreatic cancer: results from a systematic review and meta-analysis. Fam Cancer 2009; 8: 109-117.

11. Landi S. Genetic predisposition and environmental risk factors to pancreatic cancer: A review of the literature. Mutat Res 2009; 681: 299-307.

12. IARC. IARC Monographs on the evaluation of carcinogenic risks to humans. Vol. 83. Tobacco smoke and involuntary smoking. Lyon: International Agency for Research on Cancer 2004.

13. Iodice S, Gandini S, Maisonneuve P, Lowenfels AB. Tobacco and the risk of pancreatic cancer: a review and meta-analysis. Langenbecks Arch Surg 2008; 393: 535-545.

14. Secretan B, Straif $K$, Baan R et al. A review of human carcinogens--Part E: tobacco, areca nut, alcohol, coal smoke, and salted fish. Lancet Oncol 2009; 10: 1033-1034.

15. Lynch SM, Vrieling A, Lubin JH et al. Cigarette smoking and pancreatic cancer: a pooled analysis from the pancreatic cancer cohort consortium. Am J Epidemiol 2009; 170: 403-413. 
16. IARC. IARC Monographs on the evaluation of carcinogenic risks to humans. Vol. 100E. Personal Habits and Indoor Combustions. Lyon: International Agency for Research on Cancer 2012.

17. Bertuccio P, La Vecchia C, Silverman DT et al. Cigar and pipe smoking, smokeless tobacco use and pancreatic cancer: an analysis from the International Pancreatic Cancer Case-Control Consortium (PanC4). Ann Oncol 2011; 22: 1420-1426.

18. Calle EE, Rodriguez C, Walker-Thurmond K, Thun MJ. Overweight, obesity, and mortality from cancer in a prospectively studied cohort of U.S. adults. N Engl J Med 2003; 348: 1625-1638.

19. Larsson SC, Orsini N, Wolk A. Body mass index and pancreatic cancer risk: A metaanalysis of prospective studies. Int J Cancer 2007; 120: 1993-1998.

20. Renehan AG, Tyson M, Egger $M$ et al. Body-mass index and incidence of cancer: a systematic review and meta-analysis of prospective observational studies. Lancet 2008; 371: 569-578.

21. World Cancer Research Fund and American Institute for Cancer Research. Food, Nutrition, Physical Activity and Pancreatic Cancer. Washington DC: American Institute for Cancer Research 2012.

22. Huxley R, Ansary-Moghaddam A, Berrington de Gonzalez A et al. Type-Il diabetes and pancreatic cancer: a meta-analysis of 36 studies. Br J Cancer 2005; 92: 20762083.

23. Ben $Q, X u M, N i n g ~ X$ et al. Diabetes mellitus and risk of pancreatic cancer: A metaanalysis of cohort studies. Eur J Cancer 2011; 47: 1928-1937.

24. Eijgenraam $\mathrm{P}$, Heinen $\mathrm{MM}$, Verhage BA et al. Diabetes type II, other medical conditions and pancreatic cancer risk: a prospective study in The Netherlands. $\mathrm{Br}$ J Cancer 2013.

25. Duell EJ, Lucenteforte E, Olson SH et al. Pancreatitis and pancreatic cancer risk: a pooled analysis in the International Pancreatic Cancer Case-Control Consortium (PanC4). Ann Oncol 2012; 23: 2964-2970.

26. Olson SH. Selected medical conditions and risk of pancreatic cancer. Mol Carcinog 2012; 51: 75-97.

27. World Cancer Research Fund and American Institute for Cancer Research. Food, Nutrition, Physical Activity and the Prevention of Cancer: a Global Perspective. Washington DC: American Institute for Cancer Research 2007.

28. Tramacere I, Scotti L, Jenab $M$ et al. Alcohol drinking and pancreatic cancer risk: a meta-analysis of the dose-risk relation. Int J Cancer 2010; 126: 1474-1486.

29. Lucenteforte E, La Vecchia C, Silverman D et al. Alcohol consumption and pancreatic cancer: a pooled analysis in the International Pancreatic Cancer CaseControl Consortium (PanC4). Ann Oncol 2012; 23: 374-382.

30. World Health Organization Statistical Information System. World Health Statistics 2012. Part II. Highlighted topics Available at: 
http://www.who.int/gho/publications/world_health_statistics/EN_WHS2012_Par t2.pdf Last accessed June 2013. 


\title{
Chapter 2. Pancreatic Cancer: Overview OF DESCRIPTIVE EPIDEMIOLOGY
}

\author{
Cristina Bosetti, Paola Bertuccio, Eva Negri, Carlo La Vecchia, \\ Maurice P. Zeegers, Paolo Boffetta
}

Molecular Carcinogenesis 2012; 51: 3-13 


\begin{abstract}
Pancreatic cancer mortality rates have been increasing in high-income countries between the 1950's and the 1980's, and have leveled off or declined thereafter, particularly in men. To provide a global overview of recent pancreatic cancer mortality, we analyzed official death certification data derived from the World Health Organization for 35 European countries and 19 other countries over the period 19802007. In 2007, the highest mortality rates from pancreatic cancer were in the Baltic countries, and some central/eastern and northern European countries (over 9.5/100,000 men and 6/100,000 women), while the lowest ones were in Latin America and Hong Kong (below 5/100,000 men and 3/100,000 women). Japan, the USA, Russia and the European Union (EU), as well as the largest countries in the EU, had rates 7$9 / 100,000$ men and 5-6/100,000 women. In the early 2000's, rates have been approximately stable in many European countries, as in the USA, Japan and Australia. In Nordic countries and the UK, where declines in rates have been observed since the 1980 's, mortality from pancreatic cancer seems to have reached a plateau, and have tended to rise over most recent calendar years. Some persisting rises were still found in men from a few countries of southern and central/eastern Europe (with low rates in the past), as well as in the EU overall, and in women from European and Asian countries. Recent trends were generally more favorable in young adults (30-49 years), suggesting that overall trends are likely to improve in the next future.
\end{abstract}




\section{Introduction}

Pancreatic cancer is an highly aggressive cancer and represents the $7^{\text {th }}$ most frequent cause of cancer death worldwide (the $3^{\text {th }}$ one in the USA and the European Union, EU) with an estimated 266,000 deaths, out 277,000 new cases in the world in 2008 [1, 2]. Rates are higher in more high-income areas of the world, intermediate in South and Central America and eastern Asia, and lowest in low-income areas.

Mortality from pancreatic cancer has been increasing in high-income countries between the 1950's and the 1980's, and has been leveling off or declined thereafter, particularly in men. In men from the EU, rates increased up to the late 1980's and leveled off thereafter around 7.5/100,000 (age-standardized rate, world standard population), while they modestly rose in women, to reach $5 / 100,000$ in the early 2000's [3, 4]. In the USA, mortality from pancreatic cancer has been stable or declining since the mid 1970's in men, but it has been slightly increasing up to more recent calendar years in women [5]. In Japan rates leveled off since the late 1980's in men (around 8.7/100,000 in 2004), but less so in women $(5.1 / 100,000)$ [6].

To provide a global overview of recent rates of pancreatic cancer mortality in Europe and other areas of the world, we considered mortality up to 2007 in 54 countries, and the EU as a whole. We also used joinpoint regression [7] to analyze trends in pancreatic mortality between 1980 and 2007 for the 19 major countries considered.

\section{Materials and methods}

Official death certification data from pancreatic cancer for 35 European countries and other 19 countries in the world providing reliable data over the period 1980-2007 were derived from the World Health Organization (WHO) database [8].

In Europe, we excluded Albania, Macedonia and Republic of Moldova whose national coverage was below 90\%, and Cyprus, whose data were available only for a few recent years in the WHO database. Countries of the former Soviet were also not included because of the generally low national coverage. Israel was included among European countries, according to the WHO definition. The EU was defined as the 27 member states as in 2004, excluding Cyprus. For the Americas, only 13 countries with more than 2 million inhabitants and with sufficiently detailed age-stratified mortality data were included (i.e., Canada and the USA, Argentina, Brazil, Chile, Colombia, Costa Rica, Cuba, Ecuador, Mexico, Puerto Rico, Uruguay and Venezuela). Mortality data from pancreatic cancer were also available for 4 Asian countries (i.e., Hong Kong, Japan, Republic of Korea and Singapore), and for Australia and New Zealand. In a few countries, data were missing for one or more calendar years. No extrapolation was made for missing years.

In the 1980s, most countries utilized the 9th Revision of the International Classification of Diseases (ICD) [9], but some still used the $8^{\text {th }}$ Revision [10]; in the 1990's, most 
countries adopted the $10^{\text {th }}$ Revision [11]. Since differences between various revisions were generally minor, pancreatic cancer deaths were recoded for all countries according to the $10^{\text {th }}$ Revision of the ICD (code=C25).

Estimates of the resident populations for the corresponding calendar periods, based on official censuses, were extracted from the same WHO database [8]. For the Americas, data from certain years onwards were not available in the WHO database and were thus extracted from the Pan American Health Organization (PAHO) database [12]. Since the PAHO publication provided sex and 5-years age groups (from 0-4 to 80 or more years) for selected years only (i.e., 1995, 2000, 2005), sex- and age-specific data for missing years were estimated by interpolation using the last available year in the WHO database.

From the matrices of certified deaths and resident population, we computed agespecific rates for each calendar year, and age group (from 0, 1-4 to 85 or more years, except for selected Latin American countries (Argentina, Chile, Costa Rica, Cuba and Mexico) for which 80 or more years was the last age group available. Age-standardized mortality rates per 100,000 men and women were computed using the direct method on the basis of the world standard population [13] at all ages and, for selected countries, in population aged 30-49 years.

To identify significant changes in mortality trends for 19 major countries, we performed joinpoint regression analysis using the "Joinpoint" software from the Surveillance Research Program of the US National Cancer Institute [14]. This allows to identify years where a significant change in the linear slope of the trend (on a logscale) is detected over the study period [7]. The estimated annual percent change (APC) was then computed for each of the identified trends by fitting a regression line to the natural logarithm of the rates using calendar year as a regressor variable (i.e., given $\mathrm{y}=\mathrm{a}+\mathrm{bx}$, where $\mathrm{y}=\ln ($ rate $)$ and $\mathrm{x}=$ calendar year, the APC is estimated as $100 *\left(e^{\mathrm{b}}\right.$ 1)).

\section{Results}

Table 1 gives the overall age-standardized mortality rates from pancreatic cancer per 100,000 men and women in selected European countries and in the EU as a whole around 1997 (1995-99), 2002 (2000-2004) and in 2007 (when available), and the corresponding percent changes.

In the EU, mortality rates in men were constant between 1997 and 2002 around 7.5$7.6 / 100,000$, and increased to $8 / 100,000$ in 2006. In countries of northern Europe, including the United Kingdom and Sweden where mortality from pancreatic cancer was high in the past, rates have been declining between 1997 and 2002, while a reversal of trends was observed in the last 5 years. Trends were declining in countries of central/eastern Europe with highest rates, such as Croatia, the Czech Republic, and 
Hungary, but not in Russia, where mortality rates reached 8.5/100,000 men in 2006. In contrast, in previously low rates countries from southern Europe, including France, Italy, Greece, but also Bulgaria and Romania, pancreatic cancer rates were still increasing over the last decade. In EU women, mortality from pancreatic cancer increased from 4.8/100,000 in 1997 to 5.3/100,000 in 2006. Over the last decade, female mortality rates rose in most European countries, a few exception being Austria, Denmark and Portugal, where a decrease over the most recent years was observed.

Table 1. Overall age-adjusted (world population) mortality rates from pancreatic cancer per 100,000 men and women in selected European countries and in the European Union (EU), around 1997 (1995-99), 2002 (2000-04) and in 2007 (unless otherwise indicated), and the corresponding changes in rates.

\begin{tabular}{|c|c|c|c|c|c|c|c|c|c|c|c|c|}
\hline \multirow[b]{2}{*}{ Country } & \multicolumn{6}{|c|}{ Men } & \multicolumn{6}{|c|}{ Women } \\
\hline & 1997 & 2002 & 2007 & $\begin{array}{c}\text { N. } \\
\text { deaths }^{*}\end{array}$ & $\begin{array}{c}\% \\
\text { change } \\
2002 / \\
1997\end{array}$ & $\begin{array}{c}\% \\
\text { change } \\
2007 / \\
2002\end{array}$ & 1997 & 2002 & 2007 & $\begin{array}{c}\text { N. } \\
\text { deaths }\end{array}$ & $\begin{array}{c}\% \\
\text { change } \\
2002 / \\
1997\end{array}$ & $\begin{array}{c}\% \\
\text { change } \\
2007 / \\
2002\end{array}$ \\
\hline Austria & 8.87 & 8.75 & 8.65 & 652 & -1.4 & -1.1 & 5.98 & 6.31 & 6.29 & 727 & 5.5 & -0.3 \\
\hline Belarus (2002-03) & - & 7.02 & 6.78 & 400 & & -3.4 & - & 3.23 & 3.18 & 331 & - & -1.5 \\
\hline Bulgaria & 6.88 & 7.38 & 8.69 & 577 & 7.3 & 17.8 & 3.5 & 3.91 & 4.45 & 419 & 11.7 & 13.8 \\
\hline Croatia & 8.65 & 8.52 & 8.34 & 319 & -1.5 & -2.1 & 4.91 & 4.71 & 5.53 & 312 & -4.1 & 17.4 \\
\hline Czech Republic & 10.8 & 10.94 & 10.72 & 897 & 1.3 & -2.0 & 6.83 & 7.01 & 6.96 & 884 & 2.6 & -0.7 \\
\hline Denmark (2006) & 7.81 & 7.86 & 8.87 & 441 & 0.6 & 12.8 & 6.41 & 6.54 & 6.17 & 400 & 2.0 & -5.7 \\
\hline Estonia & 10.7 & 10.45 & 10.66 & 103 & -2.3 & 2.0 & 4.51 & 5.17 & 5.32 & 105 & 14.6 & 2.9 \\
\hline Greece & 6.26 & 6.54 & 7.07 & 813 & 4.5 & 8.1 & 3.8 & 3.86 & 4.49 & 673 & 1.6 & 16.3 \\
\hline Hungary & 11.23 & 10.95 & 10.66 & 838 & -2.5 & -2.6 & 6.61 & 6.57 & 7.15 & 909 & -0.6 & 8.8 \\
\hline Iceland & 8.85 & 7.04 & 8.13 & 19 & -20.5 & 15.5 & 7.51 & 5.28 & 7.88 & 20 & -29.7 & 49.2 \\
\hline Ireland & 7.46 & 7.09 & 8.06 & 238 & -5.0 & 13.7 & 5.39 & 5.3 & 5.48 & 227 & -1.7 & 3.4 \\
\hline Israel & 7.32 & 8.76 & 7.97 & 351 & 19.7 & -9.0 & 5.01 & 5.68 & 5.07 & 306 & 13.4 & -10.7 \\
\hline Italy (2000-03) & 7.36 & 7.4 & 7.63 & 4750 & 0.5 & 3.1 & 4.72 & 5.06 & 5.3 & 5084 & 7.2 & 4.7 \\
\hline Latvia (1996-99) & 11.74 & 10.82 & 9.59 & 153 & -7.8 & -11.4 & 5.32 & 5.26 & 5.62 & 178 & -1.1 & 6.8 \\
\hline Lithuania & 10.18 & 9.81 & 11.1 & 249 & -3.6 & 13.1 & 4.47 & 4.62 & 4.3 & 189 & 3.4 & -6.9 \\
\hline Luxembourg (2006) & 7.28 & 8.55 & 5.85 & 20 & 17.4 & -31.6 & 4.64 & 5.53 & 2.68 & 18 & 19.2 & -51.5 \\
\hline Republic of Moldova & 7.27 & 7.55 & 8.24 & 166 & 3.9 & 9.1 & 3.81 & 3.61 & 4.39 & 129 & -5.2 & 21.6 \\
\hline Romania & 7.5 & 8.17 & 8.7 & 1421 & 8.9 & 6.5 & 3.75 & 4.13 & 4.55 & 1050 & 10.1 & 10.2 \\
\hline \multicolumn{13}{|l|}{ Russian Federation } \\
\hline$(1999 / 2006)$ & 7.5 & 8.52 & 8.49 & 7117 & 13.6 & -0.4 & 3.7 & 4.28 & 4.52 & 6999 & 15.7 & 5.6 \\
\hline Slovakia (2005) & 9.45 & 9.75 & 10.47 & 352 & 3.2 & 7.4 & 4.89 & 5.01 & 5.88 & 315 & 2.5 & 17.4 \\
\hline Slovenia & 7.87 & 8.17 & 9.39 & 158 & 3.8 & 14.9 & 5.26 & 5.14 & 5.37 & 141 & -2.3 & 4.5 \\
\hline Spain (2005) & 6.06 & 6.44 & 6.33 & 2420 & 6.3 & -1.7 & 3.42 & 3.75 & 3.81 & 2171 & 9.6 & 1.6 \\
\hline Sweden & 7.5 & 7.41 & 7.57 & 714 & -1.2 & 2.2 & 6.39 & 6.47 & 6.61 & 822 & 1.3 & 2.2 \\
\hline Switzerland & 6.81 & 6.84 & 6.81 & 484 & 0.4 & -0.4 & 4.94 & 4.82 & 5.34 & 542 & -2.4 & 10.8 \\
\hline United Kingdom & 6.39 & 6.37 & 6.63 & 3763 & -0.3 & 4.1 & 4.68 & 4.76 & 5.11 & 3996 & 1.7 & 7.4 \\
\hline EU (2006) & 7.51 & 7.62 & 7.95 & 30289 & 1.5 & 4.3 & 4.78 & 4.98 & 5.32 & 30365 & 4.2 & 6.8 \\
\hline
\end{tabular}

${ }^{*}$ Number of deaths in the more recent year available. 
Overall age-standardized mortality rates from pancreatic cancer per 100,000 men and women from other selected countries of the world around 1997 (1995-99), 2002 (2000-2004) and 2007 (when available), and the corresponding percent changes are given in Table 2.

In the USA and Japan, where mortality has been declining since the previous decades, but also in Argentina, Colombia, Puerto Rico and Hong Kong, rates declined between 1997 and 2002, with a reversal of trends over the most recent years. Mortality was declining over the last decade in Costa Rica and New Zealand, and in the last 5 years only in other countries, including Mexico and Australia. In women from Argentina, the USA, and New Zealand rates declined between 1997 and 2002, but, as for men, trends showed a reversal over the last 5 years. Mortality declined over the last decade in most other American countries, with the exception of Puerto Rico, while they increased in Asian countries.

Table 2. Overall age-adjusted (world population) mortality rates from pancreatic cancer per 100,000 men and women in other selected countries of the world, around 1997 (1995-99), 2002 (2000-04) and in 2007 (unless otherwise indicated), and the corresponding changes in rates.

\begin{tabular}{|c|c|c|c|c|c|c|c|c|c|c|c|c|}
\hline \multirow[b]{2}{*}{ Country } & \multicolumn{6}{|c|}{ Men } & \multicolumn{6}{|c|}{ Women } \\
\hline & 1997 & 2002 & 2007 & $\begin{array}{c}\text { N. } \\
\text { deaths* }\end{array}$ & $\begin{array}{c}\% \\
\text { change } \\
2002 / \\
1997\end{array}$ & $\begin{array}{c}\% \\
\text { change } \\
2007 / \\
2002\end{array}$ & 1997 & 2002 & 2007 & $\begin{array}{c}\text { N. } \\
\text { deaths }\end{array}$ & $\begin{array}{c}\% \\
\text { change } \\
2002 / \\
1997\end{array}$ & $\begin{array}{c}\% \\
\text { change } \\
2007 / \\
2002\end{array}$ \\
\hline \multicolumn{13}{|l|}{ AMERICA } \\
\hline Argentina (1997-99) & 7.26 & 7.05 & 7.45 & 1773 & -2.9 & 5.7 & 5.04 & 4.94 & 5.26 & 1907 & -2.0 & 6.5 \\
\hline Brazil (1996-99/2005) & 3.28 & 3.36 & 3.61 & 2858 & 2.4 & 7.4 & 2.41 & 2.66 & 2.81 & 2871 & 10.4 & 5.6 \\
\hline Canada & 6.98 & 6.8 & - & - & -2.6 & - & 5.17 & 5.1 & - & - & -1.4 & - \\
\hline Chile (1997-99/2005) & 4.42 & 4.63 & 4.44 & 393 & 4.8 & -4.1 & 3.7 & 4.16 & 4.14 & 488 & 12.4 & -0.5 \\
\hline \multicolumn{12}{|l|}{ Colombia (1997- } & $99 / 2000-$ \\
\hline $02,2004 / 2006)$ & 2.81 & 2.75 & 2.94 & 527 & -2.1 & 6.9 & 2.8 & 2.68 & 2.65 & 586 & -4.3 & -1.1 \\
\hline \multicolumn{13}{|l|}{ Costa Rica (1997- } \\
\hline 99/2006) & 4.34 & 4.19 & 4.06 & 80 & -3.5 & -3.1 & 3.76 & 3.69 & 3.26 & 78 & -1.9 & -11.7 \\
\hline Cuba & . & 4.3 & 4.21 & 387 & & -2.1 & . & 3.37 & 3.27 & 360 & & -3.0 \\
\hline \multicolumn{13}{|l|}{ Ecuador (1997- } \\
\hline 99/2006) & 2.26 & 2.26 & 2.21 & 131 & 0.0 & -2.2 & 2.31 & 2.32 & 1.98 & 137 & 0.4 & -14.7 \\
\hline Mexico (1998-99) & 3.66 & 3.69 & 3.41 & 1602 & 0.8 & -7.6 & 3.56 & 3.44 & 3.27 & 1783 & -3.4 & -4.9 \\
\hline \multicolumn{13}{|l|}{ Puerto Rico } \\
\hline$(1999 / 2000-03 / 2005)$ & 3.99 & 3.46 & 3.83 & 115 & -13.3 & 10.7 & 2.17 & 2.25 & 2.51 & 106 & 3.7 & 11.6 \\
\hline USA (2005) & 7.33 & 7.28 & 7.39 & 16147 & -0.7 & 1.5 & 5.3 & 5.27 & 5.38 & 16613 & -0.6 & 2.1 \\
\hline \multicolumn{13}{|l|}{ Uruguay (1997- } \\
\hline $99 / 2000-01,2004)$ & 7.77 & 7.51 & - & - & -3.3 & - & 5.18 & 5.48 & - & - & 5.8 & - \\
\hline Venezuela (1996-99) & 3.34 & 2.93 & 2.94 & 337 & -12.3 & 0.3 & 2.87 & 2.78 & 3.05 & 385 & -3.1 & 9.7 \\
\hline \multicolumn{13}{|l|}{ ASIA, OCEANIA } \\
\hline Hong Kong & 4.1 & 3.92 & 4.29 & 240 & -4.4 & 9.4 & 2.54 & 2.76 & 2.86 & 194 & 8.7 & 3.6 \\
\hline Japan & 8.62 & 8.51 & 8.68 & 13029 & -1.3 & 2.0 & 4.82 & 4.95 & 5.17 & 11605 & 2.7 & 4.4 \\
\hline \multicolumn{13}{|l|}{ Republic of Korea } \\
\hline (2006) & 7.14 & 7.59 & 7.32 & 1898 & 6.3 & -3.6 & 3.63 & 3.96 & 4.19 & 1565 & 9.1 & 5.8 \\
\hline Singapore (2006) & 4.87 & 5.41 & 5.24 & 107 & 11.1 & -3.1 & 3.2 & 3.68 & 3.78 & 94 & 15.0 & 2.7 \\
\hline Australia (2006) & 6.07 & 6.19 & 5.95 & 997 & 2.0 & -3.9 & 4.53 & 4.5 & 4.43 & 978 & -0.7 & -1.6 \\
\hline New Zealand (2006) & 5.81 & 5.6 & 4.8 & 156 & -3.6 & -14.3 & 4.73 & 4.06 & 4.44 & 199 & -14.2 & 9.4 \\
\hline
\end{tabular}

*Number of deaths in the more recent year available. 
In 2007, the highest mortality rates in men were in the Baltic countries, the Czech Republic, Hungary, Slovakia and Slovenia, and Nordic countries (over 9/100,000), while the lowest ones were in Latin America and Hong Kong (below 5/100,000) (Figure 1). Japan, the USA, Russia and the EU, as well as the largest countries in the EU, had rates within the relatively narrow range of 7 to $9 / 100,000$. In women, the highest mortality rates were in Hungary, the Czech Republic and Nordic countries (over 6/100,000), the lowest ones in Portugal, Luxemburg, Hong Kong, and Latin America (below 3/100,000). Most large countries had rates within the relatively narrow range of 5 to $6 / 100,000$.

Figure 1. Age-standardized (world population) death certification rates per 100,000 for cancers of the pancreas in men and women from selected countries worldwide, 20052007.

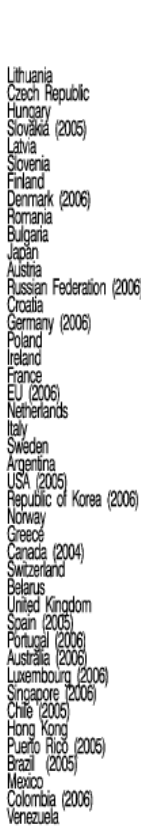

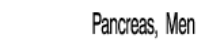
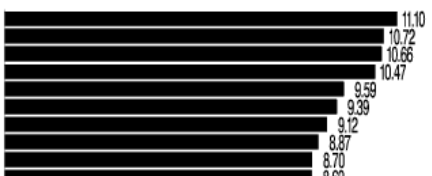

(b)

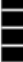

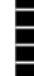
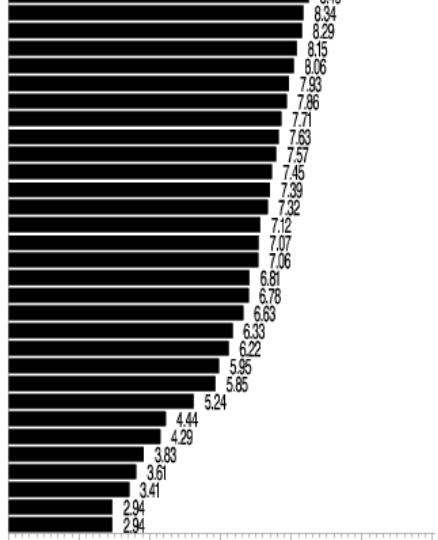

$\begin{array}{lllllll}0 & 2 & 4 & 6 & 8 & 10 & 12\end{array}$
Pancreas, Women

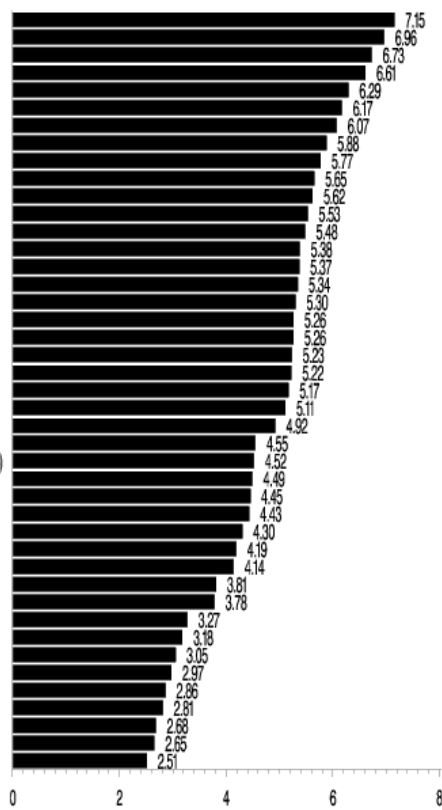

We also considered trends in population aged 30-49 years in 19 selected countries worldwide and in the EU as a whole (Table 3).

Rates in male young adults showed favorable trends over the last decade in most countries considered, the major exceptions being the Russian Federation and Spain. The highest male rates in 2007 were in Hungary $(4.8 / 100,000)$, Russia (4.3), Romania 
(3.3) and the Czech Republic (3.2), while most other countries had rates between 1 and $2 / 100,000$. In young women, too, trends were more favorable than those in the overall female populations, with declines in mortality - at least over the last 5 years - in several countries worldwide, including Germany, Poland, Romania, Sweden, the United Kingdom, the USA, and Brazil. Rates were, however, still rising in other European countries, as well as in the EU and in Argentina. As for men, the highest female rates were in Hungary $(2.8 / 100,000)$ and Russia (1.6), while most other countries had rates between 1 and 1.5/100,000.

Table 3. Age-adjusted (world population) mortality rates from pancreatic cancer per 100,000 men and women aged 30-49 years in selected countries worldwide of the world, around 1997 (1995-99), 2002 (2000-04) and in 2007 (unless otherwise indicated), and the corresponding changes in rates.

\begin{tabular}{|c|c|c|c|c|c|c|c|c|c|c|c|c|}
\hline \multirow[b]{2}{*}{ Country } & \multicolumn{6}{|c|}{ Men } & \multicolumn{6}{|c|}{ Women } \\
\hline & 1997 & 2002 & 2007 & $\begin{array}{c}\text { N. } \\
\text { deaths }\end{array}$ & $\begin{array}{c}\% \\
\text { change } \\
2002 / \\
1997\end{array}$ & $\begin{array}{c}\% \\
\text { change } \\
2007 / \\
2002\end{array}$ & 1997 & 2002 & 2007 & $\begin{array}{c}\text { N. } \\
\text { deaths* }\end{array}$ & $\begin{array}{c}\% \\
\text { change } \\
2002 / \\
1997\end{array}$ & $\begin{array}{c}\% \\
\text { change } \\
2007 / \\
2002\end{array}$ \\
\hline \multicolumn{13}{|l|}{ EUROPE } \\
\hline Czech Republic & 3.81 & 3.46 & 3.24 & 45 & -9.2 & -6.4 & 2.04 & 1.75 & 1.40 & 19 & -14.2 & -20.0 \\
\hline France & 2.46 & 2.46 & 2.23 & 190 & 0.0 & -9.3 & 1.08 & 1.20 & 1.43 & 125 & 11.1 & 19.2 \\
\hline Germany (2006) & 2.51 & 2.28 & 2.12 & 284 & -9.2 & -7.0 & 1.31 & 1.30 & 1.27 & 163 & -0.8 & -2.3 \\
\hline Hungary & 5.15 & 5.34 & 4.82 & 62 & 3.7 & -9.7 & 2.06 & 2.40 & 2.77 & 37 & 16.5 & 15.4 \\
\hline Italy (2000-03) & 2.19 & 2.04 & 1.83 & 164 & -6.8 & -10.3 & 1.06 & 1.16 & 1.44 & 129 & 9.4 & 24.1 \\
\hline Netherlands & 1.94 & 1.75 & 2.03 & 52 & -9.8 & 16.0 & 1.46 & 1.49 & 1.43 & 35 & 2.1 & -4.0 \\
\hline Poland $(1995-96,1999)$ & 3.45 & 3.43 & 2.88 & 155 & -0.6 & -16.0 & 1.52 & 1.49 & 1.41 & 76 & -2.0 & -5.4 \\
\hline Romania & 4.25 & 4.20 & 3.25 & 92 & -1.2 & -22.6 & 1.63 & 1.55 & 1.18 & 35 & -4.9 & -23.9 \\
\hline \multicolumn{13}{|l|}{ Russian Federation } \\
\hline (1999/2006) & 3.93 & 4.28 & 4.29 & 921 & 8.9 & 0.2 & 1.36 & 1.48 & 1.63 & 381 & 8.8 & 10.1 \\
\hline Spain (2005) & 2.38 & 2.41 & 2.42 & 155 & 1.3 & 0.4 & 1.04 & 1.12 & 1.35 & 86 & 7.7 & 20.5 \\
\hline Sweden & 1.72 & 1.61 & 1.11 & 14 & -6.4 & -31.1 & 1.48 & 1.37 & 1.27 & 15 & -7.4 & -7.3 \\
\hline United Kingdom & 1.72 & 1.81 & 1.66 & 145 & 5.2 & -8.3 & 1.08 & 1.06 & 1.03 & 91 & -1.9 & -2.8 \\
\hline \multicolumn{13}{|l|}{ European Union } \\
\hline (2006) & 2.60 & 2.55 & 2.32 & 1465 & -1.9 & -9.0 & 1.26 & 1.31 & 1.35 & 850 & 4.0 & 3.1 \\
\hline \multicolumn{13}{|l|}{ AMERICA } \\
\hline USA (2005) & 2.20 & 2.11 & 2.10 & 932 & -7.7 & -1.3 & 1.30 & 1.29 & 1.50 & 679 & 7.1 & -2.0 \\
\hline Argentina & 2.46 & 2.27 & 2.24 & 99 & -0.8 & 3.1 & 1.41 & 1.51 & 1.48 & 69 & 7.9 & 26.8 \\
\hline Brazil (2005) & 1.31 & 1.30 & 1.34 & 299 & 7.0 & -2.9 & 0.76 & 0.82 & 1.04 & 253 & 0.9 & -9.6 \\
\hline Mexico & 1.28 & 1.37 & 1.33 & 158 & -4.1 & -0.5 & 1.14 & 1.15 & 1.04 & 133 & -0.8 & 16.3 \\
\hline \multicolumn{13}{|l|}{ ASIA, OCEANIA } \\
\hline Japan & 2.54 & 2.31 & 2.10 & 337 & -9.1 & -9.1 & 1.25 & 1.16 & 0.85 & 135 & -7.2 & -26.7 \\
\hline \multicolumn{13}{|l|}{ Republic of Korea } \\
\hline (2006) & 2.43 & 2.28 & 1.75 & 151 & -6.2 & -23.2 & 0.97 & 1.00 & 0.90 & 75 & 3.1 & -10.0 \\
\hline Australia (2006) & 1.62 & 1.58 & 1.39 & 41 & -2.5 & -12.0 & 0.94 & 1.11 & 1.03 & 31 & 18.1 & -7.2 \\
\hline
\end{tabular}

*Number of deaths in the more recent year available.

The main findings from the joinpoint regression analysis of mortality from pancreatic cancer in 19 selected countries worldwide and in the EU as a whole over the period 1980-2007 (whenever available) are given in Figure 2 and Table 4. 
Mortality rates from pancreatic cancer in men, after earlier rises, have been leveling off or declining since the late 1980's in Germany, Hungary, Poland, as well as in Japan and Korea. Rates have been declining between the early 1980's and the mid/late 1990's in the Netherlands, Sweden, the United Kingdom, the USA, and Australia to level off - or even slightly increase - thereafter. Rates have been constant over more recent calendar years in the Czech Republic, Argentina, and Mexico. Conversely, mortality has been moderately upwards throughout the period considered in the EU, as well as in France, Italy, Romania, the Russian Federation, Spain, and Brazil. In women, rates have been slightly increasing between 1980 and 2007 in most countries, except in Nordic ones and the United Kingdom in Europe, and in the USA and Australia, where had approximately stable rates.

Figure 2. Joinpoint analysis for pancreatic cancer mortality in selected countries worldwide, 1980-2007. — $\longrightarrow$ Men; o — Women.
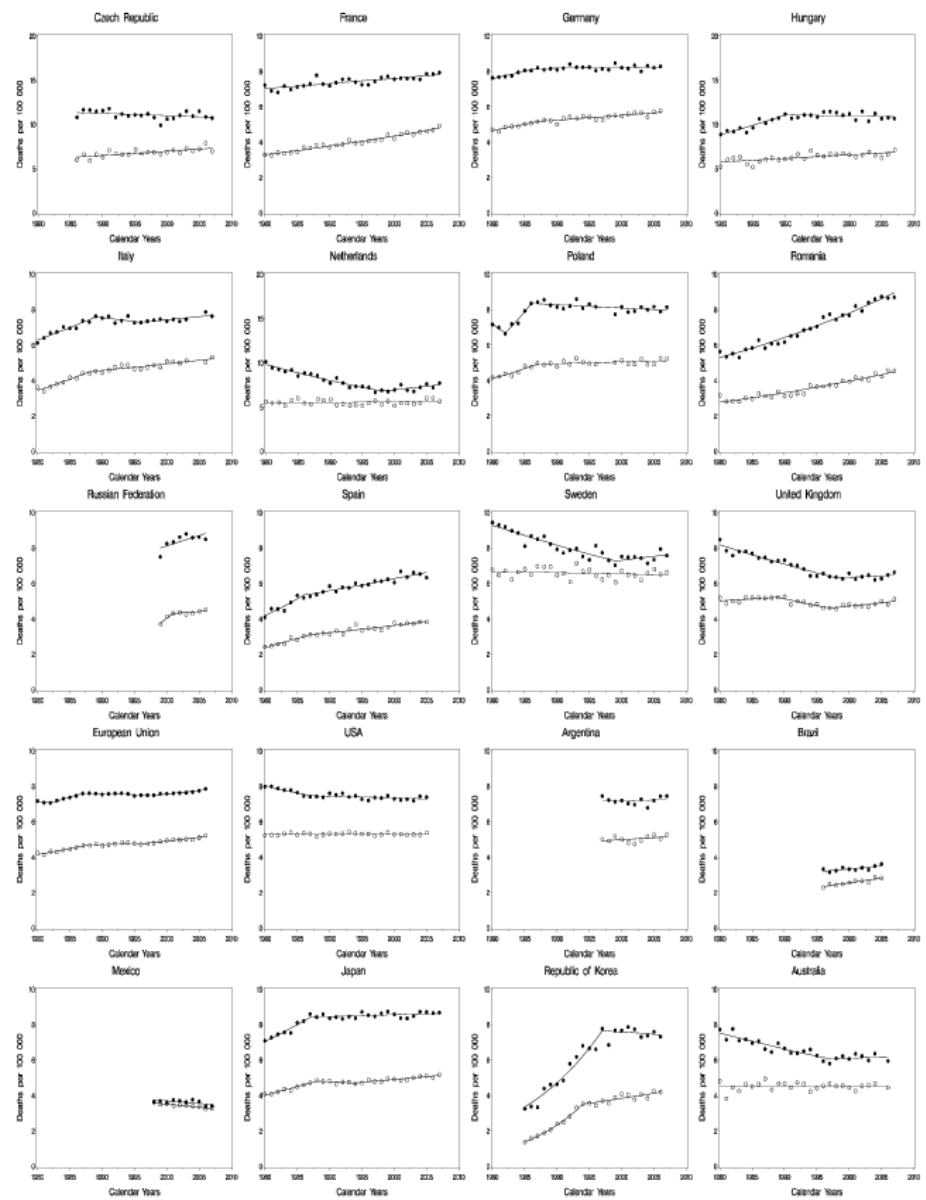
Table 4. Joinpoint analysis for mortality from pancreatic cancer in men and women from selected countries worldwide, 1980-2007.

\begin{tabular}{|c|c|c|c|c|c|c|c|c|}
\hline \multirow{2}{*}{ Country } & \multicolumn{2}{|c|}{ Trend 1} & \multicolumn{2}{|c|}{ Trend 2} & \multicolumn{2}{|c|}{ Trend 3} & \multicolumn{2}{|c|}{ Trend 4} \\
\hline & Years & APC & Years & APC & Years & APC & Years & APC \\
\hline \multicolumn{9}{|l|}{ Men } \\
\hline Czech Republic & $1986-2007$ & -0.2 & & & & & & \\
\hline France & $1980-2007$ & $0.4^{*}$ & & & & & & \\
\hline Germany & $1980-1987$ & $1^{*}$ & 1987-2006 & 0.1 & & & & \\
\hline Hungary & $1980-1990$ & $2.3^{*}$ & 1990-2007 & -0.1 & & & & \\
\hline Italy & 1980-1989 & $2.1^{*}$ & 1989-1996 & -0.6 & $1996-2007$ & $0.5^{*}$ & & \\
\hline Netherlands & 1980-1998 & $-2^{*}$ & 1998-2007 & $1.2^{*}$ & & & & \\
\hline Poland & 1980-1982 & -3.7 & 1982-1986 & $5.8^{*}$ & $1986-2007$ & $-0.2^{*}$ & & \\
\hline Romania & $1980-2007$ & $2^{*}$ & & & & & & \\
\hline Russian Federation & 1999-2006 & 1.4 & & & & & & \\
\hline Spain & 1980-1986 & $4.2^{*}$ & 1986-2005 & $1.1^{*}$ & & & & \\
\hline Sweden & 1980-1999 & $-1.3^{*}$ & 1999-2007 & 0.6 & & & & \\
\hline United Kingdom & 1980-1998 & $-1.4^{*}$ & 1998-2007 & 0.3 & & & & \\
\hline European Union & 1980-1982 & -0.6 & 1982-1987 & $1.5^{*}$ & $1987-1998$ & $-0.1^{*}$ & $1998-2006$ & $0.5^{*}$ \\
\hline USA & 1980-1987 & $-1.1^{*}$ & 1987-2005 & $-0.1^{*}$ & & & & \\
\hline Argentina & 1997-2007 & 0.1 & & & & & & \\
\hline Brazil & 1996-2005 & $1^{*}$ & & & & & & \\
\hline Mexico & 1998-2007 & -0.7 & & & & & & \\
\hline Japan & 1980-1987 & $2.6^{*}$ & 1987-2007 & $0.1^{*}$ & & & & \\
\hline Republic of Korea & 1985-1997 & $7.2^{*}$ & 1997-2006 & -0.3 & & & & \\
\hline Australia & 1980-1997 & $-1.3^{*}$ & 1997-2006 & 0.2 & & & & \\
\hline \multicolumn{9}{|l|}{ Women } \\
\hline Czech Republic & $1986-2007$ & $0.7^{*}$ & & & & & & \\
\hline France & $1980-2007$ & $1.4^{*}$ & & & & & & \\
\hline Germany & 1980-1987 & $1.5^{*}$ & $1987-2006$ & $0.5^{*}$ & & & & \\
\hline Hungary & $1980-2007$ & $0.7^{*}$ & & & & & & \\
\hline Italy & $1980-1988$ & $3.4^{*}$ & $1988-2007$ & $0.8^{*}$ & & & & \\
\hline Netherlands & $1980-2007$ & 0.1 & & & & & & \\
\hline Poland & $1980-1987$ & $2.6^{*}$ & 1987-2007 & 0.2 & & & & \\
\hline Romania & $1980-2007$ & $1.8^{*}$ & & & & & & \\
\hline Russian Federation & 1999-2001 & 7 & 2001-2006 & 0.6 & & & & \\
\hline Spain & 1980-1987 & $3.8^{*}$ & 1987-2005 & $1.2^{*}$ & & & & \\
\hline Sweden & $1980-2007$ & -0.1 & & & & & & \\
\hline United Kingdom & 1980-1989 & 0.4 & 1989-1997 & $-1.6^{*}$ & $1997-2007$ & $0.8^{*}$ & & \\
\hline European Union & $1980-1988$ & $1.5^{*}$ & 1988-1997 & 0.2 & $1997-2006$ & $0.8^{*}$ & & \\
\hline \multicolumn{9}{|l|}{ AMERICA } \\
\hline USA & $1980-2005$ & 0 & & & & & & \\
\hline Argentina & 1997-2007 & 0.4 & & & & & & \\
\hline Brazil & 1996-2005 & $2.1^{*}$ & & & & & & \\
\hline Mexico & 1998-2007 & $-1^{*}$ & & & & & & \\
\hline \multicolumn{9}{|l|}{ ASIA, OCEANIA } \\
\hline Japan & $1980-1988$ & $2.3^{*}$ & 1988-1994 & -0.4 & $1994-2007$ & $0.7^{*}$ & & \\
\hline Republic of Korea & 1985-1994 & $10.9^{*}$ & 1994-2006 & $1.5^{*}$ & & & & \\
\hline Australia & 1980-2006 & 0 & & & & & & \\
\hline
\end{tabular}

APC: annual percent change. ${ }^{*}$ Significantly different from $0(p<0.05)$. 


\section{Discussion}

The present updated global analysis of pancreatic cancer mortality shows that in the early 2000's, rates have been approximately stable in many European countries, as in the USA, Japan and Australia. In Japan, mortality from pancreatic cancer is relatively high, while overall mortality from all cancer remains $10 \%$ lower than in the USA and $20 \%$ lower than in the EU [2]. In Nordic countries and the United Kingdom, where declines in rates have been observed since the 1980's, mortality from pancreatic cancer seems to have reached a plateau, and have tended to rise over most recent calendar years. Some persisting rises were, however, still found in a few countries of southern and central/eastern Europe (with low rates in the past), as well as in the EU overall, and in women from European and Asian countries. Recent trends were generally more favorable in young adults (30-49 years), suggesting that overall trends are likely to improve in the next future $[15,16]$.

Estimates of mortality from pancreatic cancer are also available from the GLOBOCAN 2008 report $[1,2]$. In the absence of national mortality data, sample mortality data were used for 31 countries (including China) providing data covering only part of the population, or extrapolating mortality from incidence data of local or neighboring country cancer registries in the same region. GLOBOCAN estimates of pancreatic cancer mortality for countries not providing mortality data are considerably lower than those given by national mortality data reviewed in the present report, and range in men from 1.2/100,000 in western Africa and 1.3/100,000 in southeastern Asia, to $1.8 / 100,000$ in East Mediterranean regions and 3.9/100,000 in the western Pacific region. The extent of undercertification in most of these areas is difficult to quantify, and consequently the validity of such estimates is undefined. We decided therefore to exclude those data from our report.

Tobacco smoking is the major recognized risk factor for pancreatic cancer, with a relative risk (RR) of approximately 2 for current smokers compared to never smokers [17-20]. Any ecologic (correlation) analysis of tobacco smoking and pancreatic cancer would be extremely difficult to interpret on account of the different cohort patterns of smoking, and the time-duration risk relation between tobacco and pancreatic cancer. Generation specific smoking prevalence data would, in fact be required. Nevertheless, trends in pancreatic cancer mortality at least in part reflect the different patterns in tobacco consumption in subsequent generations of men and women in various countries worldwide, with declines since the mid XX century in most western and northern European countries, as well as in the USA and Japan [21-26]. Thus, the pancreatic mortality rates started to decrease earlier in countries where smoking control has been earlier (the United Kingdom, USA and Australia), while upwards trends were still observed in men from various countries of central/eastern Europe, as well as in women, for whom smoking has been increasing up to more recent generations. However, the modest increases in pancreatic mortality in various 
countries, as well as in the EU overall, are in contrast with the persisting declines in lung cancer rates [4, 5], suggesting that other factors, besides smoking, influenced recent trends in pancreatic cancer mortality.

Overweight/obesity as well as diabetes - that is a correlate of overweight - have also been related to pancreatic cancer risk. The RR of pancreatic cancer is approximately 1.5 for obese subjects [27-29], and 2 to 3 for diabetics [19, 30, 31]. The increased prevalence of overweight and obesity [32] - and consequently of type 2 diabetes [33] in several areas of the world over the last few decades may, therefore, partly explain why mortality from pancreatic cancer has not declined in the same way not only as lung cancer, but also as upper digestive tract or bladder neoplasms [4, 5].

Other recognized risk factors for pancreatic cancer, i.e. pancreatitis [34] and heavy alcohol drinking $[35,36]$, cause a small proportion of pancreatic cancers only on a population level, and consequently have a negligible effect on national mortality trends.

No strong association has been found between diet and pancreatic cancer, except for possible increased risk for high intake of and meat [37-39] and low intake of fruit and vegetables $[19,39,40]$; the potential impact of diet on mortality trends is thus undefined.

The diagnosis of this neoplasm poses difficulties and less than $50 \%$ of cases worldwide has been histologically confirmed [19]. Certification accuracy and validity of pancreatic cancer also varies across calendar years and between countries, and it is likely lower in poorer and middle/low-income areas of the world. At least part of the earlier trends, as well as the rises in some countries of southern and central/eastern Europe, may be due to improved accuracy in the diagnosis and certification of the disease, following the introduction of ultrasound, computerized tomography, endoscopic retrograde cholangio-pancreatography and fine needle aspiration [41]. It is unlikely, however, that diagnosis accuracy has played a major role over more recent calendar periods in most high-income countries of Europe and North America, as well as in Japan, also given the consistency of trends in these countries.

Progress in the treatment of pancreatic cancer has been negligible over the last two decades, and survival has remained very low (5-year relative survival <5\%) [41] [42, 43]; thus, changes in treatment cannot thus explain the leveling off in mortality rates over the last decades in many countries.

In conclusion, this analysis confirms a leveling off in pancreatic cancer mortality in various areas of the world after decades of steady rises, although modest increases are observed in countries of southern and central/eastern Europe, as well as in women. In contrast to the favorable effect of the decline in smoking prevalence, at least in men, other factors, including mainly increased overweight and diabetes are likely to have had an unfavorable role on pancreatic cancer mortality. Pancreatic cancer remains, 
therefore, one of the few sites for which mortality has not declined over the last two decades in Europe, North America, and Japan. 


\section{References}

1. Ferlay J, Shin HR, Bray F et al. Estimates of worldwide burden of cancer in 2008: GLOBOCAN 2008. Int J Cancer 2010; 127: 2893-2917.

2. Ferlay J, Shin HR, Bray F et al. GLOBOCAN 2008, Cancer Incidence and Mortality Worldwide: IARC Cancer Base No. 10 [Internet]. Available at: http://globocan.iarc.fr 2010.

3. Levi F, Lucchini F, Negri E, La Vecchia C. Pancreatic cancer mortality in Europe: the leveling of an epidemic. Pancreas 2003; 27: 139-142.

4. La Vecchia C, Bosetti C, Lucchini F et al. Cancer mortality in Europe, 2000-2004, and an overview of trends since 1975. Ann Oncol 2010; 21: 1323-1360.

5. Edwards BK, Ward E, Kohler BA et al. Annual report to the nation on the status of cancer, 1975-2006, featuring colorectal cancer trends and impact of interventions (risk factors, screening, and treatment) to reduce future rates. Cancer 2010; 116: 544-573.

6. Qiu D, Katanoda K, Marugame T, Sobue T. A Joinpoint regression analysis of long-term trends in cancer mortality in Japan (1958-2004). Int J Cancer 2009; 124: 443-448.

7. Kim HJ, Fay MP, Feuer EJ, Midthune DN. Permutation tests for joinpoint regression with applications to cancer rates. (Erratum in: Stat Med 2001;20: 655). Stat Med 2000; 19: 335-351.

8. World Health Organization Statistical Information System. WHO mortality database Available at: http://www3.who.int/whosis/menu.cfm/ Last accessed July 2010.

9. World Health Organization. International Classification of Disease: 9th revision. Geneva: World Health Organization 1977.

10. World Health Organization. International Classification of Disease: 8th revision. Geneva: World Health Organization 1967.

11. World Health Organization. International Classification of Disease and related Health Problems: 10th revision. Geneva: World Health Organization 1992.

12. Pan American Health Organization (PAHO). Pan American Tobacco Information Online System. Available at: http://www.paho.org/tobacco/PatiosHome.asp Last accessed 2010.

13. Doll R, Smith PG. Comparison between registries: age-standardized rates. Vol. IV. IARC Sci PubI No. 42. In Waterhouse JAH, Muir CS, Shanmugaratnam K et al. (eds): Cancer Incidence in Five Continents. Lyon: IARC 1982; 671-675.

14. National Cancer Institute. Joinpoint Regression Program, version 3.4.3. Available at: http://srab.cancer.gov/joinpoint/ April 2010.

15. Doll R. Progress against cancer: an epidemiologic assessment. The 1991 John C. Cassel Memorial Lecture. Am J Epidemiol 1991; 134: 675-688. 
16. Muir CS, Fraumeni JF, Jr., Doll R. The interpretation of time trends. Cancer Surv 1994; 19-20: 5-21.

17. Silverman DT, Dunn JA, Hoover RN et al. Cigarette smoking and pancreas cancer: a case-control study based on direct interviews. J Natl Cancer Inst 1994; 86: 1510-1516.

18. IARC. IARC Monographs on the evaluation of carcinogenic risks to humans. Vol. 83. Tobacco smoke and involuntary smoking. Lyon: International Agency for Research on Cancer 2004.

19. Anderson KE, Mack TM, Silverman DT. Cancer of the pancreas. In Schottenfeld D, Fraumeni JFJr (eds): Cancer Epidemiology and Prevention. New York: Oxford University Press 2006; 721-762.

20. Iodice S, Gandini S, Maisonneuve P, Lowenfels AB. Tobacco and the risk of pancreatic cancer: a review and meta-analysis. Langenbecks Arch Surg 2008; 393: 535-545.

21. Franceschi S, Naett C. Trends in smoking in Europe. Eur J Cancer Prev 1995; 4: 271-284.

22. World Health Organization. Tobacco or Health: a global status report. Geneva, Switzerland: WHO 1997.

23. Tyczynski JE, Bray F, Aareleid T et al. Lung cancer mortality patterns in selected Central, Eastern and Southern European countries. Int J Cancer 2004; 109: 598610.

24. Marugame T, Kamo K, Sobue T et al. Trends in smoking by birth cohorts born between 1900 and 1977 in Japan. Prev Med 2006; 42: 120-127.

25. Fitzsimmons D, Osmond C, George S, Johnson CD. Trends in stomach and pancreatic cancer incidence and mortality in England and Wales, 1951-2000. Br J Surg 2007; 94: 1162-1171.

26. World Health Organization Regional Office for Europe. Health for all database (HFA-DB). Available at: http://data.euro.who.int/hfadb/ Last accessed 2010.

27. Calle EE, Rodriguez C, Walker-Thurmond K, Thun MJ. Overweight, obesity, and mortality from cancer in a prospectively studied cohort of U.S. adults. N Engl J Med 2003; 348: 1625-1638.

28. Renehan $A G$, Tyson $M$, Egger $M$ et al. Body-mass index and incidence of cancer: a systematic review and meta-analysis of prospective observational studies. Lancet 2008; 371: 569-578.

29. Arslan AA, Helzlsouer KJ, Kooperberg C et al. Anthropometric measures, body mass index, and pancreatic cancer: a pooled analysis from the Pancreatic Cancer Cohort Consortium (PanScan). Arch Intern Med 2010; 170: 791-802.

30. Huxley R, Ansary-Moghaddam A, Berrington de Gonzalez A et al. Type-II diabetes and pancreatic cancer: a meta-analysis of 36 studies. $\mathrm{Br}$ J Cancer 2005; 92: 2076-2083. 
31. Lipworth L, Zucchetto A, Bosetti C et al. Diabetes mellitus and other medical conditions and pancreatic cancer: a case-control study. Diabetes Metab Res Rev 2011; 27: 255-261.

32. Finucane MM, Stevens GA, Cowan MJ et al. National, regional, and global trends in body-mass index since 1980: systematic analysis of health examination surveys and epidemiological studies with 960 country-years and 9.1 million participants. Lancet 2011; 377: 557-567.

33. King $H$, Aubert RE, Herman WH. Global burden of diabetes, 1995-2025: prevalence, numerical estimates, and projections. Diabetes Care 1998; 21: 1414-1431.

34. Raimondi $S$, Lowenfels $A B$, Morselli-Labate $A M$ et al. Pancreatic cancer in chronic pancreatitis; aetiology, incidence, and early detection. Best Pract Res Clin Gastroenterol 2010; 24: 349-358.

35. Genkinger JM, Spiegelman D, Anderson KE et al. A pooled analysis of 14 cohort studies of anthropometric factors and pancreatic cancer risk. Int J Cancer 2010.

36. Tramacere I, Scotti L, Jenab $M$ et al. Alcohol drinking and pancreatic cancer risk: a meta-analysis of the dose-risk relation. Int J Cancer 2010; 126: 1474-1486.

37. Tavani A, La Vecchia C, Gallus S et al. Red meat intake and cancer risk: a study in Italy. Int J Cancer 2000; 86: 425-428.

38. Li D, Day RS, Bondy ML et al. Dietary mutagen exposure and risk of pancreatic cancer. Cancer Epidemiol Biomarkers Prev 2007; 16: 655-661.

39. World Cancer Research Fund and American Institute for Cancer Research. Food, Nutrition, Physical Activity and the Prevention of Cancer: a Global Perspective. Washington, DC: AICR. 2007.

40. Maisonneuve $P$, Lowenfels $A B$. Epidemiology of pancreatic cancer: an update. Dig Dis 2010; 28: 645-656.

41. Sharma C, Eltawil KM, Renfrew PD et al. Advances in diagnosis, treatment and palliation of pancreatic carcinoma: 1990-2010. World J Gastroenterol 2011; 17: 867-897.

42. Karim-Kos HE, de Vries E, Soerjomataram I et al. Recent trends of cancer in Europe: a combined approach of incidence, survival and mortality for 17 cancer sites since the 1990s. Eur J Cancer 2008; 44: 1345-1389.

43. Klint A, Engholm $\mathrm{G}$, Storm $\mathrm{HH}$ et al. Trends in survival of patients diagnosed with cancer of the digestive organs in the Nordic countries 1964-2003 followed up to the end of 2006. Acta Oncol 2010; 49: 578-607. 
Chapter 3. The International Pancreatic Cancer Case-Control Consortium 



\section{Chapter 3.1. Cigarette Smoking ANd Pancreatic Cancer: an Analysis from the International Pancreatic Cancer CaSe- Control Consortium}

C. Bosetti, E. Lucenteforte, D. T. Silverman, G. Petersen, P. M. Bracci, B. T. Ji, E. Negri, D. Li, H. A. Risch, S. H. Olson, S. Gallinger, A. B. Miller, H. Bas Bueno-de-Mesquita, R. Talamini, J. Polesel, P. Ghadirian, P. A. Baghurst, W. Zatonski, E. Fontham, W. R. Bamlet, E. A. Holly, P. Bertuccio, Y. T. Gao, M. Hassan, H. Yu, R. C. Kurtz, M. Cotterchio, J. Su, P. Maisonneuve, E. J. Duell, P. Boffetta, C. La Vecchia 


\section{Abstract}

To further evaluate the dose-response relationship between cigarette smoking and pancreatic cancer and to examine the effects of temporal variables, we analyzed data from 12 case-control studies within the International Pancreatic Cancer Case-Control Consortium (PanC4), including 6507 pancreatic cases and 12,890 controls. We estimated summary odds ratios (ORs), by pooling study-specific ORs using randomeffects models. Compared with never smokers, the OR was 1.2 (95\% confidence interval, $\mathrm{Cl}, 1.0-1.3$ ) for former smokers and 2.2 (95\% $\mathrm{Cl} 1.7-2.8$ ) for current cigarette smokers, with a significant increasing trend in risk with increasing number of cigarettes among current smokers ( $O R=3.4$ for $\geq 35$ cigarettes/day, $p$ for trend $<0.0001$ ). Risk increased in relation to duration of cigarette smoking up to 40 years of smoking $(O R=2.4)$. No trend in risk was observed for age at starting cigarette smoking, whereas risk decreased with increasing time since cigarette cessation, the OR being 0.98 after 20 years. This uniquely large pooled analysis confirms that current cigarette smoking is associated with a 2-fold increased risk of pancreatic cancer, and that the risk increases with number of cigarettes smoked and with duration of smoking. Risk of pancreatic cancer reaches the level of never smokers 20 years after quitting. 


\section{Introduction}

Cigarette smoking is the best established risk factor for pancreatic cancer $[1,2]$. A meta-analysis of 82 cohort and case-control studies published between 1950 and 2007 [3] reported a summary relative risk (RR) of pancreatic cancer of 1.7 (95\% confidence interval, $\mathrm{Cl}, 1.6-1.9)$ for current smokers, and of $1.2(95 \% \mathrm{Cl}, 1.1-1.3)$ for former smokers. It also showed that the risk persisted up to 10 years after quitting smoking, although no detailed analysis of the dose and duration-risk relations was conducted. In the International Pancreatic Cancer Cohort Consortium nested case-control study [4], that included 1,481 cases and 1,539 controls, the RR was 1.1 (95\% Cl, 0.9-1.3) for former smokers, and $1.8(95 \% \mathrm{Cl}, 1.4-2.3)$ for current smokers. Significant trends in risk were observed with increased number of cigarettes smoked and duration of exposure, the RR being 1.75 for 30 or more cigarettes smoked per day, and 2.1 for 50 or more years of smoking, whereas RR for those who had quit for more than 15 years was similar to that of never smokers.

To further evaluate the dose-response relationship between cigarette smoking and pancreatic cancer and the role of various temporal factors such as age at starting and time since stopping we analyzed the original data from a series of case-control studies within the International Pancreatic Cancer Case-Control Consortium (PanC4) $[5,6]$. This uniquely large dataset allowed us to investigate in detail cigarette smoking on pancreatic cancer, with careful adjustment for major potential confounding factors for pancreatic cancer.

\section{Methods}

\section{Studies}

The PanC4 consortium identified 12 case-control studies ${ }^{1}$ of pancreatic cancer that collected data on cigarette smoking using structured questionnaires [7-18]. Eight studies [7-14] ${ }^{1}$ were conducted in North America, two in Europe [15, 16], one in China [17], and one was the IARC-coordinated Surveillance of Environmental Aspects Related to Cancer in Humans (SEARCH) study from Canada, Europe and Australia [18]. A summary description of the individual studies is presented in Table 1.

The present pooled analysis includes on a total of 6507 cases of adenocarcinoma of the exocrine pancreas and 12,890 controls. The data included in the pooled analysis may differ slightly from those in published reports of the individual studies due to missing data for relevant variables. In all studies, cases and controls were interviewed in-person, with the exception of the Ontario, Canada study that used self-administered questionnaires and included 63 case-proxy respondents [14]; the SEARCH study [18],

\footnotetext{
${ }^{1}$ Including the unpublished Louisiana State University (LSU) study.
} 
where proxy interviews were conducted for 474 cases and 332 controls; and the Shanghai study [17] where 155 cases and 150 controls were proxy-interviewed.

Table 1. Summary description of individual studies included in the International Pancreatic Cancer Case-Control Consortium (PanC4) on cigarette smoking and pancreatic cancer.

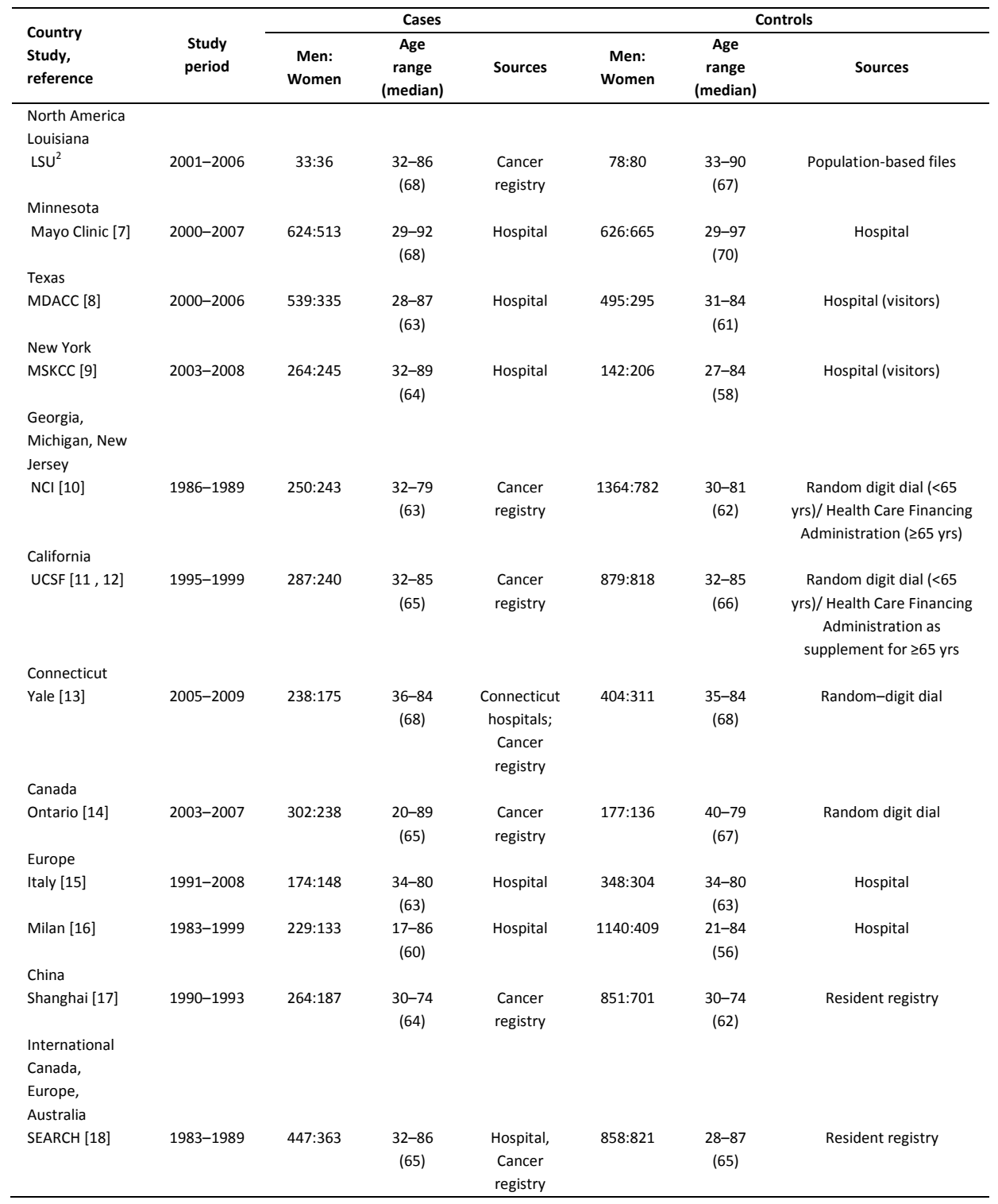

\section{${ }^{2}$ Unpublished data.}


LSU, Louisiana State University; MDACC, MD Anderson Cancer Center; MSKCC, Memorial Sloan-Kettering Cancer Center; $\mathrm{NCl}$, National Cancer Institute; SEARCH, Surveillance of Environmental Aspects Related to Cancer in Humans; UCSF University of California, San Francisco.

The original datasets were restructured either by the original study investigators or by the central coordinators using a uniform format for data harmonization. In addition to the smoking-related data, for each study we considered individual data on sociodemographic characteristics, anthropometric measures, alcohol consumption, and history of diabetes and of pancreatitis.

\section{Exposure variables}

All studies in this pooled analysis provided information about cigarette smoking status (never, former and current smoker), number of cigarettes smoked per day, duration of smoking, age at start smoking, and years since quitting or age at quitting smoking, for former smokers. Though questions about cigarette smoking were similar across studies, we conducted a careful and detailed examination of the comparability of smoking-related questions to harmonize the data from the multiple studies included in this pooled analysis.

For the present analyses, ever cigarette smokers were defined as participants who had smoked at least 100 cigarettes in their lifetime $[7-9,11,13,14,17]$, or more than 1 cigarette per day for at least 1 year $[15,16,18]$. In the $\mathrm{NCl}$, information was only available for regular smokers, i.e., those who smoked at least 1 cigarette per day for at least 6 months [10]. Former cigarette smokers were defined as those who had quit smoking for at least 1 year prior to interview in all studies.

\section{Statistical analysis}

To estimate the association between cigarette smoking and pancreatic cancer risk, we used a 2-stage modeling approach [19]. In the first stage, we assessed the association between cigarette smoking and pancreatic cancer for each study by estimating the odds ratios (ORs) and the corresponding $95 \% \mathrm{Cls}$ using multivariable unconditional logistic regression models [20]. These models included terms for age $(<50,50-54,55-$ $59,60-64,65-69,70-74, \geq 75$ years $)$, sex, education $\left(\leq 8^{\text {th }}\right.$ grade, $9^{\text {th }}-11^{\text {th }}$ grade, $12^{\text {th }}$ grade or high school graduates, some college or college graduates, $\geq 1$ year of graduate school), race/ethnicity (non-Hispanic white, Hispanic, non-Hispanic black, other), body mass index (BMI, $<20,20-<25,25-<30, \geq 30 \mathrm{~kg} / \mathrm{m}^{2}$ ), history of diabetes ( $\geq$ 1 year before diagnosis/interview), alcohol consumption (never drinkers, 1-6 drinks per day, drinkers $\geq 6$ drinks per day), and study centre, for multicentre studies. In the second stage of the analysis, summary estimates were computed using random-effects models [21], weighting study-specific ORs by the inverse of the sum of their variance and the estimated between-study variance component. Heterogeneity between 
studies was evaluated using the $Q$ test statistic [22]. To test for the significance of linear trends in pancreatic cancer risk across levels of cigarette smoking, we first estimated the trends in each study and then used the Wald test to estimate the $p$ value of the summary variable, from the random-effects models [19].

To investigate whether the effect of cigarette smoking was homogeneous within strata of selected covariates, we conducted analyses stratified by sex, age $(<65, \geq 65$ years), alcohol consumption (never drinkers, 1-4 drinks per day, drinkers $\geq 4$ drinks per day), race/ethnicity (non-Hispanic White, other races), study area (North America, Europe, other race/ethnicity), source of controls (population-based, hospital-based), type of respondents (in-person, proxy). Significance of the heterogeneity across individual strata was assessed using a $\chi^{2}$ statistic [22].

We also conducted a sensitivity analysis to evaluate the undue influence of a study on the overall summary estimates, by excluding one study at a time from the pooled analysis. Moreover, we performed a cumulative meta-analysis to determine whether the association between cigarette smoking and pancreatic cancer risk changed over time.

In addition to the two-stage analysis, we conducted an aggregate analysis where data from all studies were pooled into a single large data set [19]. The association between cigarette smoking and pancreatic cancer risk was determined using multivariable unconditional multiple logistic regression models [20]. Models included terms for study area, as well as for the confounding factors from the study-specific models and the study-confounder interactions. The results were not substantially different from those obtained in the two-stage analysis approach, and therefore are not reported here.

\section{Results}

Table 2 shows the distribution of 6507 pancreatic cancer cases and 12,890 controls by sex, age, and other potential confounding factors. Cases and controls have a similar sex distribution; cases were somewhat older than controls, were more frequently nonHispanic White, had a higher level of education, a higher BMI, and more frequently reported a history of diabetes and pancreatitis. 
Table 2. Distribution of 6507 cases of pancreatic cancer and 12,890 controls according to sex, age, race and other selected covariates. International Pancreatic Cancer CaseControl Consortium (PanC4).

\begin{tabular}{|c|c|c|c|c|}
\hline \multirow{2}{*}{ Characteristics } & \multicolumn{2}{|c|}{ Cases } & \multicolumn{2}{|c|}{ Controls } \\
\hline & N. & (\%) & N. & (\%) \\
\hline \multicolumn{5}{|l|}{ Sex } \\
\hline Men & 3651 & $(56.1)$ & 7362 & (57.1) \\
\hline Women & 2856 & $(43.9)$ & 5528 & (42.9) \\
\hline \multicolumn{5}{|l|}{ Age (years) } \\
\hline$<55$ & 1198 & $(18.4)$ & 3155 & (24.4) \\
\hline $55-59$ & 905 & (13.9) & 1816 & (14.1) \\
\hline $60-64$ & 1091 & $(16.8)$ & 1983 & (15.4) \\
\hline $65-69$ & 1148 & $(17.6)$ & 2146 & (16.7) \\
\hline $70-75$ & 1084 & $(16.7)$ & 2041 & (15.8) \\
\hline$\geq 75$ & 1081 & $(16.6)$ & 1749 & (13.6) \\
\hline \multicolumn{5}{|l|}{ Race/ethnicity } \\
\hline Non-Hispanic White & 5409 & $(83.1)$ & 9478 & (73.5) \\
\hline Non-Hispanic Black & 356 & $(5.5)$ & 1119 & $(8.7)$ \\
\hline Hispanic & 115 & (1.8) & 220 & (1.7) \\
\hline Others & 622 & (9.5) & 1761 & (13.7) \\
\hline missing & 5 & $(0.1)$ & 312 & (2.4) \\
\hline \multicolumn{5}{|l|}{ Education } \\
\hline$<8^{\text {th }}$ grade & 1291 & $(19.8)$ & 3570 & (27.7) \\
\hline $9^{\text {th }}-11^{\text {th }}$ grade & 823 & $(12.7)$ & 1624 & (12.6) \\
\hline $12^{\text {th }}$ grade/high school & 1349 & $(20.7)$ & 2186 & (17.0) \\
\hline Some college/college & 1991 & (30.6) & 3588 & $(27.8)$ \\
\hline$\geq 1$ year graduate school & 1006 & $(15.5)$ & 1835 & (14.2) \\
\hline missing & 47 & $(0.7)$ & 87 & $(0.7)$ \\
\hline \multicolumn{5}{|l|}{ Body mass index $\left(\mathrm{kg} / \mathrm{m}^{2}\right)$} \\
\hline$<20$ & 462 & (7.1) & 1111 & $(8.6)$ \\
\hline $20-<25$ & 2396 & $(36.8)$ & 5658 & (43.9) \\
\hline $25-<30$ & 2363 & $(36.3)$ & 4473 & (34.7) \\
\hline$\geq 30$ & 1201 & $(18.5)$ & 1488 & (11.5) \\
\hline missing & 85 & $(1.3)$ & 160 & $(1.3)$ \\
\hline \multicolumn{5}{|l|}{ Alcohol drinking (drinks/day) } \\
\hline $0-<1$ & 3853 & $(59.2)$ & 7478 & (58.0) \\
\hline $1-<4$ & 1432 & $(22.0)$ & 3563 & (27.6) \\
\hline$\geq 4$ & 697 & $(10.7)$ & 1492 & (11.6) \\
\hline missing & 525 & (8.1) & 357 & $(2.8)$ \\
\hline \multicolumn{5}{|l|}{ History of diabetes } \\
\hline No & 5052 & (77.6) & 11710 & (90.8) \\
\hline Yes & 1378 & $(21.2)$ & 1109 & $(8.6)$ \\
\hline missing & 77 & $(1.2)$ & 71 & $(0.6)$ \\
\hline \multicolumn{5}{|l|}{ History of pancreatitis ${ }^{\mathrm{b}}$} \\
\hline No & 4674 & $(71.8)$ & 10703 & (83.0) \\
\hline Yes & 313 & $(4.8)$ & 112 & $(0.9)$ \\
\hline missing & 1520 & (23.4) & 2075 & (16.5) \\
\hline
\end{tabular}

LSU, Louisiana State University; MSKCC, Memorial Sloan-Kettering Cancer Center; NCI, National Cancer Institute; SEARCH, Surveillance of Environmental Aspects Related to 
Cancer in Humans; UCSF, University of California, San Francisco. ${ }^{a}$ No information was available in the MSKCC study. ${ }^{b}$ No information was available in the Italian and Mayo Clinic study.

The pooled ORs for pancreatic cancer according to cigarette smoking habits are given in Table 3. Compared with never smokers, the OR was 1.40 (95\% Cl 1.24-1.55) for ever cigarette smokers, 1.17 (95\% Cl 1.02-1.34) for former cigarette smokers, and 2.20 (95\% $\mathrm{Cl}$ 1.71-2.83) for current cigarette smokers. A significant trend in risk was observed with increased number of cigarettes smoked (OR=3.4, 95\% Cl 2.4-4.9 for $\geq 35$ cigarettes/day, $\mathrm{p}$ for trend<0.0001). Among current smokers, the risk increased with increased duration of cigarette smoking for up to 40 years of smoking (OR=2.43, 95\% $\mathrm{Cl}$ 1.91-3.09), but did not increase further after 40 years. No trend in risk was observed for age at starting cigarette smoking in current smokers, whereas a significant decreasing trend in risk was found with increased time since quitting cigarette smoking. After $\geq 20$ years, risk estimates were not different from non smokers $(O R=0.98)$. Sensitivity analyses showed that no single study unduly influenced the magnitude or the statistical significance of these summary estimates.

Table 3. Pooled odds ratios (ORs) and $95 \%$ confidence intervals ( $\mathrm{Cls}$ ) for pancreatic cancer according to cigarette smoking habits among 6507 cases and 12,890 controls. International Pancreatic Cancer Case-Control Consortium (PanC4).

\begin{tabular}{|c|c|c|c|c|c|}
\hline & \multicolumn{2}{|c|}{ Cases } & \multicolumn{2}{|c|}{ Controls } & \multirow{2}{*}{$\mathrm{OR}^{\mathrm{a}}(95 \% \mathrm{Cl})$} \\
\hline & N. & (\%) & $\mathbf{N}$. & (\%) & \\
\hline Never smoker & 2373 & $(36.5)$ & 5557 & $(43.1)$ & $1^{b}$ \\
\hline Ever cigarette smoker & 3962 & $(60.9)$ & 6980 & $(54.2)$ & $1.40(1.24-1.59)$ \\
\hline Former smoker & 2327 & $(35.8)$ & 4214 & $(32.7)$ & $1.17(1.02-1.34)$ \\
\hline Current smoker & 1635 & $(25.2)$ & 2766 & (21.5) & $2.20(1.71-2.83)$ \\
\hline Other than cigarettes smoker & 164 & (2.5) & 336 & (2.6) & $1.17(0.80-1.70)$ \\
\hline missing & 8 & $(0.1)$ & 17 & (0.1) & \\
\hline \multicolumn{6}{|l|}{ Intensity (cigarettes/day) ${ }^{c}$} \\
\hline$<15$ & 440 & (6.8) & 1017 & (7.9) & $1.60(1.24-2.06)$ \\
\hline $15-<25$ & 722 & $(11.1)$ & 1182 & (9.2) & $2.30(1.76-3.01)$ \\
\hline $25-<35$ & 253 & (3.9) & 294 & (2.3) & $2.76(1.92-3.97)$ \\
\hline$\geq 35$ & 172 & (2.6) & 210 & (1.6) & $3.38(2.36-4.86)$ \\
\hline missing & 48 & (0.7) & 63 & $(0.5)$ & \\
\hline$p$-value for trend ${ }^{d}$ & & & & & $<0.0001$ \\
\hline \multicolumn{6}{|l|}{ Duration (yrs) ${ }^{c}$} \\
\hline$<20$ & 92 & (1.4) & 301 & (2.3) & $1.46(0.89-2.40)$ \\
\hline $20-<30$ & 219 & (3.4) & 501 & (3.9) & $1.85(1.44-2.37)$ \\
\hline $30-<40$ & 465 & (7.1) & 684 & (5.3) & $2.43(1.91-3.09)$ \\
\hline$\geq 40$ & 837 & $(12.9)$ & 1227 & (9.5) & $2.10(1.58-2.78)$ \\
\hline missing & 22 & $(0.3)$ & 53 & (0.4) & \\
\hline
\end{tabular}




\begin{tabular}{|c|c|c|c|c|c|}
\hline & \multicolumn{2}{|c|}{ Cases } & \multicolumn{2}{|c|}{ Controls } & \multirow{2}{*}{$\mathrm{OR}^{\mathrm{a}}(95 \% \mathrm{Cl})$} \\
\hline & N. & (\%) & N. & (\%) & \\
\hline$p$-value for trend ${ }^{d}$ & & & & & 0.067 \\
\hline \multicolumn{6}{|l|}{ Age at start $(\mathrm{yrs})^{\mathrm{c}}$} \\
\hline$<16$ & 356 & (5.5) & 541 & $(4.2)$ & $1.98(1.49-2.62)$ \\
\hline $16-<20$ & 547 & (8.4) & 867 & (6.7) & $2.20(1.69-2.87)$ \\
\hline $20-<23$ & 296 & $(4.5)$ & 534 & $(4.2)$ & $1.96(1.47-2.61)$ \\
\hline$\geq 23$ & 414 & (6.4) & 785 & (6.1) & $2.06(1.48-2.87)$ \\
\hline missing & 22 & $(0.3)$ & 39 & $(0.3)$ & \\
\hline$p$-value for trend ${ }^{d}$ & & & & & 0.439 \\
\hline \multicolumn{6}{|l|}{ Years since quitting } \\
\hline $1-<10$ & 640 & (9.8) & 1032 & (8.0) & $1.64(1.36-1.97)$ \\
\hline $10-<15$ & 301 & $(4.6)$ & 525 & (4.1) & $1.42(1.11-1.82)$ \\
\hline $15-<20$ & 267 & (4.1) & 503 & (3.9) & $1.12(0.86-1.44)$ \\
\hline $20-<30$ & 469 & (7.2) & 963 & (7.5) & $0.98(0.77-1.23)$ \\
\hline$\geq 30$ & 616 & (9.5) & 1136 & (8.8) & $0.98(0.83-1.16)$ \\
\hline missing & 34 & $(0.5)$ & 55 & $(0.4)$ & \\
\hline$p$-value for trend ${ }^{d}$ & & & & & $<0.0001$ \\
\hline \multicolumn{6}{|l|}{ Years since quitting } \\
\hline Current cigarette smoker & 1637 & (25.2) & 2769 & (21.5) & $1^{\mathrm{b}}$ \\
\hline $1-<10$ & 640 & (9.8) & 1032 & (8.0) & $0.73(0.56-0.95)$ \\
\hline $10-<15$ & 301 & (4.6) & 525 & (4.1) & $0.62(0.49-0.80)$ \\
\hline $15-<20$ & 267 & (4.1) & 503 & (3.9) & $0.46(0.35-0.60)$ \\
\hline $20-<30$ & 469 & (7.2) & 963 & (7.5) & $0.41(0.30-0.56)$ \\
\hline$\geq 30$ & 616 & (9.5) & 1136 & (8.8) & $0.42(0.29-0.60)$ \\
\hline missing & 34 & (0.5) & 55 & $(0.4)$ & \\
\hline$p$-value for trend $d^{d}$ & & & & & $<0.0001$ \\
\hline
\end{tabular}

${ }^{a}$ Pooled ORs were computed using random-effects models. Study-specific ORs were adjusted for age, sex, race/ethnicity, education, body mass index, history of diabetes, history of pancreatitis, alcohol drinking, and study center for multicentric studies. ${ }^{b}$ Reference category. ${ }^{c}$ Current smokers only. ${ }^{d}$ Including current smokers only.

The cumulative meta-analysis for pancreatic cancer risk in current cigarette smokers showed a trend of increasing risk according to year of publication: the OR for current versus never smokers was 1.74 in the initial study published in 1994, 1.75 in the studies published up to 2007, and rose to 2.2 when studies published 2007 and 2010 were added (Figure 1). 
Figure 1. Cumulative meta-analysis of pancreatic cancer risk in current cigarette smokers as compared to never smokers. International Pancreatic Cancer Case-Control Consortium (PanC4).

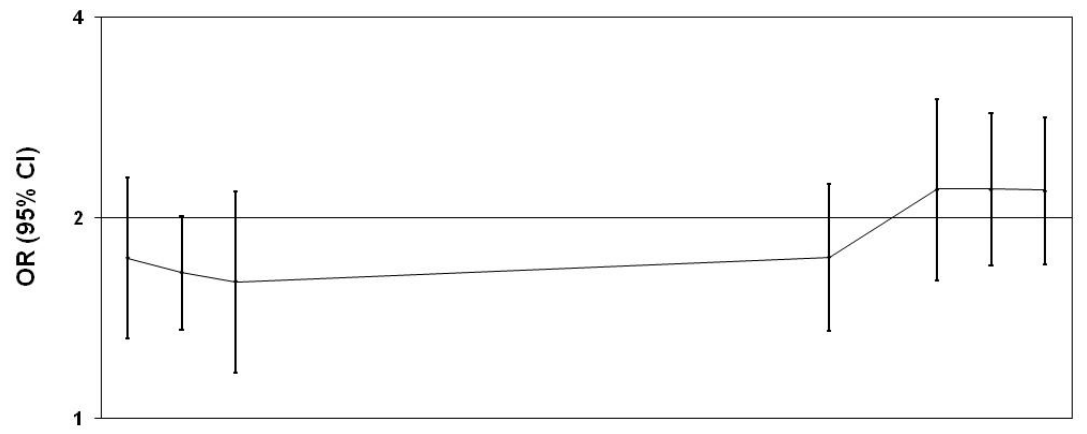

199419951996199719981999200020012002200320042005200620072008200920102010 a

\section{Year of publication}

OR, odds ratio; $95 \% \mathrm{Cl}, 95 \%$ confidence intervals.

ancluding the unpublished Louisiana State University (LSU) study.

Figure 2. Study-specific and pooled odd ratios ${ }^{a}$ (ORs) for pancreatic cancer according to ever cigarette smokers as compared to never smokers. International Pancreatic Cancer Case-Control Consortium (PanC4).

$\begin{array}{lcccc}\text { Study } & \text { Never } & \text { Ever } & \text { OR } & 95 \% \text { Cl } \\ & \text { Ca:Co } & \text { Ca:Co } & & \\ & & & & \\ \text { Italy } & 133: 328 & 186: 319 & 1.48 & 1.08-2.03 \\ \text { LSU } & 25: 69 & 44: 89 & 1.20 & 0.60-2.40 \\ \text { Mayo } & 427: 670 & 676: 591 & 1.81 & 1.51-2.17 \\ \text { MD Anderson } & 373: 404 & 477: 369 & 1.32 & 1.06-1.64 \\ \text { Milan } & 137: 582 & 224: 955 & 1.13 & 0.86-1.49 \\ \text { MSKCC } & 227: 161 & 267: 172 & 0.85 & 0.61-1.18 \\ \text { NCl } & 135: 734 & 338: 1301 & 1.60 & 1.26-2.03 \\ \text { Search } & 228: 657 & 568: 980 & 1.74 & 1.41-2.15 \\ \text { Shanghai } & 223: 902 & 228: 650 & 1.49 & 1.14-1.94 \\ \text { Toronto } & 197: 129 & 318: 168 & 1.15 & 0.82-1.61 \\ \text { UCSF } & 163: 651 & 348: 970 & 1.24 & 0.98-1.57 \\ \text { Yale } & 105: 270 & 288: 416 & 1.75 & 1.30-2.35 \\ & & & & \\ \text { Pooled } & 2373: 5557 & 3962: 6980 & 1.40 & 1.24-1.58 \\ & & & & \\ \text { Heterogeneity between studies: } \chi^{2}(11 \mathrm{df})=29 ; \mathrm{p}=0.0026 & \end{array}$

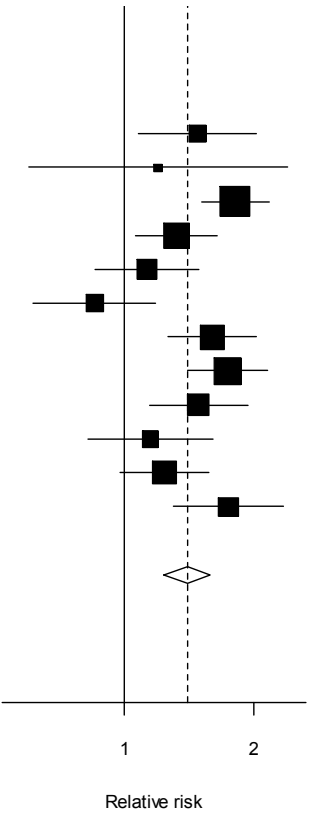


LSU, Louisiana State University; MSKCC, Memorial Sloan-Kettering Cancer Center; NCl, National Cancer Institute; SEARCH, Surveillance of Environmental Aspects Related to Cancer in Humans; UCSF, University of California, San Francisco.

${ }^{a}$ Study-specific ORs were adjusted for age, sex, race/ethnicity, education, body mass index, history of diabetes, history of pancreatitis, alcohol drinking, and study center for multicentric studies. Pooled ORs were computed using random-effects models.

A forest plot of the study-specific and the pooled ORs for pancreatic cancer risk for ever versus never cigarette smokers is presented in Figure 2.

The corresponding forest plots for numbers of cigarettes smoked per day among current smokers are given in Figure 3. The pooled estimate for ever cigarette smokers as compared to never smokers was 1.40 , with significant heterogeneity in ORs across studies $(p=0.003)$. Similarly, for current smokers of <15 (Figure 3a), 15-24 (Figure 3b) and $\geq 25$ (Figure $3 c$ ) cigarettes per day, all pooled estimates were significantly elevated, although between-study heterogeneity was observed for each level of cigarette smoking.

Figure 3. Study-specific and pooled odd ratios ${ }^{a}$ (ORs) for pancreatic cancer according to level of cigarette smoking in current smokers as compared to never smokers. International Pancreatic Cancer Case-Control Consortium (PanC4).

(a) $<15$ cigarettes/day

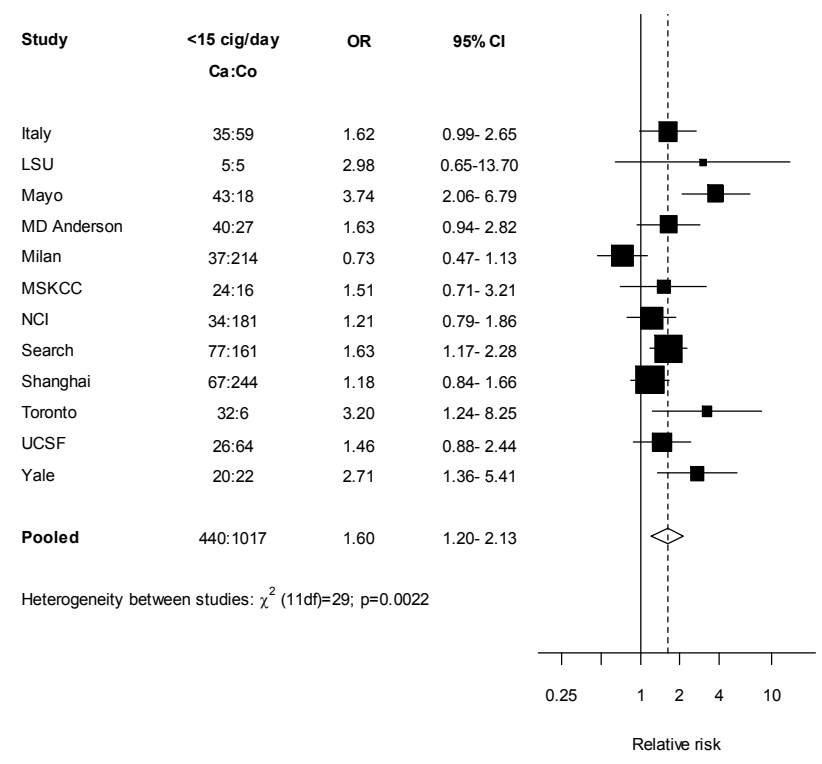


(b) 15-24 cigarettes/day

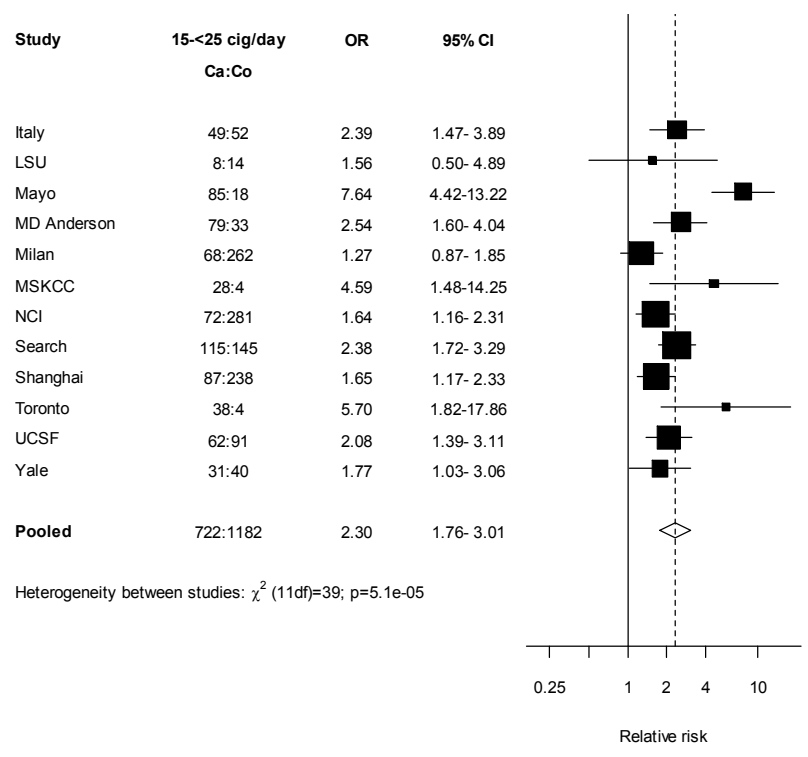

(c) $\geq 15$ cigarettes/day

$\begin{array}{lccc}\text { Study } & \begin{array}{c}\text { 25 or more cig/day } \\ \text { Ca:Co }\end{array} & \text { OR } & \mathbf{9 5 \%} \mathbf{C l} \\ & & & \\ & 14: 16 & 1.99 & 0.88-4.49 \\ \text { LSU } & 5: 7 & 2.07 & 0.47-9.16 \\ \text { Mayo } & 40: 8 & 7.65 & 3.40-17.21 \\ \text { MD Anderson } & 39: 12 & 3.95 & 1.94-8.05 \\ \text { Milan } & 32: 154 & 1.16 & 0.72-1.87 \\ \text { MSKCC } & 6: 5 & 0.92 & 0.23-3.64 \\ \text { NCI } & 57: 129 & 2.89 & 1.93-4.32 \\ \text { Search } & 85: 74 & 3.15 & 2.14-4.63 \\ \text { Shanghai } & 33: 38 & 4.21 & 2.48-7.16 \\ \text { Toronto } & 40: 4 & 6.07 & 2.00-18.44 \\ \text { UCSF } & 39: 41 & 3.04 & 1.82-5.07 \\ \text { Yale } & 35: 16 & 4.60 & 2.33-9.08 \\ & & & \\ \text { Pooled } & 425: 504 & 3.03 & 2.23-4.12 \\ & & & \\ \text { Heterogeneity between } & \text { studies: } \chi^{2}(11 \mathrm{df})=30 ; \mathrm{p}=0.0018\end{array}$

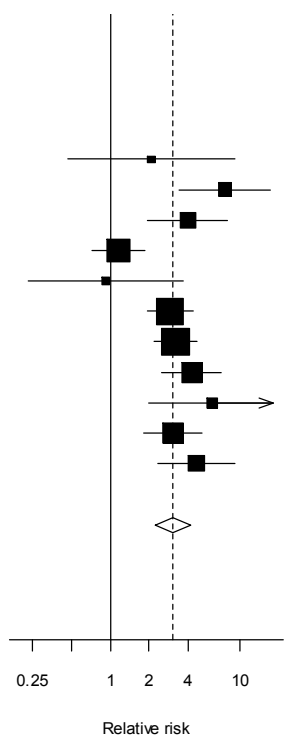

LSU, Louisiana State University; MSKCC, Memorial Sloan-Kettering Cancer Center; NCl, National Cancer Institute; SEARCH, Surveillance of Environmental Aspects Related to Cancer in Humans; UCSF, University of California, San Francisco.

${ }^{a}$ Study-specific ORs were adjusted for age, sex, race/ethnicity, education, body mass index, history of diabetes, history of pancreatitis, alcohol drinking, and study center for multicentric studies. Pooled ORs were computed using random-effects models. 
The association between number of cigarettes smoked and pancreatic cancer risk was further assessed in analyses stratified by sex, age, alcohol drinking, race/ethnicity, study area, source of controls and type of respondents (Table 4). The association appeared somewhat stronger - though not significantly - in women, in participants younger than 65 years, and in proxy respondents; no meaningful differences in risk estimates were observed across strata of other covariates considered.

Table 4. Pooled odds ratios ${ }^{a}$ (ORs) and corresponding $95 \%$ confidence intervals (Cls) for pancreatic cancer according to cigarette smoking in strata of selected covariates among 6507 cases and 12,890 controls. International Pancreatic Cancer Case-Control Consortium (PanC4).

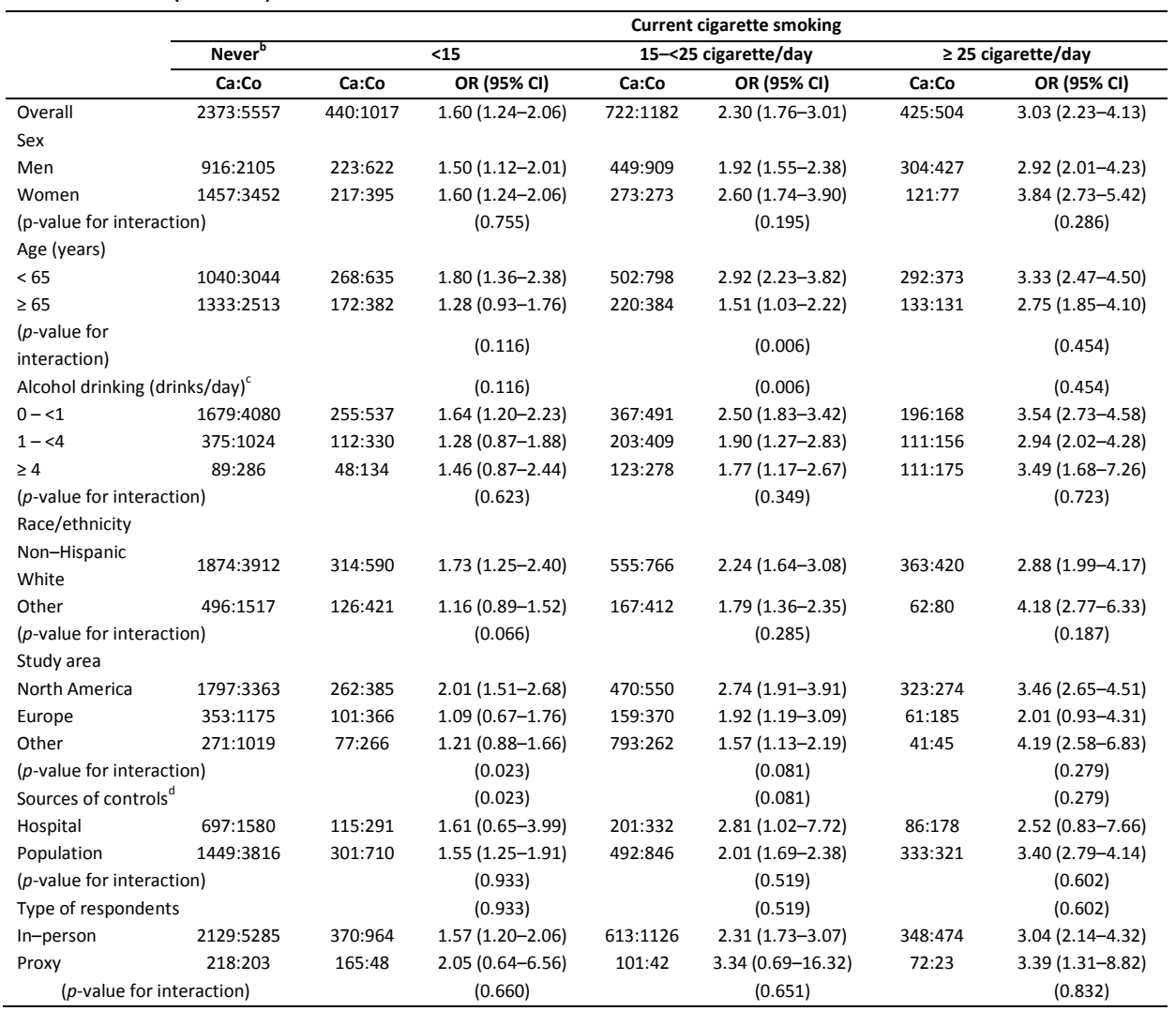

${ }^{\text {a }}$ Pooled ORs were computed using random-effects models. Study-specific ORs were adjusted for age, sex, race/ethnicity, education, body mass index, history of diabetes, history of pancreatitis, alcohol drinking, and study center for multicentric studies. 
${ }^{b}$ Reference category. ${ }^{c}$ No information was available in the MSKCC study. ${ }^{d}$ Excluding the MSKCC study including both hospital and population controls. Ca:Co, Cases:Controls.

\section{Discussion}

This uniquely large collaborative pooled analysis within the PanC4 consortium allowed us to provide more accurate estimates of the relationship between cigarette smoking and pancreatic cancer risk. Results from our analyses confirm that current cigarette smoking is associated with a 2-fold increased risk of pancreatic cancer, and that the risk increases with increasing number of cigarettes smoked and duration of smoking. $A$ $20 \%$ excess risk of pancreatic cancer was found among former smokers, that declines with time since quitting, and reached the level of never cigarette smokers 20 years after quitting.

The increased pancreatic cancer risk in current cigarette smokers in our data is consistent with that of two previous meta- and pooled-analyses [3, 4] and with the results from a subsequent study of the European Prospective Investigation into Cancer and Nutrition (EPIC) cohort [23] which reported a 70\% increased risk (95\% Cl 1.4-2.2) for current smokers, on the basis of 524 pancreatic cancer cases among 465,910 participants. The OR estimate for current cigarette smokers in our data was slightly higher that that reported in previous investigations $[3,4,23]$. This can be explained by the better distinction between current and former smokers that was possible in our analysis, but not in the studies included in the meta-analysis by lodice et al. [3], as well as in prospective studies [4, 23], where smoking habits are generally assessed at the time of recruitment or last interview, and may have changed in subsequent years [24], i.e. some current smokers at baseline may have quit before diagnosis.

The significant dose-risk association with increasing number of cigarettes smoked is consistent with that reported in the pooled analysis of cohort studies [4]. However, case-control studies data allowed us to assess this association specifically among current smokers, something that was not possible in cohort studies where the effect pertained to ever smokers.

With reference to duration of smoking, we observed that risk of pancreatic cancer increased in relation to years of smoking, up to 40 years of smoking. This confirms the importance of long-term duration of smoking as a pancreatic cancer risk factor $[1,4]$. The results of our study also confirmed the decline in risk of pancreatic cancer with increasing time since quitting cigarette smoking [3,4]. More specifically our large population and detailed smoking data allowed us to confirm that after 20 years of smoking cessation risk of pancreatic cancer approaches that of never smokers. This result was in close agreement with the findings from the International Pancreatic Cancer Cohort Consortium [4]. 
The Panc4 study had a number of strengths. It included original and detailed data about cigarette smoking for more than 6000 pancreatic cancer cases and more than 12,000 controls, which provided a unique opportunity to investigate and quantify accurately the dose- and duration-risk relationships, and, among former smokers, the pattern of risk with years since quitting. Our study included a relatively large number of heavy and long-term smokers, as well as a large number of former smokers increasing our ability to examine smoking behaviors in greater detail than previous studies. We were able to uniformly and carefully account for study design variables and potential confounding factors for pancreatic cancer, including education, BMI, history of diabetes and pancreatitis, and heavy alcohol consumption. We also conducted stratified analyses by selected covariates and showed that our risk estimates were consistent across strata of sex, age, race, study area and alcohol consumption.

Although there was significant heterogeneity between the 12 studies included in our pooled analysis, this was not explained by sex, age, study areas, source of controls or other selected covariates considered, and was largely attributable to the Mayo [7] and Milan studies only [16]. This may be due to different background risk levels in various populations, bias or simply the play of chance. Because $\mathrm{N}$-nitrosamines are considered the major tobacco carcinogens for the pancreas $[25,26]$, some of the heterogeneity might be also related to different $\mathrm{N}$-nitrosamines yield of cigarettes in various countries [27, 28]. In the absence of comprehensive data, however, any inference on this issue remains speculative.

Both hospital-based and population-based case-controls are prone to potential bias. Hospital controls may have been admitted to hospital for conditions related to tobacco use that could lead to an underestimation of the true association, whereas population controls may have a lower participation of smokers that could result in an overestimation of risk. Although the results from one meta-analysis [3] showed that RR estimates were higher in hospital-based than in population-based case-control studies, our stratified analyses by source of controls did not support this, showing no consistent differences in risk estimates when using hospital or population controls. Tobacco consumption is frequently under-reported [29], and this may have biased our risk estimates, particularly if misclassification of smoking differed between cases and controls. However, information on smoking habits in case-control studies has proven to be satisfactorily reliable [30]. Further, the similarities of our findings with those from cohort studies [4] argue against a major role of recall bias and misclassification. Although proxy respondents may have reported tobacco consumption less completely than participants, we found no evidence of stronger associations in studies based on in-person interviews versus those using proxy respondents.

There is no early diagnosis or effective chemotherapy for pancreatic cancer [31]. Most patients cannot undergo curative surgery, thus - even in the optimal series, 5-year 
survival is less than 5\% [32]. Consequently, primary prevention is the only way to reduce pancreatic cancer, and control of tobacco smoking is the key measure, since it could avoid $15-25 \%$ of pancreatic cancers in various populations $[4,16,33]$. 


\section{References}

1. IARC. IARC Monographs on the Evaluation of the Carcinogenic Risks to Humans. Vol. 83. Tobacco smoke and involuntary smoking. IARC, Lyon 2004.

2. Secretan $B$, Straif $K$, Baan $R$ et al. A review of human carcinogens--Part $E$ : tobacco, areca nut, alcohol, coal smoke, and salted fish. Lancet Oncol 2009; 10: 1033-1034.

3. Iodice S, Gandini S, Maisonneuve P, Lowenfels AB. Tobacco and the risk of pancreatic cancer: a review and meta-analysis. Langenbecks Arch Surg 2008; 393: 535-545.

4. Lynch SM, Vrieling A, Lubin JH et al. Cigarette smoking and pancreatic cancer: a pooled analysis from the pancreatic cancer cohort consortium. Am J Epidemiol 2009; 170: 403-413.

5. The Pancreatic Cancer Case Control Consortium (PanC4). Available at: http://panc4.org/ 2007.

6. Bertuccio P, La Vecchia C, Silverman DT et al. Cigar and pipe smoking, smokeless tobacco use and pancreatic cancer: an analysis from the International Pancreatic Cancer Case-Control Consortium (PanC4). Ann Oncol 2011; 22:1420-1426.

7. McWilliams RR, Bamlet WR, de Andrade $M$ et al. Nucleotide excision repair pathway polymorphisms and pancreatic cancer risk: evidence for role of MMS19L. Cancer Epidemiol Biomarkers Prev 2009; 18: 1295-1302.

8. Hassan MM, Bondy ML, Wolff RA et al. Risk factors for pancreatic cancer: casecontrol study. Am J Gastroenterol 2007; 102: 2696-2707.

9. Olson SH, Orlow I, Simon J et al. Allergies, variants in IL-4 and IL-4R alpha genes, and risk of pancreatic cancer. Cancer Detect Prev 2007; 31: 345-351.

10. Silverman DT, Dunn JA, Hoover RN et al. Cigarette smoking and pancreas cancer: a case-control study based on direct interviews. J Natl Cancer Inst 1994; 86: 15101516.

11. Chan JM, Wang F, Holly EA. Sweets, sweetened beverages, and risk of pancreatic cancer in a large population-based case-control study. Cancer Causes Control 2009; 20: 835-846.

12. Bracci PM, Wang F, Hassan MM et al. Pancreatitis and pancreatic cancer in two large pooled case-control studies. Cancer Causes Control 2009; 20: 1723-1731.

13. Risch HA, Yu H, Lu L, Kidd MS. ABO blood group, Helicobacter pylori seropositivity, and risk of pancreatic cancer: a case-control study. J Natl Cancer Inst 2010; 102: 502-505.

14. Anderson LN, Cotterchio M, Gallinger S. Lifestyle, dietary, and medical history factors associated with pancreatic cancer risk in Ontario, Canada. Cancer Causes Control 2009; 20: 825-834.

15. Talamini R, Polesel J, Gallus $S$ et al. Tobacco smoking, alcohol consumption and pancreatic cancer risk: A case-control study in Italy. Eur J Cancer 2010; 46: 370376. 
16. Fernandez E, La Vecchia C, Decarli A. Attributable risks for pancreatic cancer in northern Italy. Cancer Epidemiol Biomarkers Prev 1996; 5: 23-27.

17. Ji BT, Chow WH, Dai $Q$ et al. Cigarette smoking and alcohol consumption and the risk of pancreatic cancer: a case-control study in Shanghai, China. Cancer Causes Control 1995; 6: 369-376.

18. Boyle $P$, Maisonneuve $P$, Bueno de Mesquita B et al. Cigarette smoking and pancreas cancer: a case control study of the search programme of the IARC. Int J Cancer 1996; 67: 63-71.

19. Smith-Warner SA, Spiegelman D, Ritz J et al. Methods for pooling results of epidemiologic studies: the Pooling Project of Prospective Studies of Diet and Cancer. Am J Epidemiol 2006; 163: 1053-1064.

20. Breslow NE, Day NE. Statistical methods in cancer research. Vol. I. The analysis of case-control studies. IARC Sci Publ No. 32. Lyon, France: IARC 1980.

21. DerSimonian R, Laird N. Meta-analysis in clinical trials. Control Clin Trials 1986; 7 : 177-188.

22. Greenland S. Quantitative methods in the review of epidemiologic literature. Epidemiol Rev 1987; 9: 1-30.

23. Vrieling A, Bueno-de-Mesquita HB, Boshuizen $\mathrm{HC}$ et al. Cigarette smoking, environmental tobacco smoke exposure and pancreatic cancer risk in the European Prospective Investigation into Cancer and Nutrition. Int J Cancer 2010; 126: 2394-2403.

24. Bosetti C, Negri E, Tavani A et al. Smoking and acute myocardial infarction among women and men: A case-control study in Italy. Prev Med 1999; 29: 343-348.

25. Schuller HM. Mechanisms of smoking-related lung and pancreatic adenocarcinoma development. Nat Rev Cancer 2002; 2: 455-463.

26. Duell EJ. Epidemiology and potential mechanisms of tobacco smoking and heavy alcohol consumption in pancreatic carcinogenesis. Mol Carcinog 2012; 51:40-52.

27. Gray N, Boyle P. The case of the disappearing nitrosamines: a potentially global phenomenon. Tob Control 2004; 13: 13-16.

28. Gray N, Zaridze D, Robertson C et al. Variation within global cigarette brands in tar, nicotine, and certain nitrosamines: analytic study. Tob Control 2000; 9: 351.

29. Rebagliato M. Validation of self reported smoking. J Epidemiol Community Health 2002; 56: 163-164.

30. D' Avanzo B, La Vecchia C, Katsouyanni K et al. Reliability of information on cigarette smoking and beverage consumption provided by hospital controls. Epidemiology 1996; 7: 312-315.

31. Hidalgo M. Pancreatic cancer. N Engl J Med 2010; 362: 1605-1617.

32. Levi F, Randimbison L, Te VC et al. Trends in survival for patients diagnosed with cancer in Vaud, Switzerland, between 1974 and 1993. Ann Oncol 2000; 11: 957963. 
33. Maisonneuve $P$, Lowenfels AB. Epidemiology of pancreatic cancer: an update. Dig Dis 2010; 28: 645-656. 



\section{CHAPTER 3.2. UlCER, GASTRIC SURGERY AND Pancreatic Cancer Risk: an Analysis FROM THE INTERNATIONAL PANCREATIC Cancer Case-Control Consortium}

C. Bosetti, E. Lucenteforte, P. M. Bracci, E. Negri, R. E. Neale, H. A. Risch,

S. H. Olson, S. Gallinger, A. B. Miller, H. Bas Bueno-de-Mesquita, R. Talamini, J. Polesel, P. Ghadirian, P. A. Baghurst, W. Zatonski, E. Fontham, E. A. Holly, Y. T. Gao, H. Yu, R. C. Kurtz, M. Cotterchio, P. Maisonneuve ${ }^{1}$, M.P. Zeegers, E.J. Duell, P. Boffetta, C. La Vecchia 


\section{Abstract}

Peptic ulcer and its treatments have been reported to increase pancreatic cancer risk, although the evidence is inconsistent, we pooled 10 case-control studies within the Pancreatic Cancer Case-Control Consortium (PanC4), including 4717 pancreatic cancer cases and 9374 controls, and estimated summary odds ratios (OR) using multivariable logistic regression models. The OR for pancreatic cancer was 1.10 (95\% confidence interval, $\mathrm{Cl}, 0.98-1.23$ ) for history of ulcer ( $\mathrm{OR}=1.08$ for gastric and 0.97 for duodenal ulcer). The association was stronger for a diagnosis within two years prior to cancer diagnosis ( $O R=2.43$ for peptic, 1.75 for gastric, and 1.98 for duodenal ulcer). The OR was 1.53 (95\% $\mathrm{Cl} 1.15-2.03)$ for history of gastrectomy; however, the excess risk was limited to a gastrectomy within two years prior to cancer diagnosis (OR=6.18, $95 \% \mathrm{Cl}$ 1.82-20.96), while no significant increased risk was observed for a longer history of gastrectomy. No associations were observed for antacids, H2-receptor antagonists or proton-pump inhibitors.

This uniquely large collaborative study does not support the hypothesis that peptic ulcer and its treatment materially affects pancreatic cancer risk. The increased risk for short-term history of ulcer and gastrectomy suggests that any such associations may be due to increased cancer surveillance. 


\section{Introduction}

The association between peptic ulcer and the risk of pancreatic cancer has been examined in at least 15 epidemiologic studies, with inconclusive results [1, 2]. Several of the studies showed no meaningful associations and a few others reported modestly increased risks of pancreatic cancer among participants with a history of gastric, but not, duodenal ulcer. With reference to gastrectomy for benign gastroduodenal diseases, seven out of 15 studies found significantly increased risk of pancreatic cancer, and five of these indicated that the excess risk persisted for more than 20 years after surgery [2]. Most previous studies included a relatively small number of participants, were unable to distinguish gastric from duodenal ulcer, could not quantify time-dependent variables, and, more importantly, did not carefully account for tobacco smoking, which is associated with both peptic ulcer [3] and pancreatic cancer [4].

If an association with ulcer or gastrectomy exists, it may help to elucidate the role of gastric secretion in pancreatic cancer etiology. Gastric secretion influences hormonal and neurological regulation of the pancreas [5] and detoxification of endogenous and exogenous substances in the duodenum and small intestine is less efficient after gastrectomy. Further, gastrectomy can increase endogenous production of $\mathrm{N}$-nitroso compounds, possibly due to changes in bacterial growth [6].

In order to provide further information, we pooled original data from 10 case-control studies within the Pancreatic Cancer Case-Control Consortium (PanC4, http://www.panc4.org) where information on ulcer, gastrectomy, and use of medications for ulcers was available, and adequate adjustment was possible for tobacco and other major relevant covariates.

\section{Methods}

\section{Studies}

The present pooled analysis included 4717 cases of adenocarcinoma of the exocrine pancreas and 9374 controls derived from 10 case-control studies of pancreatic cancer within the PanC4 consortium. These provided information on peptic ulcer and/or gastric surgery, with some studies containing additional information about medication use $[7-15]^{3}$. The main characteristics of the studies are described in Supplemental Table 1.

Five studies were conducted in the USA, and the others in Canada, Europe, Shanghai, and Australia. In all studies, cases and controls were interviewed in-person, with the exception of the Toronto study where participants completed mailed questionnaires and included 63 case-proxy respondents, the SEARCH study where proxy interviews

\footnotetext{
${ }^{3}$ Including the unpublished Queensland study.
} 
were conducted for 474 cases and 332 controls, and the Shanghai study where 155 cases and 150 controls were proxy-interviewed (for a total of 692 or $13.7 \%$ of cases and 472 or $4.3 \%$ of controls).

Supplemental Table 1. Studies included in the analyses of peptic ulcer and its treatments and pancreatic cancer risk. International Pancreatic Cancer Case-Control Consortium (PanC4).

\begin{tabular}{|c|c|c|c|c|c|c|c|}
\hline \multirow{2}{*}{$\begin{array}{l}\text { Country, study } \\
\text { [Reference] }\end{array}$} & \multirow[b]{2}{*}{$\begin{array}{l}\text { Study } \\
\text { period }\end{array}$} & \multicolumn{3}{|c|}{ Cases } & \multicolumn{3}{|c|}{ Controls } \\
\hline & & $\begin{array}{c}\text { Men: } \\
\text { Women }\end{array}$ & $\begin{array}{c}\text { Age range } \\
\text { (median) }\end{array}$ & Sources & $\begin{array}{c}\text { Men: } \\
\text { Women }\end{array}$ & $\begin{array}{l}\text { Age range } \\
\text { (median) }\end{array}$ & Sources \\
\hline \multicolumn{8}{|l|}{ North America } \\
\hline Louisiana, LSU [15] & $\begin{array}{l}2001- \\
2006\end{array}$ & $33: 36$ & $32-86(68)$ & $\begin{array}{l}\text { Cancer } \\
\text { registry }\end{array}$ & $78: 80$ & $33-90(67)$ & Population-based files \\
\hline $\begin{array}{l}\text { New York, MSKCC } \\
\text { [7] }\end{array}$ & $\begin{array}{c}2003- \\
2008\end{array}$ & $264: 245$ & $32-89(64)$ & Hospital & $142: 206$ & $27-84(58)$ & Hospital (visitors) \\
\hline California, UCSF [8] & $\begin{array}{l}1995- \\
1999\end{array}$ & $287: 240$ & $32-85(65)$ & $\begin{array}{l}\text { Cancer } \\
\text { registry }\end{array}$ & $879: 818$ & $32-85(66)$ & $\begin{array}{c}\text { Random digit dial }(<65 \\
\text { yrs)/ Health Care } \\
\text { Financing } \\
\text { Administration as } \\
\text { supplement for } \geq 65 \\
\text { yrs }\end{array}$ \\
\hline Connecticut, Yale [9] & $\begin{array}{l}2005- \\
2009\end{array}$ & $238: 175$ & $36-84(68)$ & $\begin{array}{l}\text { Hospitals } \\
\text { and Cancer } \\
\text { registry from } \\
\text { Connecticut }\end{array}$ & 404:311 & $35-84(68)$ & Random-digit dial \\
\hline Canada, Toronto [10] & $\begin{array}{l}2003- \\
2007\end{array}$ & $302: 238$ & $20-89(65)$ & $\begin{array}{l}\text { Cancer } \\
\text { registry }\end{array}$ & $177: 136$ & $40-79(67)$ & Random digit dial \\
\hline \multicolumn{8}{|l|}{ Europe } \\
\hline Italy [35] & $\begin{array}{c}1991- \\
2008\end{array}$ & $174: 148$ & $34-80(63)$ & Hospital & $348: 304$ & $34-80(63)$ & Hospital \\
\hline Milan $[11,12]$ & $\begin{array}{l}1983- \\
1999\end{array}$ & $229: 133$ & $17-86(60)$ & Hospital & $1140: 409$ & $21-84(56)$ & Hospital \\
\hline \multicolumn{8}{|l|}{ China } \\
\hline Shanghai [13] & $\begin{array}{c}1990- \\
1993\end{array}$ & $264: 187$ & $31-74(64)$ & $\begin{array}{l}\text { Cancer } \\
\text { registry }\end{array}$ & $851: 701$ & $30-74(62)$ & Resident registry \\
\hline \multicolumn{8}{|l|}{ Australia } \\
\hline Queensland $^{\mathrm{a}}$ & $\begin{array}{l}2007- \\
2011\end{array}$ & 426: 288 & $29-98(67)$ & Population & $424: 287$ & $34-94(67)$ & Population \\
\hline $\begin{array}{l}\text { Canada, Europe, } \\
\text { Australia, SEARCH } \\
{[14]}\end{array}$ & $\begin{array}{c}1983- \\
1989\end{array}$ & $447: 363$ & $32-86(65)$ & $\begin{array}{l}\text { Hospital, } \\
\text { Cancer } \\
\text { registry }\end{array}$ & $858: 821$ & $28-87(65)$ & Resident registry \\
\hline
\end{tabular}

LSU, Louisiana School of Public Health; MSKCC, Memorial Sloan-Kettering Cancer Center; SEARCH, Surveillance of Environmental Aspects Related to Cancer in Humans; UCSF University of California, San Francisco.

${ }^{a}$ Unpublished data.

For the present analyses, the original datasets were restructured either by the original study investigators or by our central coordinators using a uniform format for data harmonization. From each study, individual data on socio-demographic characteristics, anthropometric measures, tobacco smoking, alcohol consumption, and history of diabetes and pancreatitis were collected.

Information on ulcer, related medications and gastrectomy varied among the studies, and we conducted a careful and detailed examination of the comparability of ulcer- 
related questions before combining the data. Six of the studies provided information on history of gastric ulcer (Milan, LSU, MSKCC, Shanghai, Yale, Queensland), four on history of duodenal ulcer (Milan, MSKCC, Shanghai, Yale, Queensland), and three on history peptic ulcer with no distinction between gastric and duodenal ulcer (Italy, UCSF, SEARCH, Toronto). All studies, except Shanghai, provided the corresponding age at first diagnosis. Information on gastrectomy was provided by the Milan, UCSF, SEARCH, LSU, Shanghai, and Yale studies, with corresponding age at surgery available in the Milan, UCSF, SEARCH, and Yale studies. With reference to medications for ulcer treatment, two studies (SEARCH, Queensland) specifically asked for use of antacids, four (Milan, SEARCH, Shanghai, Queensland) for use of histamine-2 (H2)-receptor antagonists, one (Queensland) for use of proton-pump inhibitors (PPIs), while two studies (UCSF, Toronto) had an open question asking for various medications used, including antacids, H2-receptor antagonists, and PPIs. In all studies information on ulcer, related medications and gastrectomy was self-reported. In studies providing information separately for gastric and duodenal ulcer, a variable for peptic ulcer was created by combining information for the two conditions, and age at first diagnosis of peptic ulcer was defined as the earliest reported age at diagnosis.

\section{Statistical analysis}

To estimate the association between gastric and duodenal ulcer, their medications, gastric surgery and pancreatic cancer risk, we conducted an aggregate analysis pooling data from all studies into a single large data set [16]. Summary odds ratios (OR) and the corresponding $95 \%$ confidence intervals $(\mathrm{Cl})$, were estimated using multiple logistic regression models that included terms for study, study centre (for multicenter studies), age (5-years group), sex, education ( $\leq 8^{\text {th }}$ grade, $9-11^{\text {th }}$ grade, $12^{\text {th }}$ grade or high-school graduates, some college or college graduates, $\geq 1$ year of graduate school), race/ethnicity (non-Hispanic white, Hispanic, non-Hispanic black, other), body mass index (BMI, $<20,20-<25,25-<30, \geq 30 \mathrm{~kg} / \mathrm{m}^{2}$ ), tobacco smoking (never smokers, current cigarette smokers of 1-20 cigarettes per day, current cigarette smokers of $>20$ cigarettes per day, ex-cigarette smokers since $<10$ years, ex-cigarette smokers since $>10$ years, smokers of products other than cigarettes, as well as a continuous term for current number of cigarettes), alcohol consumption (never drinkers, 1-4 drinks per day, drinkers $\geq 4$ drinks per day), history of diabetes, and history of pancreatitis. Tests for linear trend of ORs were based on ordinal coding of the categories and the corresponding $\chi^{2}$ statistic. Study-specific ORs and pooled ORs with $95 \% \mathrm{Cls}$ were plotted for visual comparison.

To investigate whether the effect of history of ulcer/gastrectomy was homogeneous in strata of selected covariates, we conducted analyses stratified by sex, age, race/ethnicity, BMI, tobacco smoking, alcohol consumption, study area, and source of controls. 
Heterogeneity between studies and across the strata was based on likelihood ratio tests and the resulting $\chi^{2}$ statistics. Sensitivity analyses excluding proxy-respondents and participants with a history of pancreatitis were also conducted.

\section{Results}

Table 1 shows the distribution of 4717 pancreatic cancer cases and 9374 controls by sex, age, and other potential confounding factors. Cases and controls have a similar sex distribution.

Table 1. Distribution of pancreatic cancer cases and controls by sex, age, race and other covariates, International Pancreatic Cancer Case-Control Consortium (PanC4).

\begin{tabular}{|c|c|c|c|c|}
\hline \multirow{2}{*}{ Characteristics } & \multicolumn{2}{|c|}{ Cases } & \multicolumn{2}{|c|}{ Controls } \\
\hline & No. & (\%) & No. & (\%) \\
\hline \multicolumn{5}{|l|}{ Sex } \\
\hline Men & 2664 & (56.5) & 5301 & (56.6) \\
\hline Women & 2053 & (43.5) & 4073 & (43.5) \\
\hline \multicolumn{5}{|l|}{ Age (years) } \\
\hline$<50$ & 441 & $(9.4)$ & 1323 & (14.1) \\
\hline $50-54$ & 431 & (9.1) & 999 & (10.7) \\
\hline $55-59$ & 655 & (13.9) & 1300 & (13.9) \\
\hline $60-64$ & 791 & $(16.8)$ & 1507 & (16.1) \\
\hline $65-69$ & 834 & (17.7) & 1582 & (16.9) \\
\hline $70-75$ & 791 & $(16.8)$ & 1489 & (15.9) \\
\hline$\geq 75$ & 774 & (16.4) & 1174 & (12.5) \\
\hline \multicolumn{5}{|l|}{ Education } \\
\hline$\leq 8^{\text {th }}$ grade & 1184 & $(25.1)$ & 3117 & (33.4) \\
\hline $9^{\text {th }}-11^{\text {th }}$ grade & 820 & (17.4) & 1340 & (14.3) \\
\hline $12^{\text {th }}$ grade or high school graduate & 739 & $(15.7)$ & 1229 & (13.1) \\
\hline Some college or college graduate & 1229 & (26.1) & 2340 & (25.0) \\
\hline$\geq 1$ year of graduate school & 688 & $(14.6)$ & 1275 & (13.6) \\
\hline Missing & 57 & (1.2) & 73 & (0.8) \\
\hline \multicolumn{5}{|l|}{ Race/ethnicity } \\
\hline Non-Hispanic White & 3749 & (79.5) & 6937 & (74.0) \\
\hline Non-Hispanic Black & 118 & $(2.5)$ & 146 & (1.6) \\
\hline Hispanic & 40 & $(0.9)$ & 123 & (1.3) \\
\hline Others & 618 & (13.1) & 1766 & (18.8) \\
\hline Missing & 192 & (4.1) & 402 & (4.3) \\
\hline \multicolumn{5}{|l|}{ Body mass index $\left(\mathrm{kg} / \mathrm{m}^{2}\right)$} \\
\hline$<20$ & 418 & $(8.9)$ & 973 & (10.4) \\
\hline $20-<25$ & 1846 & $(39.1)$ & 4285 & $(45.7)$ \\
\hline $25-<30$ & 1630 & (34.6) & 3016 & (32.2) \\
\hline$\geq 30$ & 731 & $(15.5)$ & 987 & (10.5) \\
\hline Missing & 92 & $(2.0)$ & 113 & (1.2) \\
\hline \multicolumn{5}{|l|}{ Tobacco smoking } \\
\hline Never smokers & 1696 & (36.0) & 4097 & (43.7) \\
\hline Current smokers, $\leq 20$ cigarettes/day & 841 & (17.8) & 1607 & (17.1) \\
\hline
\end{tabular}




\begin{tabular}{|c|c|c|c|c|}
\hline \multirow{2}{*}{ Characteristics } & \multicolumn{2}{|c|}{ Cases } & \multicolumn{2}{|c|}{ Controls } \\
\hline & No. & (\%) & No. & (\%) \\
\hline Current smokers, $>20$ cigarettes/day & 416 & $(8.8)$ & 449 & $(4.8)$ \\
\hline Ex-smokers, $\leq 10$ years since quitting & 533 & $(11.3)$ & 852 & (9.1) \\
\hline Ex-smokers, $>10$ years since quitting & 1058 & $(22.4)$ & 2066 & $(22.0)$ \\
\hline Smokers of other products & 96 & $(2.0)$ & 187 & (2.0) \\
\hline Missing & 77 & (1.6) & 116 & (1.2) \\
\hline \multicolumn{5}{|l|}{ Alcohol drinking (drinks/day) $)^{a}$} \\
\hline $0-<1$ & 2274 & $(48.2)$ & 5038 & (53.7) \\
\hline $1-<4$ & 1168 & $(24.8)$ & 2741 & $(29.2)$ \\
\hline$\geq 4$ & 613 & $(13.4)$ & 1145 & $(12.2)$ \\
\hline Missing & 644 & (13.7) & 450 & (4.8) \\
\hline \multicolumn{5}{|l|}{ History of diabetes } \\
\hline No & 3837 & $(81.3)$ & 8618 & (91.9) \\
\hline Yes & 873 & $(18.5)$ & 750 & (8.0) \\
\hline Missing & 7 & $(0.2)$ & 6 & (0.1) \\
\hline \multicolumn{5}{|l|}{ History of pancreatitis ${ }^{b}$} \\
\hline No & 4120 & $(87.3)$ & 8610 & (91.9) \\
\hline Yes & 235 & $(5.0)$ & 97 & (1.0) \\
\hline Missing & 362 & (7.7) & 667 & (7.1) \\
\hline
\end{tabular}

Cases were somewhat older than controls, they were more frequently white and ever smokers, had a higher level of education, a higher BMI, and reported a history of diabetes and pancreatitis more frequently.

The distribution of pancreatic cancer cases and controls by history of peptic ulcer and the corresponding OR are given in Table 2.

Table 2. Distribution of pancreatic cancer cases and controls, and corresponding odds ratios $(\mathrm{OR})$ and $95 \%$ confidence intervals $(\mathrm{Cl})$, by history of gastric or duodenal ulcer. International Pancreatic Cancer Case-Control Consortium (PanC4).

\begin{tabular}{|c|c|c|c|c|c|}
\hline & \multicolumn{2}{|c|}{ Cases } & \multicolumn{2}{|c|}{ Controls } & \multirow{2}{*}{$\mathrm{OR}^{\mathrm{a}}(95 \% \mathrm{Cl})$} \\
\hline & No. & (\%) & No. & (\%) & \\
\hline \multicolumn{6}{|c|}{$\begin{array}{l}\text { History of gastric or duodenal } \\
\text { ulcer }\end{array}$} \\
\hline No & 3976 & $(84.3)$ & 8146 & (86.9) & $1^{\mathrm{b}}$ \\
\hline Yes & 673 & $(14.3)$ & 1183 & $(12.6)$ & $1.10(0.98-1.23)$ \\
\hline Missing & 68 & (1.4) & 45 & (0.5) & \\
\hline \multicolumn{6}{|c|}{ Years since diagnosis $^{c}$} \\
\hline No & 3610 & $(86.0)$ & 6835 & (87.9) & $1^{b}$ \\
\hline$\leq 2$ years & 87 & (2.1) & 63 & $(0.8)$ & $2.43(1.68-3.50)$ \\
\hline $3-10$ years & 97 & (2.3) & 172 & $(2.2)$ & $1.03(0.78-1.36)$ \\
\hline$>10$ years & 376 & (9.0) & 680 & (8.7) & $0.96(0.83-1.11)$ \\
\hline
\end{tabular}




\begin{tabular}{|c|c|c|c|c|c|}
\hline & \multicolumn{2}{|c|}{ Cases } & \multicolumn{2}{|c|}{ Controls } & \multirow{2}{*}{$\mathrm{OR}^{\mathrm{a}}(95 \% \mathrm{Cl})$} \\
\hline & No. & (\%) & No. & (\%) & \\
\hline Missing & 28 & (0.7) & 27 & (0.4) & \\
\hline$p$-value for trend & & & & & 0.90 \\
\hline \multicolumn{6}{|c|}{ Age at first diagnosis ${ }^{c}$} \\
\hline No & 3610 & $(86.0)$ & 6835 & $(87.9)$ & $1^{b}$ \\
\hline$\leq 40$ years & 259 & $(6.2)$ & 495 & (6.4) & $0.95(0.80-1.13)$ \\
\hline$>40$ years & 301 & $(7.2)$ & 420 & (5.4) & $1.19(1.00-1.41)$ \\
\hline Missing & 28 & $(0.7)$ & 27 & (0.4) & \\
\hline$p$-value for trend & & & & & 0.12 \\
\hline \multicolumn{6}{|l|}{ History of gastric ulcer ${ }^{d}$} \\
\hline No & 2751 & $(90.3)$ & 6276 & $(93.3)$ & $1^{\mathrm{b}}$ \\
\hline Yes & 248 & $(8.1)$ & 440 & (6.5) & $1.08(0.91-1.29)$ \\
\hline Missing & 46 & $(1.5)$ & 14 & $(0.2)$ & \\
\hline \multicolumn{6}{|c|}{ Years since diagnosis ${ }^{\mathrm{e}}$} \\
\hline No & 1865 & $(92.2)$ & 3267 & $(94.2)$ & $1^{\mathrm{b}}$ \\
\hline$\leq 2$ years & 22 & $(1.1)$ & 17 & $(0.5)$ & $1.75(0.86-3.56)$ \\
\hline $3-10$ years & 28 & $(1.4)$ & 39 & (1.1) & $1.14(0.65-1.98)$ \\
\hline$>10$ years & 97 & $(4.8)$ & 139 & $(4.0)$ & $0.86(0.64-1.15)$ \\
\hline Missing & 10 & $(0.5)$ & 6 & $(0.2)$ & \\
\hline$p$-value for trend & & & & & 0.51 \\
\hline \multicolumn{6}{|c|}{ Age at first diagnosis ${ }^{\mathrm{e}}$} \\
\hline No & 1865 & $(92.2)$ & 3267 & $(94.2)$ & $1^{b}$ \\
\hline$\leq 40$ years & 63 & (3.1) & 93 & (2.7) & $0.94(0.66-1.36)$ \\
\hline$>40$ years & 84 & $(4.2)$ & 102 & (2.9) & $1.01(0.73-1.40)$ \\
\hline Missing & 10 & $(0.5)$ & 6 & $(0.2)$ & \\
\hline$p$-value for trend & & & & & 0.95 \\
\hline \multicolumn{6}{|l|}{ History of duodenal ulcer ${ }^{f}$} \\
\hline No & 2766 & (92.9) & 6125 & $(93.2)$ & $1^{\mathrm{b}}$ \\
\hline Yes & 167 & $(5.6)$ & 432 & $(6.6)$ & $0.97(0.79-1.18)$ \\
\hline Missing & 43 & (1.4) & 15 & $(0.2)$ & \\
\hline \multicolumn{6}{|c|}{ Years since diagnosis ${ }^{\mathrm{g}}$} \\
\hline No & 1859 & (95.0) & 3122 & $(94.4)$ & $1^{\mathrm{b}}$ \\
\hline$\leq 2$ years & 14 & $(0.7)$ & 11 & $(0.3)$ & $1.98(0.78-5.02)$ \\
\hline $3-10$ years & 12 & $(0.6)$ & 35 & (1.1) & $0.96(0.47-1.99)$ \\
\hline$>10$ years & 65 & $(3.3)$ & 135 & (4.1) & $0.95(0.68-1.33)$ \\
\hline Missing & 6 & $(0.3)$ & 6 & $(0.2)$ & \\
\hline$p$-value for trend & & & & & 0.87 \\
\hline \multicolumn{6}{|c|}{ Age at first diagnosis ${ }^{\mathrm{g}}$} \\
\hline$\leq 40$ years & 43 & $(2.2)$ & 113 & (3.4) & $0.82(0.55-1.22)$ \\
\hline$>40$ years & 48 & (2.5) & 68 & (2.1) & $1.32(0.87-2.01)$ \\
\hline Missing & 6 & $(0.3)$ & 6 & $(0.2)$ & \\
\hline$p$-value for trend & & & & & 0.50 \\
\hline $\begin{array}{l}{ }^{\mathrm{a}} \text { Pooled ORs were } \\
\text { center (for multicer } \\
\text { tobacco smoking, } \\
{ }^{\mathrm{b}} \text { Reference categor }\end{array}$ & $\begin{array}{l}\text { om lo } \\
\text { ), age, } \\
\text { king, } \\
\text { age a }\end{array}$ & $\begin{array}{l}\text { regre } \\
\text { race/ } \\
\text { ry of } \\
\text { t diagr }\end{array}$ & $\begin{array}{l}\text { mode } \\
\text { city, ec } \\
\text { tes, a } \\
\text { for pa }\end{array}$ & $\begin{array}{l}\text { djustec } \\
\text { ation, } \\
\text { histor }\end{array}$ & $\begin{array}{l}\text { or study, stud } \\
\text { dy mass index } \\
\text { of pancreatitis } \\
\text { ith a history o }\end{array}$ \\
\hline
\end{tabular}


'Information from the Milan, UCSF, LSU, MSKCC, Shanghai, Yale, Queensland studies. e Information from the Milan, LSU, MSKCC, Yale, Queensland studies. ${ }^{\mathrm{f}}$ Information from the Milan, UCSF, MSKCC, Shanghai, Yale, Queensland studies. ${ }^{g}$ Information from the Milan, MSKCC, Yale, Queensland studies.

Six hundred and seventy-three cases (14.3\%) and 1183 controls (12.6\%) reported a history of peptic ulcer, corresponding to an OR of 1.10 (95\% Cl 0.98-1.23).

Figure 1 shows the study-specific ORs, along with the overall estimate of pancreatic cancer risk by history of peptic ulcer. No significant heterogeneity was observed between studies $(p=0.99)$.

Figure 1. Study-specific and pooled odd ratios ${ }^{a}$, with corresponding $95 \%$ confidence intervals $(\mathrm{Cl})$, for pancreatic cancer by history of gastric or duodenal ulcer.

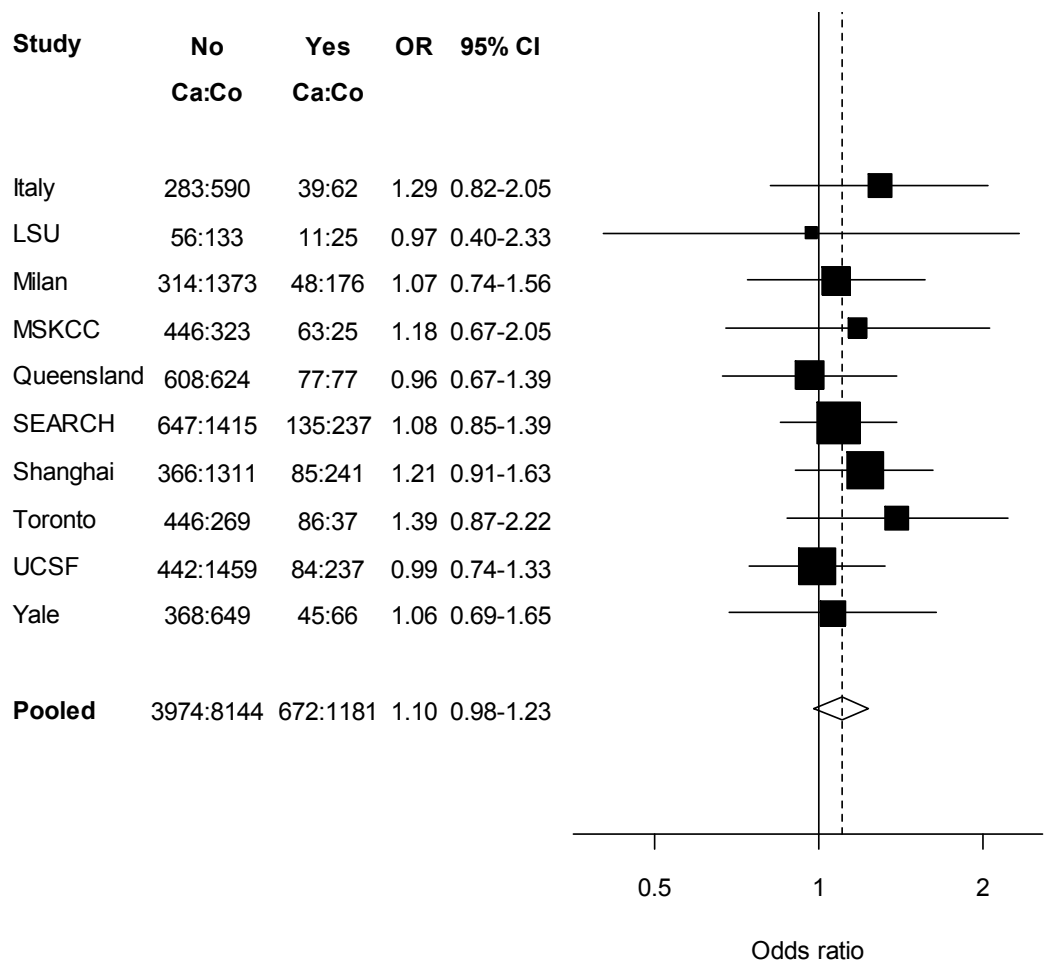

${ }^{\mathrm{a} S t u d y-s p e c i f i c ~ O R s ~ w e r e ~ a d j u s t e d ~ f o r ~ s t u d y ~ c e n t e r ~(f o r ~ m u l t i c e n t e r ~ s t u d i e s), ~ a g e, ~ s e x, ~}$ education, race/ethnicity, body mass index, tobacco smoking, alcohol consumption, history of diabetes, and history of pancreatitis. Pooled ORs were further adjusted for study. 
LSU, Louisiana School of Public Health; MSKCC, Memorial Sloan-Kettering Cancer Center; SEARCH, Surveillance of Environmental Aspects Related to Cancer in Humans; UCSF, University of California, San Francisco.

An increased risk of pancreatic cancer was observed in participants whose peptic ulcer occurred within two years of cancer diagnosis (OR=2.43, 95\% Cl 1.68-3.50), while no association was found for those with an earlier diagnosis (OR=1.03 for 3-10 years and 0.96 for $>10$ years, Table 2 ).

Table 2. Distribution of pancreatic cancer cases and controls, and corresponding odds ratios (OR) and $95 \%$ confidence intervals $(\mathrm{Cl})$, by history of gastric or duodenal ulcer. International Pancreatic Cancer Case-Control Consortium (PanC4).

\begin{tabular}{|c|c|c|c|c|c|}
\hline & \multicolumn{2}{|c|}{ Cases } & \multicolumn{2}{|c|}{ Controls } & \multirow{2}{*}{$\mathrm{OR}^{\mathrm{a}}(95 \% \mathrm{Cl})$} \\
\hline & No. & (\%) & No. & (\%) & \\
\hline \multicolumn{6}{|c|}{ History of gastric or duodenal } \\
\hline \multicolumn{6}{|l|}{ ulcer } \\
\hline No & 3976 & $(84.3)$ & 8146 & $(86.9)$ & $1^{b}$ \\
\hline Yes & 673 & $(14.3)$ & 1183 & $(12.6)$ & $1.10(0.98-1.23)$ \\
\hline Missing & 68 & (1.4) & 45 & $(0.5)$ & \\
\hline \multicolumn{6}{|c|}{ Years since diagnosis $^{c}$} \\
\hline No & 3610 & $(86.0)$ & 6835 & $(87.9)$ & $1^{b}$ \\
\hline$\leq 2$ years & 87 & (2.1) & 63 & $(0.8)$ & $2.43(1.68-3.50)$ \\
\hline $3-10$ years & 97 & (2.3) & 172 & (2.2) & $1.03(0.78-1.36)$ \\
\hline$>10$ years & 376 & (9.0) & 680 & (8.7) & $0.96(0.83-1.11)$ \\
\hline Missing & 28 & (0.7) & 27 & (0.4) & \\
\hline$p$-value for trend & & & & & 0.90 \\
\hline \multicolumn{6}{|c|}{ Age at first diagnosis ${ }^{c}$} \\
\hline No & 3610 & $(86.0)$ & 6835 & $(87.9)$ & $1^{\mathrm{b}}$ \\
\hline$\leq 40$ years & 259 & (6.2) & 495 & (6.4) & $0.95(0.80-1.13)$ \\
\hline$>40$ years & 301 & (7.2) & 420 & (5.4) & $1.19(1.00-1.41)$ \\
\hline Missing & 28 & (0.7) & 27 & (0.4) & \\
\hline$p$-value for trend & & & & & 0.12 \\
\hline \multicolumn{6}{|l|}{ History of gastric ulcer $^{d}$} \\
\hline No & 2751 & $(90.3)$ & 6276 & $(93.3)$ & $1^{b}$ \\
\hline Yes & 248 & (8.1) & 440 & (6.5) & $1.08(0.91-1.29)$ \\
\hline Missing & 46 & (1.5) & 14 & $(0.2)$ & \\
\hline \multicolumn{6}{|c|}{ Years since diagnosis $^{\mathrm{e}}$} \\
\hline No & 1865 & $(92.2)$ & 3267 & $(94.2)$ & $1^{\mathrm{b}}$ \\
\hline$\leq 2$ years & 22 & (1.1) & 17 & $(0.5)$ & $1.75(0.86-3.56)$ \\
\hline $3-10$ years & 28 & (1.4) & 39 & (1.1) & $1.14(0.65-1.98)$ \\
\hline$>10$ years & 97 & (4.8) & 139 & (4.0) & $0.86(0.64-1.15)$ \\
\hline Missing & 10 & (0.5) & 6 & (0.2) & \\
\hline$p$-value for trend & & & & & 0.51 \\
\hline \multicolumn{6}{|c|}{ Age at first diagnosis ${ }^{\mathrm{e}}$} \\
\hline No & 1865 & $(92.2)$ & 3267 & $(94.2)$ & $1^{b}$ \\
\hline$\leq 40$ years & 63 & (3.1) & 93 & (2.7) & $0.94(0.66-1.36)$ \\
\hline$>40$ years & 84 & (4.2) & 102 & (2.9) & $1.01(0.73-1.40)$ \\
\hline
\end{tabular}




\begin{tabular}{|c|c|c|c|c|c|}
\hline & \multicolumn{2}{|c|}{ Cases } & \multicolumn{2}{|c|}{ Controls } & \multirow{2}{*}{$\mathrm{OR}^{\mathrm{a}}(95 \% \mathrm{Cl})$} \\
\hline & No. & (\%) & No. & (\%) & \\
\hline Missing & 10 & $(0.5)$ & 6 & $(0.2)$ & \\
\hline$p$-value for trend & & & & & 0.95 \\
\hline \multicolumn{6}{|c|}{ History of duodenal ulcer ${ }^{f}$} \\
\hline No & 2766 & (92.9) & 6125 & (93.2) & $1^{b}$ \\
\hline Yes & 167 & (5.6) & 432 & $(6.6)$ & $0.97(0.79-1.18)$ \\
\hline Missing & 43 & (1.4) & 15 & $(0.2)$ & \\
\hline \multicolumn{6}{|c|}{ Years since diagnosis $^{\mathrm{g}}$} \\
\hline No & 1859 & $(95.0)$ & 3122 & (94.4) & $1^{b}$ \\
\hline$\leq 2$ years & 14 & $(0.7)$ & 11 & $(0.3)$ & $1.98(0.78-5.02)$ \\
\hline $3-10$ years & 12 & (0.6) & 35 & $(1.1)$ & $0.96(0.47-1.99)$ \\
\hline$>10$ years & 65 & (3.3) & 135 & $(4.1)$ & $0.95(0.68-1.33)$ \\
\hline Missing & 6 & $(0.3)$ & 6 & $(0.2)$ & \\
\hline$p$-value for trend & & & & & 0.87 \\
\hline \multicolumn{6}{|c|}{ Age at first diagnosis ${ }^{\mathrm{g}}$} \\
\hline$\leq 40$ years & 43 & $(2.2)$ & 113 & $(3.4)$ & $0.82(0.55-1.22)$ \\
\hline$>40$ years & 48 & (2.5) & 68 & $(2.1)$ & $1.32(0.87-2.01)$ \\
\hline Missing & 6 & (0.3) & 6 & $(0.2)$ & \\
\hline$p$-value for trend & & & & & 0.50 \\
\hline
\end{tabular}

${ }^{a}$ Pooled ORs were computed from logistic regression models adjusted for study, study center (for multicenter studies), age, sex, race/ethnicity, education, body mass index, tobacco smoking, alcohol drinking, history of diabetes, and history of pancreatitis. ${ }^{b}$ Reference category. ${ }^{C}$ Younger age at first diagnosis for participants with a history of gastric ulcer and duodenal ulcer. Information not available in the Shanghai study. 'Information from the Milan, UCSF, LSU, MSKCC, Shanghai, Yale, Queensland studies. e Information from the Milan, LSU, MSKCC, Yale, Queensland studies. 'Information from the Milan, UCSF, MSKCC, Shanghai, Yale, Queensland studies. ${ }^{\mathrm{g}}$ Information from the Milan, MSKCC, Yale, Queensland studies.

The risk was slightly higher for participants with a first diagnosis of ulcer after age 40 years $(\mathrm{OR}=1.17$ ) compared with those with a diagnosis when younger than age 40 years (OR=0.95). When we analyzed gastric and duodenal ulcer separately, no association was observed either for gastric $(O R=1.08)$ or for duodenal $(O R=0.97)$ ulcer. In both cases, study-specific estimates were not significantly heterogeneous ( $p=0.65$ and 0.28 , respectively). For both ulcers an increased risk (although not significant) was observed for a first diagnosis within two years ( $O R=1.75$ and 1.98, respectively). No difference in risk estimates were observed for age at first diagnosis of gastric ulcer ( $O R=0.94$ for $\leq 40$ years and 1.01 for $>40$ years of age), while the association was somewhat stronger for a diagnosis of duodenal ulcer after 40 years of age (OR=1.32) as compared to a diagnosis before age $40(O R=0.82)$. Similar ORs were observed when comparing participants with a history of gastric or duodenal ulcer with those who had 
no history of peptic ulcer $(\mathrm{OR}=1.10,95 \% \mathrm{Cl}$ 0.92-1.32 and $\mathrm{OR}=0.98,95 \% \mathrm{Cl} 0.80-1.20$, respectively, data not shown in tables).

Ninety-one cases (3.5\%) and 142 controls (1.9\%) reported a history of gastrectomy, with a corresponding OR for pancreatic cancer of 1.53 (95\% Cl 1.15-2.03, Table 3).

Table 3. Distribution of pancreatic cancer cases and controls, and corresponding odds ratios (OR) $95 \%$ and confidence intervals $(\mathrm{Cl})$, by history of gastrectomy. International Pancreatic Cancer Case-Control Consortium (PanC4).

\begin{tabular}{|c|c|c|c|c|c|}
\hline & \multicolumn{2}{|c|}{ Cases } & \multicolumn{2}{|c|}{ Controls } & \multirow{2}{*}{$O R^{a}(95 \% \mathrm{Cl})$} \\
\hline & No. & (\%) & No. & (\%) & \\
\hline \multicolumn{6}{|l|}{ History of gastrectomy ${ }^{b}$} \\
\hline No & 2481 & (94.3) & 7157 & (97.4) & $1^{c}$ \\
\hline Yes & 91 & $(3.5)$ & 142 & $(1.9)$ & $1.53(1.15-2.03)$ \\
\hline Missing & 60 & (2.3) & 51 & $(0.7)$ & \\
\hline \multicolumn{6}{|c|}{ Years since gastrectomy $^{d}$} \\
\hline No & 1995 & $(96.7)$ & 5504 & $(98.2)$ & $1^{\mathrm{c}}$ \\
\hline$\leq 2$ years & 11 & $(0.5)$ & 4 & $(0.1)$ & $6.18(1.82-20.96)$ \\
\hline $3-10$ & 12 & (0.6) & 16 & $(0.3)$ & $1.53(0.69-3.39)$ \\
\hline$>10$ years & 35 & $(1.7)$ & 74 & $(1.3)$ & $1.01(0.65-1.55)$ \\
\hline Missing & 11 & $(0.5)$ & 10 & $(0.2)$ & \\
\hline$p$-value for trend & & & & & 0.47 \\
\hline \multicolumn{6}{|c|}{ Age at gastrectomy ${ }^{d}$} \\
\hline No & 1995 & $(96.7)$ & 5504 & $(98.2)$ & $1^{\mathrm{c}}$ \\
\hline$\leq 40$ years & 20 & $(1.0)$ & 40 & $(0.7)$ & $1.27(0.71-2.27)$ \\
\hline$>40$ years & 38 & (1.8) & 54 & (1.0) & $1.33(0.85-2.06)$ \\
\hline Missing & 11 & $(0.5)$ & 10 & $(0.2)$ & \\
\hline$p$-value for trend & & & & & 0.15 \\
\hline
\end{tabular}

${ }^{\mathrm{a}}$ Pooled ORs were computed from logistic regression models adjusted for study, study center (for multicenter studies), age, sex, race/ethnicity, education, body mass index, tobacco smoking, alcohol drinking, history of diabetes, and history of pancreatitis. binformation from the Milan, UCSF, SEARCH, LSU, Shanghai, and Yale studies. ${ }^{c}$ Reference category. ${ }^{d}$ Information from the Milan, UCSF, SEARCH, and Yale studies.

Figure 2 shows the study-specific ORs, along with the overall estimate of pancreatic cancer risk by history of gastrectomy. As for ulcer, there was no significant heterogeneity between studies $(p=0.38)$. The risk estimates were similar in studies investigating gastrectomy among participants with a history of ulcer (OR=1.83, 95\% Cl 1.06-3.16, UCSF, SEARCH, LSU and Shanghai studies) and among those asking about gastrectomy independently from history of ulcer $(\mathrm{OR}=1.42,95 \% \mathrm{Cl} 1.01-1.98$, Milan and Yale studies, data not shown in tables). When we analyzed the relation by time since surgery, the excess risk appeared limited to a gastrectomy within two years prior 
to cancer diagnosis ( $\mathrm{OR}=6.18,95 \% \mathrm{Cl} 1.82-20.96)$, while no significant association was observed for earlier gastrectomy ( $O R=1.53$ for $3-10$ years and 1.01 for $>10$ years, Table 3). Similar risk estimates were observed for participants with a gastrectomy at less or after age 40 years (OR=1.27 and 1.33 , respectively).

Figure 2. Study-specific and pooled odd ratios ${ }^{a}$, with corresponding $95 \%$ confidence intervals $(\mathrm{Cl})$, for pancreatic cancer by history of gastrectomy.

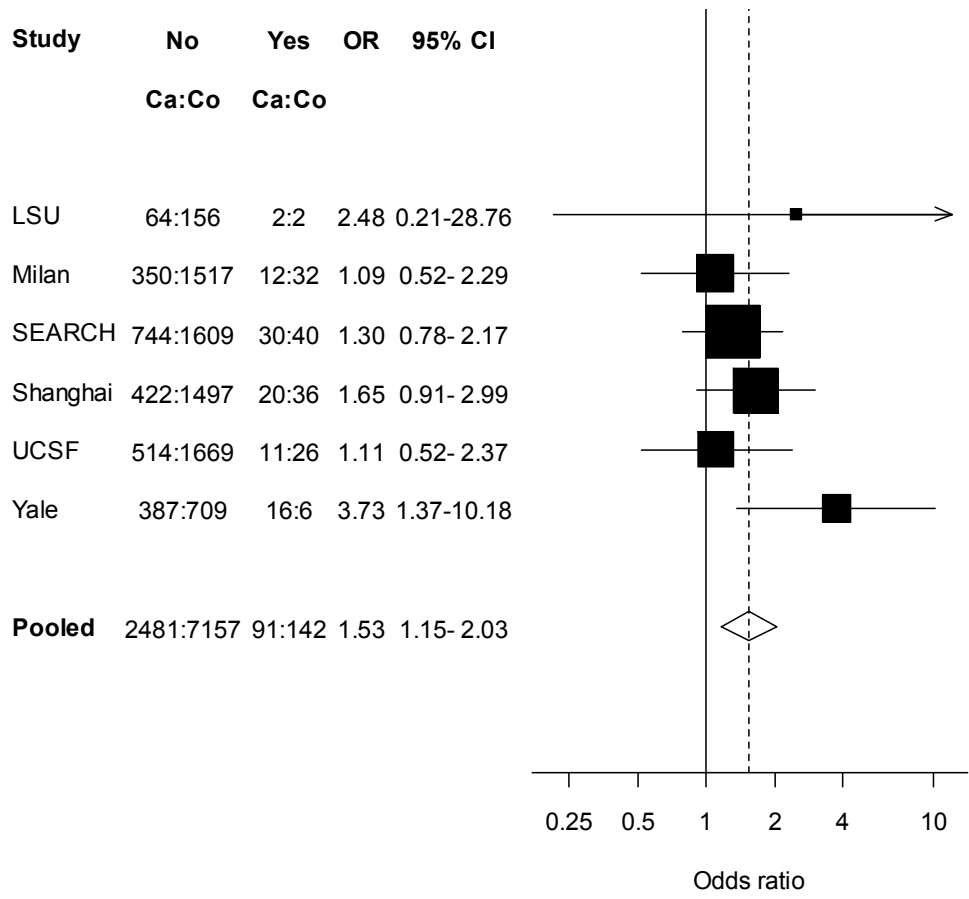

LSU, Louisiana School of Public Health; SEARCH, Surveillance of Environmental Aspects Related to Cancer in Humans; UCSF, University of California, San Francisco.

${ }^{a}$ Study-specific ORs were adjusted for study center (for multicenter studies), age, sex, education, race/ethnicity, body mass index, tobacco smoking, alcohol drinking, history of diabetes, and history of pancreatitis. Pooled ORs were further adjusted by study.

Supplemental Table 2 shows the association between gastrectomy and pancreatic cancer (overall and excluding surgeries within two years before cancer diagnosis) by strata of selected covariates. The association was somewhat stronger in men $(O R=1.73$ for overall gastrectomy and 1.47 for gastrectomy more than two years prior to cancer diagnosis) than in women ( $O R=1.47$ and 0.40$)$, and in current smokers ( $O R=2.04$ and 2.10) as compared with never smokers $(O R=1.00$ and 0.50$)$ and ex-smokers ( 1.33 and 0.85 ). No difference in risk estimates were observed across strata of other covariates 
considered, including age, race/ethnicity, BMI, alcohol consumption, study area and source of controls. The associations were similar when we restricted the analyses to participants with no history of pancreatitis $(\mathrm{OR}=1.62,95 \% \mathrm{Cl} 1.22-2.16$, for overall gastrectomy and $\mathrm{OR}=1.23,95 \% \mathrm{Cl} 0.83-1.80$, for gastrectomy more than two years before cancer diagnosis) and to those who responded in-person (OR=1.76, $95 \% \mathrm{Cl}$ 1.28-2.42, for overall gastrectomy and $\mathrm{OR}=1.32,95 \% \mathrm{Cl} 0.86-2.01$, for gastrectomy more than two years before cancer diagnosis, data not shown in tables). Likewise, risk estimates for ulcer were consistent in strata of all covariates considered, with the only exception of smoking, the RR being 0.77 for never smokers, 1.51 for current smokers, and 1.12 for ex-smokers. Moreover, risk estimates for ulcer were similar when we restricted the analyses to participants with no history of pancreatitis (OR=1.10, $95 \% \mathrm{Cl}$ $0.98-1.24$ ) and to those who responded in-person (OR=1.09, 95\% $\mathrm{Cl} 0.96-1.23$ ).

Supplemental Table 2. Pooled odds ratios (OR) and 95\% confidence intervals ( $\mathrm{Cl}$ ) for pancreatic cancer by history of gastrectomy in strata of selected covariates.

International Pancreatic Cancer Case-Control Consortium (PanC4).

\begin{tabular}{|c|c|c|c|c|c|c|}
\hline & \multicolumn{6}{|c|}{ History of gastrectomy } \\
\hline & \multicolumn{3}{|c|}{ Overall } & \multicolumn{3}{|c|}{$>2$ years since gastrectomy } \\
\hline & \multicolumn{2}{|c|}{ Cases:Controls } & \multirow{2}{*}{$O R^{a}(95 \% \mathrm{Cl})$} & \multicolumn{2}{|c|}{ Cases:Controls } & \multirow{2}{*}{$\mathrm{OR}^{\mathrm{a}}(95 \% \mathrm{Cl})$} \\
\hline & No & Yes & & No & Yes & \\
\hline Overall & $2481: 7157$ & $91: 142$ & $1.53(1.15-2.03)$ & $1995: 5504$ & $47: 90$ & $1.10(0.75-1.61)$ \\
\hline \multicolumn{7}{|l|}{ Sex } \\
\hline Men & $1392: 4074$ & $72: 108$ & $1.73(1.25-2.38)$ & $1117: 3186$ & 39:64 & $1.47(0.95-2.25)^{b}$ \\
\hline Women & 1089:3083 & $19: 34$ & $0.99(0.54-1.83)$ & $878: 2318$ & $8: 26$ & $0.40(0.17-0.95)^{b}$ \\
\hline \multicolumn{7}{|l|}{ Age (years) } \\
\hline$<65$ & 1230:4007 & $42: 62$ & $1.58(1.02-2.44)$ & 973:3016 & $19: 42$ & $0.89(0.48-1.65)$ \\
\hline$\geq 65$ & $1251: 3150$ & 49:80 & $1.46(1.00-2.13)$ & $1022: 2488$ & $28: 48$ & $1.20(0.73-1.96)$ \\
\hline \multicolumn{7}{|l|}{ Race/ethnicity } \\
\hline $\begin{array}{l}\text { Non-Hispanic } \\
\text { White }\end{array}$ & 1907:5261 & $67: 99$ & $1.51(1.09-2.11)$ & $1857: 5138$ & $44: 85$ & $1.16(0.78-1.70)$ \\
\hline Other & $574: 1896$ & $24: 43$ & $1.45(0.83-2.52)$ & $138: 366$ & 3:5 & $0.41(0.07-2.41)$ \\
\hline \multicolumn{7}{|l|}{ Education } \\
\hline $\begin{array}{l}\text { High school } \\
\text { graduate or less }\end{array}$ & $1666: 4512$ & $67: 104$ & $1.48(1.07-2.06)$ & $1255: 3123$ & $37: 66$ & $1.15(0.75-1.78)$ \\
\hline $\begin{array}{l}\text { College graduate } \\
\text { or more }\end{array}$ & $792: 2587$ & $24: 36$ & $1.81(1.03-3.18)$ & $718: 2350$ & $10: 22$ & $1.23(0.55-2.79)$ \\
\hline \multicolumn{7}{|l|}{ Body mass index } \\
\hline$\leq 25$ & $1443: 4263$ & $60: 104$ & $1.35(0.95-1.91)$ & $1068: 2848$ & $27: 62$ & $0.87(0.53-1.42)$ \\
\hline$>25$ & $1007: 2831$ & $28: 35$ & $1.92(1.12-3.27)$ & $902: 2602$ & $19: 26$ & $1.62(0.85-3.07)$ \\
\hline \multicolumn{7}{|c|}{ Tobacco smoking (drinks/day) ${ }^{c}$} \\
\hline Never smoker & $852: 3076$ & $11: 34$ & $1.00(0.49-2.05)$ & $612: 2128$ & $4: 18$ & $0.50(0.16-1.57)^{b}$ \\
\hline Current smoker & $765: 1763$ & $43: 48$ & $2.04(1.30-3.20)$ & $580: 1245$ & $22: 24$ & $2.10(1.11-3.96)^{b}$ \\
\hline Ex smokers & $771: 2100$ & 33.54 & $1.33(0.83-2.12)$ & 715:1916 & $18: 44$ & $0.85(0.47-1.54)^{b}$ \\
\hline \multicolumn{7}{|c|}{ Alcohol drinking (drinks/day) ${ }^{c}$} \\
\hline
\end{tabular}




\begin{tabular}{|c|c|c|c|c|c|c|}
\hline & \multicolumn{6}{|c|}{ History of gastrectomy } \\
\hline & \multicolumn{3}{|c|}{ Overall } & \multicolumn{3}{|c|}{$>2$ years since gastrectomy } \\
\hline & \multicolumn{2}{|c|}{ Cases:Controls } & \multirow{2}{*}{$O R^{a}(95 \% \mathrm{Cl})$} & \multicolumn{2}{|c|}{ Cases:Controls } & \multirow{2}{*}{$O R^{a}(95 \% \mathrm{Cl})$} \\
\hline & No & Yes & & No & Yes & \\
\hline $0-<1$ & $1478: 4170$ & $45: 77$ & $1.36(0.92-2.02)$ & 1099:2841 & $17: 41$ & $0.78(0.43-1.43)$ \\
\hline $1-<4$ & 643:2068 & $28: 39$ & $1.86(1.10-3.16)$ & $562: 1807$ & $16: 27$ & $1.39(0.71-2.73)$ \\
\hline$\geq 4$ & 359:919 & $18: 26$ & $1.26(0.64-2.50)$ & $333: 856$ & $14: 22$ & $1.20(0.56-2.56)$ \\
\hline \multicolumn{7}{|l|}{ Study area } \\
\hline North America & $1346: 3228$ & $43: 58$ & $1.35(0.88-2.06)$ & $1282: 3072$ & $21: 43$ & $0.73(0.42-1.29)$ \\
\hline Other areas & $1135: 3929$ & $48: 84$ & $1.63(1.11-2.38)$ & $713: 232$ & $26: 47$ & $1.47(0.87-2.47)$ \\
\hline \multicolumn{7}{|l|}{ Sources of controls ${ }^{e}$} \\
\hline Hospital & $350: 1517$ & $12: 32$ & $1.09(0.52-2.29)$ & $350: 1517$ & $12: 31$ & $1.10(0.52-2.31)$ \\
\hline Population & 2131:5640 & $79: 110$ & $1.56(1.15-2.13)$ & $1645: 3987$ & $35: 59$ & $1.01(0.65-1.58)$ \\
\hline
\end{tabular}

${ }^{\mathrm{a}}$ Pooled ORs were computed from logistic regression models adjusted for study, study center (for multicenter studies), age, sex, race/ethnicity, education, body mass index, tobacco smoking, alcohol drinking, history of diabetes, and history of pancreatitis. Reference category: no history of gastrectomy. ${ }^{b} p$-value for interaction< $<0.05$. Information not available in the Memorial Sloan-Kettering Cancer Center (MSKCC) study. ${ }^{d}$ Information not available in the Italy study. ${ }^{\mathrm{e}}$ Excluding the MSKCC study which has both hospital and population controls.

No significant associations were observed between pancreatic cancer and medications for ulcer $(O R=0.94)$, including antacids $(O R=0.93), H 2$-receptor antagonists $(O R=1.15)$ or PPIs (OR=1.16, Table 4).

Table 4. Distribution of pancreatic cancer cases and controls, and corresponding odds ratios (OR) and $95 \%$ confidence intervals $(\mathrm{Cl})$, by use of medications for ulcer. International Pancreatic Cancer Case-Control Consortium (PanC4).

\begin{tabular}{|c|c|c|c|c|c|}
\hline & \multicolumn{2}{|c|}{ Cases } & \multicolumn{2}{|c|}{ Controls } & \multirow{2}{*}{$O R^{a}(95 \% \mathrm{Cl})$} \\
\hline & No. & (\%) & No. & (\%) & \\
\hline \multicolumn{6}{|l|}{ Use of medications $^{b}$} \\
\hline No history of ulcer & 3269 & (85.0) & 6774 & (86.8) & $1^{\mathrm{c}}$ \\
\hline $\begin{array}{l}\text { History of ulcer and no } \\
\text { medication }\end{array}$ & 96 & $(2.5)$ & 207 & $(2.7)$ & $1.21(0.92-1.58)$ \\
\hline History of ulcer and medication & 388 & $(10.1)$ & 764 & $(9.8)$ & $0.94(0.81-1.07)$ \\
\hline Missing & 94 & (2.5) & 59 & $(0.8)$ & \\
\hline \multicolumn{6}{|l|}{ Use of antacids ${ }^{d}$} \\
\hline No history of ulcer & 2009 & $(84.8)$ & 3723 & $(86.5)$ & $1^{c}$ \\
\hline $\begin{array}{l}\text { History of ulcer and no } \\
\text { medication }\end{array}$ & 238 & $(10.1)$ & 383 & $(8.9)$ & $0.99(0.81-1.21)$ \\
\hline History of ulcer and medication & 102 & $(4.3)$ & 183 & $(4.3)$ & $0.93(0.70-1.22)$ \\
\hline Missing & 19 & $(0.8)$ & 14 & (0.3) & \\
\hline \multicolumn{6}{|l|}{ Use of H2-receptor antagonists ${ }^{\mathrm{e}}$} \\
\hline No history of ulcer & 2687 & (84.4) & 6404 & $(86.5)$ & $1^{c}$ \\
\hline $\begin{array}{l}\text { History of ulcer and no } \\
\text { medication }\end{array}$ & 310 & (9.7) & 645 & $(8.7)$ & $0.94(0.80-1.10)$ \\
\hline
\end{tabular}




\begin{tabular}{|c|c|c|c|c|c|}
\hline & \multicolumn{2}{|c|}{ Cases } & \multicolumn{2}{|c|}{ Controls } & \multirow{2}{*}{$\mathrm{OR}^{\mathrm{a}}(95 \% \mathrm{Cl})$} \\
\hline & No. & (\%) & No. & (\%) & \\
\hline History of ulcer and medication & 140 & $(4.4)$ & 312 & $(4.2)$ & $1.15(0.92-1.43)$ \\
\hline Missing & 45 & (1.4) & 43 & $(0.6)$ & \\
\hline \multicolumn{6}{|l|}{ Use of proton-pump inhibitors ${ }^{f}$} \\
\hline No history of ulcer & 1362 & (85.9) & 2305 & $(87.0)$ & $1^{\mathrm{c}}$ \\
\hline $\begin{array}{l}\text { History of ulcer and no } \\
\text { medication }\end{array}$ & 162 & $(10.2)$ & 289 & $(10.9)$ & $0.90(0.70-1.16)$ \\
\hline History of ulcer and medication & 56 & (3.5) & 51 & (1.9) & $1.16(0.72-1.88)$ \\
\hline Missing & 6 & $(0.4)$ & 5 & $(0.2)$ & \\
\hline
\end{tabular}

H2-receptor antagonists: histamine-2-receptor antagonists.

${ }^{a}$ Pooled ORs were computed from logistic regression models adjusted for study, study center (for multicenter studies), age, sex, race/ethnicity, education, body mass index, tobacco smoking, alcohol drinking, history of diabetes, and history of pancreatitis. bInformation from all studies, with the exception of the Italy, LSU, and Yale studies. 'Reference category. 'Information from the UCSF, SEARCH, Toronto, and Queensland studies. 'Information from the Milan, UCSF, SEARCH, Toronto, Shanghai, and Queensland studies. Information from the UCSF, Toronto, and Queensland studies.

\section{Discussion}

This collaborative analysis including data on more than 4,500 pancreatic cancer cases provides strong evidence that participants with a history of peptic (both gastric and duodenal) ulcer have no excess risk of pancreatic cancer, although a diagnosis of peptic ulcer two years before pancreatic cancer diagnosis was associated with an increased risk. Study participants who underwent gastrectomy for treatment of ulcer or other benign conditions had a $50 \%$ excess risk, but this was again limited to those who had surgery within two years before cancer diagnosis. The present analysis did not show any association with any medication for ulcer.

The results of this study confirm the evidence from several previous investigations that reported no association between peptic ulcer and subsequent pancreatic cancer risk [2]. The positive association observed in participants with a diagnosis of ulcer within two years prior to cancer diagnosis and the absence of risk for a longer time prior to diagnosis may be due to enhanced surveillance of people with newly diagnosed peptic ulcer, increasing the probability of being diagnosed with pancreatic cancer. Moreover, it is possible that peptic ulcer is an early symptom or a consequence of pancreatic cancer. Only two cohort studies $[17,18]$ reported persisting increased risks of pancreatic cancer for up to $15-20$ years following diagnosis of gastric, but not duodenal, ulcer. However, those studies were based on a small number of pancreatic cancer cases (182 and 274, respectively) and consequently included only a few participants with ulcer. Moreover, one study was a registry-based retrospective cohort 
that was unable to adjust the analysis for tobacco smoking, a possible confounding factor of the association between ulcer and pancreatic cancer [3, 4].

The observation of the two cohort studies $[17,18]$ that gastric ulcer but not duodenal ulcer was associated with pancreatic cancer risk supports the hypothesis that conditions that characterize gastric ulcer may contribute to pancreatic cancer risk. Examples of these factors include corpus colonization by Helicobacter pylori (H. pylori), atrophic corpus gastritis with hypochlorhydria, and consequent bacterial overgrowth and intragastric formation of $\mathrm{N}$-nitrosamines [6, 19]. Our data did not show any difference in pancreatic cancer risk between gastric and duodenal ulcer, thus providing no support for the hypothesis that the two conditions play distinct roles in pancreatic carcinogenesis. Similarly, a few other studies that analyzed gastric and duodenal ulcer separately $[20,21]$ - in addition to those included in our pooled analysis $[1,11,22]-$ did not find any meaningful difference in pancreatic cancer risk.

The $50 \%$ increased risk of pancreatic cancer in relation to a history of gastrectomy is consistent with evidence from previous investigations [2] and with results of a metaanalysis of 11 case-control - among which three studies included in our pooled analysis $[8,11,23]$ - and 4 cohort studies that reported an overall RR of $1.54(95 \% \mathrm{Cl}$ $1.25-1.90), 1.42(95 \% \mathrm{Cl} 1.06-1.90)$ in case-control and $1.71(95 \% \mathrm{Cl} 1.24-2.35)$ in cohort studies [24]. A role of gastric bacterial overgrowth and formation of N-nitroso compounds, possibly due to the reduced production of gastric acids following gastrectomy $[5,6]$, as well as of $H$. pylori colonization that can enhance the carcinogenic effect of nitrosamines $[25,26]$, has been postulated to explain such an association. Although a few small previous studies suggested that the increase in risk persisted more than 20 years after surgery [17, 27-29], we found that the excess risk of pancreatic cancer was evident only for participants who had undergone gastrectomy within two years prior to cancer diagnosis. Thus, as for peptic ulcer, this would indicate a likely role of detection bias, following the increased medical surveillance of participants undergoing gastrectomy. Moreover, the observation of a stronger excess risk in current smokers indicates a possible residual confounding by tobacco smoking. Our data do not support a role of any ulcer medications (including antacids, H2antagonists and PPIs) in pancreatic carcinogenesis. This is consistent with the evidence from a few studies that have reported no association with medications for ulcer [20, $21,30]$, including antacids [20], H2-antagonists, and PPIs [30]. Only a cohort study of patients prescribed with the $\mathrm{H} 2$-antagonist cimetidine [31] reported an increased risk of pancreatic cancer, as well as of other gastrointestinal cancers. However, such an association was stronger in the first few years of follow-up and has thus been attributed to possible gastrointestinal discomforts caused by pancreatic cancer (confounding by indication). Therefore, although drugs for ulcer treatment may influence pancreatic cancer risk by suppressing gastric acid secretion, enhancing 
bacterial growth and N-nitrosamine formation, and inducing hypergastrinemia [32, 33], no support for this hypothesis comes from our study as well as previous studies.

This PanC4 collaborative study has a number of strengths. These include the large dataset, the detailed information from most studies on ulcer, gastrectomy (including the age at diagnosis/surgery and the distinction between gastric and duodenal ulcer), and on various treatments, and the ability to account uniformly and carefully for study design variables and potential confounding factors for the association between these conditions and pancreatic cancer, particularly tobacco smoking. Moreover, the large available dataset allowed us to conduct stratified analyses by selected covariates and to show that our risk estimates for gastrectomy were consistent across strata of most covariates considered, including age, race, study area, race/ethnicity, BMI, alcohol consumption, and history of pancreatitis. Among the limitations of our study is that history of ulcer and its treatments was self-reported in most studies, and misclassification of ulcer location (duodenal or gastric) or with other gastrointestinal diseases (gastritis/duodenitis) is possible [34]. Accuracy of medical information may also be different between in-person and proxy respondents, although restriction of our analyses to in-person respondents yielded similar results. Moreover, given the retrospective design of the case-control studies included in our pooled analysis, it is possible that self-reported information on medical conditions was reported more accurately in cases than controls, although for gastrectomy, which is a major surgical treatment, recall should be reasonably accurate by controls, and similar results were observed in both hospital-based and population-based studies. Further, our risk estimates for gastrectomy are consistent with those of a meta-analysis of both casecontrol and cohort studies [24], arguing against a major role of recall bias or misclassification.

In conclusion, this uniquely large collaborative study does not support the hypothesis that peptic ulcer or its treatments materially affects pancreatic cancer risk. The increased risk observed for history of ulcer and gastrectomy within two years before cancer diagnosis, indicates that these associations may be at least in part due to increased cancer surveillance in patients undergoing gastric screening or surgery. 


\section{References}

1. Lipworth L, Zucchetto A, Bosetti C et al. Diabetes mellitus, other medical conditions and pancreatic cancer: a case-control study. Diabetes Metab Res Rev 2011; 27: 255-261.

2. Olson SH. Selected medical conditions and risk of pancreatic cancer. Mol Carcinog 2012; 51: 75-97.

3. Doll $\mathrm{R}$, Peto $\mathrm{R}$, Wheatley $\mathrm{K}$ et al. Mortality in relation to smoking: 40 years' observations on male British doctors. BMJ 1994; 309: 901-911.

4. Bosetti C, Lucenteforte E, Silverman DT et al. Cigarette smoking and pancreatic cancer: an analysis from the International Pancreatic Cancer Case-Control Consortium (Panc4). Ann Oncol 2012; 23: 1880-1888.

5. Anderson KE, Mack TM, Silverman DT. Cancer of the pancreas. In Schottenfeld D, Fraumeni JFJr (eds): Cancer Epidemiology and Prevention. New York: Oxford University Press 2006; 721-762.

6. Risch HA. Etiology of pancreatic cancer, with a hypothesis concerning the role of $\mathrm{N}$-nitroso compounds and excess gastric acidity. J Natl Cancer Inst 2003; 95: 948960.

7. Olson SH, Orlow I, Simon J et al. Allergies, variants in IL-4 and IL-4R alpha genes, and risk of pancreatic cancer. Cancer Detect Prev 2007; 31: 345-351.

8. Ko AH, Wang F, Holly EA. Pancreatic cancer and medical history in a populationbased case-control study in the San Francisco Bay Area, California. Cancer Causes Control 2007; 18: 809-819.

9. Risch HA, Yu H, Lu L, Kidd MS. ABO blood group, Helicobacter pylori seropositivity, and risk of pancreatic cancer: a case-control study. J Natl Cancer Inst 2010; 102: 502-505.

10. Anderson LN, Cotterchio M, Gallinger S. Lifestyle, dietary, and medical history factors associated with pancreatic cancer risk in Ontario, Canada. Cancer Causes Control 2009; 20: 825-834.

11. La Vecchia C, Negri E, D'Avanzo B et al. Medical history, diet and pancreatic cancer. Oncology 1990; 47: 463-466.

12. Fernandez E, La Vecchia C, Decarli A. Attributable risks for pancreatic cancer in northern Italy. Cancer Epidemiol Biomarkers Prev 1996; 5: 23-27.

13. Ji BT, Chow WH, Dai $Q$ et al. Cigarette smoking and alcohol consumption and the risk of pancreatic cancer: a case-control study in Shanghai, China. Cancer Causes Control 1995; 6: 369-376.

14. Boyle P, Maisonneuve P, Bueno de Mesquita B et al. Cigarette smoking and pancreas cancer: a case control study of the search programme of the IARC. Int J Cancer 1996; 67: 63-71. 
15. Luckett BG, Su LJ, Rood JC, Fontham ETH. Cadmium Exposure and Pancreatic Cancer in South Louisiana. Journal of Environmental and Public Health 2013; doi:10.155/2012/180186.

16. Smith-Warner SA, Spiegelman D, Ritz J et al. Methods for pooling results of epidemiologic studies: the Pooling Project of Prospective Studies of Diet and Cancer. Am J Epidemiol 2006; 163: 1053-1064.

17. Luo J, Nordenvall C, Nyren $\mathrm{O}$ et al. The risk of pancreatic cancer in patients with gastric or duodenal ulcer disease. Int J Cancer 2007; 120: 368-372.

18. Bao $\mathrm{Y}$, Spiegelman D, Li R et al. History of peptic ulcer disease and pancreatic cancer risk in men. Gastroenterology 2010; 138: 541-549.

19. Chan FK, Leung WK. Peptic-ulcer disease. Lancet 2002; 360: 933-941.

20. Mack TM, Yu MC, Hanisch R, Henderson BE. Pancreas cancer and smoking, beverage consumption, and past medical history. J Natl Cancer Inst 1986; 76: 4960.

21. Kalapothaki V, Tzonou A, Hsieh CC et al. Tobacco, ethanol, coffee, pancreatitis, diabetes mellitus, and cholelithiasis as risk factors for pancreatic carcinoma. Cancer Causes Control 1993; 4: 375-382.

22. Duell EJ, Casella DP, Burk RD et al. Inflammation, genetic polymorphisms in proinflammatory genes TNF-A, RANTES, and CCR5, and risk of pancreatic adenocarcinoma. Cancer Epidemiol Biomarkers Prev 2006; 15: 726-731.

23. Bueno de Mesquita HB, Maisonneuve P, Moerman CJ, Walker AM. Aspects of medical history and exocrine carcinoma of the pancreas: a population-based case-control study in The Netherlands. Int J Cancer 1992; 52: 17-23.

24. Gong $Y$, Zhou $Q$, Zhou $Y$ et al. Gastrectomy and risk of pancreatic cancer: systematic review and meta-analysis of observational studies. Cancer Causes Control 2012; 23: 1279-1288.

25. Stolzenberg-Solomon RZ, Blaser MJ, Limburg PJ et al. Helicobacter pylori seropositivity as a risk factor for pancreatic cancer. J Natl Cancer Inst 2001; 93: 937-941.

26. Trikudanathan G, Philip A, Dasanu CA, Baker WL. Association between Helicobacter pylori infection and pancreatic cancer. A cumulative meta-analysis. JOP 2011; 12: 26-31.

27. Caygill CP, Hill MJ, Hall CN et al. Increased risk of cancer at multiple sites after gastric surgery for peptic ulcer. Gut 1987; 28: 924-928.

28. Stael von Holstein $\mathrm{C}$, Anderson $\mathrm{H}$, Ahsberg K, Huldt B. The significance of ulcer disease on late mortality after partial gastric resection. Eur J Gastroenterol Hepatol 1997; 9: 33-40.

29. Tascilar M, van Rees BP, Sturm PD et al. Pancreatic cancer after remote peptic ulcer surgery. J Clin Pathol 2002; 55: 340-345. 
30. Bradley MC, Murray L, Cantwell MM, Hughes CM. Proton pump inhibitors and histamine-2-receptor antagonists and pancreatic cancer risk: a nested casecontrol study. Br J Cancer 2012; 106: 233-239.

31. Moller $\mathrm{H}$, Lindvig $\mathrm{K}$, Klefter $\mathrm{R}$ et al. Cancer occurrence in a cohort of patients treated with cimetidine. Gut 1989; 30: 1558-1562.

32. Smout AJ, Bogaard JW, van Hattum J, Akkermans LM. Effects of cimetidine and ranitidine on interdigestive and postprandial lower esophageal sphincter pressures and plasma gastrin levels in normal subjects. Gastroenterology 1985; 88: 557-563.

33. Gillen D, Wirz AA, Neithercut WD et al. Helicobacter pylori infection potentiates the inhibition of gastric acid secretion by omeprazole. Gut 1999; 44: 468-475.

34. Bosetti C, Tavani A, Negri E et al. Reliability of data on medical conditions, menstrual and reproductive history provided by hospital controls. J Clin Epidemiol 2001; 54: 902-906. 

Chapter 4. THE ItALIAN CASE-CONTROL STUDIES 



\section{Chapter 4.1. Diabetes Mellitus and Cancer Risk in a Network of Case- CONTROL STUDIES}

Cristina Bosetti, Valentina Rosato, Jerry Polesel, Fabio Levi, Renato Talamini, Maurizio Montella, Eva Negri, Alessandra Tavani, Antonella Zucchetto, Silvia Franceschi, Giovanni Corrao, Carlo La Vecchia

Nutrition and Cancer 2012; 64(5): 643-651 


\begin{abstract}
Diabetes has been associated to the risk of a few cancer sites, though quantification of this association in various populations remains open to discussion. We analyzed the relation between diabetes and the risk of various cancers in an integrated series of case-control studies conducted in Italy and Switzerland between 1991 and 2009. The studies included 1468 oral and pharyngeal, 505 esophageal, 230 gastric, 2390 colorectal, 185 liver, 326 pancreatic, 852 laryngeal, 3034 breast, 607 endometrial, 1031 ovarian, 1294 prostate, and 767 renal cell cancer cases, and 12,060 hospital controls. The multivariate odds ratios (OR) for subjects with diabetes as compared to those without - adjusted for major identified confounding factors for the cancers considered through logistic regression models - were significantly elevated for cancers of the oral cavity/pharynx $(O R=1.58)$, esophagus $(O R=2.52)$, colorectum $(O R=1.23)$, liver $(O R=3.52)$, pancreas $(O R=3.32)$, post-menopausal breast $(O R=1.76)$, and endometrium $(\mathrm{OR}=1.70)$. For cancers of the oral cavity, esophagus, colorectum, liver, and post-menopausal breast, the excess risk persisted over 10 years since diagnosis of diabetes. Our data confirm and further quantify the association of diabetes with colorectal, liver, pancreatic, post-menopausal breast, and endometrial cancer, and suggest that diabetes may also increase the risk oral/pharyngeal and esophageal cancer.
\end{abstract}




\section{Introduction}

Diabetes has been associated to the risk of colorectal, liver, pancreatic and endometrial cancer, though the quantification of this association in various populations remains open to discussion [1-7]. An excess risk among diabetics has also been reported for (post-menopausal) breast cancer [8,9], but residual confounding by overweight has not been ruled out. Diabetes is also possibly directly related to bladder cancer [10], and inversely related to prostate cancer risk [4], whereas data are inconsistent for other major cancer sites $[1,3,4,7]$.

In a series of case-control studies on selected cancer sites conducted in Italy between 1983 and 1992, on about 10,000 cancer cases, we reported an excess risk for cancer of the liver, pancreas and endometrium, with elevated risks up to 10 years after diagnosis of diabetes for liver and endometrium [11]. No excess risk was observed for other common neoplasms, including digestive, respiratory and breast cancers, as well as lymphohaempoietic neoplasms.

In this report, we analyze the association between diabetes and the risk of various common cancers using data from a network of case-control studies conducted in Italy and Switzerland between 1991 and 2009, providing a comprehensive evaluation of the relation with several neoplasms.

\section{Materials and methods}

Between 1991 and 2009, we conducted an integrated series of case-control studies on several neoplasms in various areas of northern (the greater Milan area; the provinces of Pordenone, Padua, Udine, Gorizia and Forli; the urban area of Genoa), central (the provinces of Rome and Latina), and southern (the urban area of Naples) Italy. We also conducted companion studies on cancers of the oral cavity and pharynx, esophagus, colorectum, larynx, breast and endometrium in the Canton of Vaud, Switzerland. They included a total of 1468 cases of oral and pharyngeal [12, 13], 505 squamous-cell esophageal [14, 15], 230 gastric [16], 2390 colorectal [17, 18], 185 liver [19], 326 pancreatic [20], 852 laryngeal [21], 3034 breast [22, 23], 607 endometrial [24], 1031 ovarian [25], 1294 prostate [26], and 767 renal cell [27] cancer, and a total of 12,060 controls (Table 1).

All studies included incident cancer cases, identified in the major teaching and general hospitals of the study areas. Controls were subjects admitted to the same network of hospitals as cases for a wide spectrum of acute, non-neoplastic conditions unrelated to known or potential risk factors for the corresponding cancer site. They were frequency-matched with cases by sex, age, and study center. Overall, $8.0 \%$ of controls were admitted for traumatic conditions, $22.5 \%$ for non-traumatic orthopedic conditions, $32.8 \%$ for acute surgical conditions, and $36.7 \%$ for miscellaneous other illnesses (including dental, ear, eye, nose, throat or skins diseases). 
Table 1. Number of cases of selected cancer sites and controls, and corresponding median age. Italy and Switzerland, 1991-2009.

\begin{tabular}{lcccc}
\hline Cancer site, references & $\begin{array}{c}\text { Cases } \\
\text { (men/women) }\end{array}$ & $\begin{array}{c}\text { Median age } \\
\text { (yrs) }\end{array}$ & $\begin{array}{c}\text { Controls } \\
\text { (men/women) }\end{array}$ & $\begin{array}{c}\text { Median age } \\
\text { (yrs) }\end{array}$ \\
\hline Oral cavity and pharynx (10, 11) & $1190 / 278$ & 58 & $2553 / 1208$ & 58 \\
Esophagus (12, 13) & $438 / 67$ & 60 & $919 / 340$ & 60 \\
Gastric (14) & $143 / 87$ & 63 & $286 / 261$ & 63 \\
Colorectum (15, 16) & $1401 / 989$ & 62 & $2586 / 2357$ & 58 \\
Liver (17) & $149 / 36$ & 66 & $278 / 126$ & 65 \\
Pancreas (18) & $174 / 152$ & 63 & $348 / 304$ & 63 \\
Larynx (19) & $770 / 82$ & 62 & $1564 / 406$ & 61 \\
Breast (20, 21) & $-/ 3034$ & 55 & $-/ 3392$ & 56 \\
Endometrium (22) & $-/ 607$ & 62 & $-/ 1366$ & 61 \\
Ovary (23) & $-/ 1031$ & 56 & $-/ 2411$ & 57 \\
Prostate (24) & $1294 /-$ & 66 & $1451 /-$ & 63 \\
Renal cell cancer (25) & $494 / 273$ & 62 & $988 / 546$ & 62 \\
\hline
\end{tabular}

The proportion of refusals of subjects approached for interview was less than $5 \%$ in Italian centers, and about $15 \%$ in Switzerland. All the studies were conducted using the same protocol, which was revised and approved by the ethical committees of the hospitals involved according to the regulations at the time of each study conduction. All participants gave informed consent.

Trained interviewers interviewed cases and controls during their hospital stay using the same structured questionnaire (or a similar one in Switzerland), including information on socio-demographic characteristics, anthropometric measures (including height and weight one year before cancer diagnosis or hospital admission), lifestyle habits (e.g., tobacco smoking, alcohol drinking), dietary habits, personal medical history, family history of cancer, and, for women, menstrual and reproductive factors, and use of oral contraceptives (OC) and hormone replacement therapy (HRT). History of diabetes mellitus and selected other medical conditions was self-reported and included age at first diagnosis.

\section{Statistical analysis}

Odds ratios (OR) of various cancers according to history of diabetes, and the corresponding $95 \%$ confidence intervals $(\mathrm{Cl})$, were estimated by unconditional multiple logistic regression models [28]. The models included terms for sex (when appropriate), age (5-year groups), study centre (categorical), year of interview (continuous) education $(<7,7-11, \geq 12$ years), alcohol drinking $(<14,14-27, \geq 28$ drinks/week), tobacco smoking (never, ex-smokers, current smokers of $<15$, current smokers of 15 24 or current smokers of $\geq 25$ cigarettes per day), and body mass index (BMI, $<20,20-$ $24,25-29, \geq 30 \mathrm{~kg} / \mathrm{m}^{2}$ ). For breast, endometrial, and ovarian cancers, models further included parity, menopausal status, age at menopause, and OC and HRT use, and, for 
breast cancer only, they also included age at first birth. Additional models were fit to assess the potential modifying effect of sex and age. To test for interaction, the difference in -2 log likelihood of the models with and without an interaction term was compared with the $\chi^{2}$ distribution with one degree of freedom. All statistical analyses were performed with SAS 9.1 statistical software (SAS Institute, Cary, NC).

\section{Results}

Table 2 gives the distribution of selected cancer cases and controls according to history of diabetes, and the corresponding ORs.

Table 2. Distribution of cases of selected cancer sites and corresponding controls, and odds ratios (OR) and $95 \%$ confidence intervals $(\mathrm{Cl})$ according to history of diabetes. Italy and Switzerland, 1991-2009.

\begin{tabular}{|c|c|c|c|c|c|c|c|c|c|c|}
\hline \multirow{3}{*}{ Cancer site } & \multicolumn{8}{|c|}{ History of diabetes } & \multirow{3}{*}{$\begin{array}{c}\mathrm{OR}^{\mathrm{a}} \\
(95 \% \mathrm{Cl})\end{array}$} & \multirow{3}{*}{$\begin{array}{c}O R^{\mathrm{b}} \\
(95 \% \mathrm{Cl})\end{array}$} \\
\hline & \multicolumn{4}{|c|}{ No } & \multicolumn{4}{|c|}{ Yes } & & \\
\hline & Cases & (\%) & Controls & (\%) & Cases & (\%) & Controls & (\%) & & \\
\hline Oral cavity/ pharynx & 1370 & (93.3) & 3580 & (95.2) & 98 & (6.7) & 181 & (4.8) & $\begin{array}{c}1.34 \\
(0.98-1.85)\end{array}$ & $\begin{array}{c}1.58 \\
(1.15-2.18)\end{array}$ \\
\hline Esophagus & 455 & (90.1) & 1197 & (95.1) & 50 & (9.9) & 62 & (4.9) & $\begin{array}{c}2.22 \\
(1.36-3.63)\end{array}$ & $\begin{array}{c}2.52 \\
(1.54-4.13)\end{array}$ \\
\hline Gastric & 213 & (92.6) & 504 & (92.1) & 17 & (7.4) & 43 & (7.9) & $\begin{array}{c}0.94 \\
(0.51-1.73)\end{array}$ & $\begin{array}{c}0.98 \\
(0.53-1.81)\end{array}$ \\
\hline Colorectum & 2229 & (93.3) & 4722 & (95.5) & 161 & (6.7) & 221 & (4.5) & $\begin{array}{c}1.23 \\
(0.99-1.53)\end{array}$ & $\begin{array}{c}1.23 \\
(0.98-1.53)\end{array}$ \\
\hline Colon & 1371 & (93.7) & 4722 & (95.5) & 92 & $(6.3)$ & 221 & (4.5) & $\begin{array}{c}1.17 \\
(0.90-1.52)\end{array}$ & $\begin{array}{c}1.16 \\
(0.89-1.50)\end{array}$ \\
\hline Rectum & 858 & (92.6) & 4722 & (95.5) & 69 & (7.4) & 221 & (4.5) & $\begin{array}{c}1.36 \\
(1.02-1.83)\end{array}$ & $\begin{array}{c}1.38 \\
(1.03-1.86)\end{array}$ \\
\hline Liver & 145 & (78.4) & 377 & (93.3) & 40 & (21.6) & 27 & (6.7) & $\begin{array}{c}3.42 \\
(1.89-6.18)\end{array}$ & $\begin{array}{c}3.52 \\
(1.94-6.39)\end{array}$ \\
\hline Pancreas & 269 & (82.5) & 615 & (94.3) & 57 & (17.5) & 37 & (5.7) & $\begin{array}{c}3.18 \\
(1.95-5.20)\end{array}$ & $\begin{array}{c}3.32 \\
(2.02-5.44)\end{array}$ \\
\hline Larynx & 782 & (91.8) & 1836 & (93.2) & 70 & $(8.2)$ & 134 & (6.8) & $\begin{array}{c}1.23 \\
(0.86-1.74)\end{array}$ & $\begin{array}{c}1.30 \\
(0.91-1.85)\end{array}$ \\
\hline $\begin{array}{l}\text { Breast/ } \\
\text { pre-peri menopause }\end{array}$ & 1134 & (98.6) & 1165 & (98.7) & 16 & (1.4) & 15 & (1.3) & $\begin{array}{c}1.35 \\
(0.64-2.86)\end{array}$ & $\begin{array}{c}1.50 \\
(0.70-3.21)\end{array}$ \\
\hline $\begin{array}{l}\text { Breast/post- } \\
\text { menopause }\end{array}$ & 1750 & (92.9) & 2103 & (95.1) & 134 & (7.1) & 109 & (4.9) & $\begin{array}{c}1.83 \\
(1.39-2.40)\end{array}$ & $\begin{array}{c}1.76 \\
(1.34-2.32)\end{array}$ \\
\hline Endometrium $^{d}$ & 545 & $(89.8)$ & 1300 & (95.2) & 62 & $(10.2)$ & 66 & (4.8) & $\begin{array}{c}2.08 \\
(1.41-3.06)\end{array}$ & $\begin{array}{c}1.70 \\
(1.14-2.53)\end{array}$ \\
\hline Ovary $^{d}$ & 986 & $(95.6)$ & 2324 & (96.4) & 45 & $(4.4)$ & 87 & (3.6) & $\begin{array}{c}1.24 \\
(0.82-1.86)\end{array}$ & $\begin{array}{c}1.21 \\
(0.80-1.82)\end{array}$ \\
\hline Prostate & 1205 & (93.1) & 1352 & (93.2) & 89 & (6.9) & 99 & (6.8) & $\begin{array}{c}0.91 \\
(0.66-1.26)\end{array}$ & $\begin{array}{c}0.92 \\
(0.66-1.27)\end{array}$ \\
\hline Renal cell & 697 & $(90.9)$ & 1423 & (92.8) & 70 & (9.1) & 111 & $(7.2)$ & $\begin{array}{c}1.30 \\
(0.94-1.80)\end{array}$ & $\begin{array}{c}1.26 \\
(0.91-1.75)\end{array}$ \\
\hline
\end{tabular}

${ }^{a}$ Estimates from logistic regression model adjusted for sex (when appropriate), age, study centre, year of interview, education, alcohol drinking, tobacco smoking. Reference category: no history of diabetes. ${ }^{b}$ Further adjusted for body mass index. ${ }^{\mathrm{c}}$ Further adjusted for age at first birth, parity, age at menopause (when appropriate), oral contraceptives use, and hormone replacement therapy use. ${ }^{d}$ Further adjusted for 
parity, menopausal status, age at menopause, oral contraceptives use, and hormone replacement therapy use.

The OR for subjects with diabetes as compared to those without diabetes were significantly elevated for cancer of the esophagus (OR=2.22, 95\% Cl 1.36-3.63), colorectum $(\mathrm{OR}=1.23,95 \% \mathrm{Cl} 0.99-1.53)$, rectum (OR=1.36, 95\% $\mathrm{Cl} 1.02-1.83$ ), liver (OR=3.42, 95\% Cl 1.89-6.18), pancreas (OR=3.18, 95\% Cl 1.95-5.20), post-menopausal breast (OR=1.83, 95\% Cl 1.39-2.40), and endometrium (OR=2.08, 95\% Cl 1.14-3.06). Borderline significant associations were found for cancers of the oral cavity and pharynx $(\mathrm{OR}=1.34,95 \% \mathrm{Cl} 0.98-1.85)$. After further adjustment for $\mathrm{BMI}$, the OR was $1.58(95 \% \mathrm{Cl} 1.15-2.18)$ for oral and pharyngeal, $2.52(95 \% \mathrm{Cl})$ for esophageal, 1.23 $(95 \% \mathrm{Cl})$ for colorectum, $1.38(95 \% \mathrm{Cl})$ for rectal, $3.52(95 \% \mathrm{Cl})$ for liver, $3.32(95 \% \mathrm{Cl})$ for pancreas, $1.76(95 \% \mathrm{Cl})$ for post-menopausal breast, and $1.70(95 \% \mathrm{Cl})$ for endometrial cancer. No significant associations were found between diabetes and gastric (OR=0.98, 95\% Cl 0.53-1.81), colon (1.16, 95\% Cl 0.89-1.50), laryngeal (OR=1.30, $95 \% \mathrm{Cl} 0.91-1.85$ ), pre-menopausal breast cancer (OR=1.50, 95\% Cl 0.70-3.21), ovarian $(\mathrm{OR}=1.21,95 \% \mathrm{Cl} 0.80-1.82)$, prostate $(\mathrm{OR}=0.92,95 \% \mathrm{Cl} 0.66-1.27)$, and renal cell (OR=1.26, $95 \% \mathrm{Cl} 0.91-1.75)$ cancer. After excluding subjects with a diagnosis of diabetes within 2 years from cancer diagnosis, the OR was 1.50 (95\% Cl 1.07-2.09) for cancer of the oral cavity and pharynx, 2.28 (95\% Cl 1.36-3.82) of the esophagus, 1.24 (95\% $\mathrm{Cl} 0.99-1.56)$ of the colorectum, 1.48 (95\% Cl 1.10-1.99) of the rectum, 3.38 (95\% $\mathrm{Cl} 1.82-6.28)$ of the liver, 2.34 (95\% Cl 1.37-4.02) of the pancreas, 1.67 (95\% Cl 1.252.23) of the post-menopausal breast, and 1.40 (95\% Cl 0.92-2.14) of the endometrium (data not shown).

Table 3 considers the role of diabetes on cancer sites associated with diabetes in this study according to age at diagnosis of diabetes ( $<40$ years, $\geq 40$ years). For all cancer sites considered, the association was stronger when diabetes was diagnosed at 40 years of age or later, with the exception of oral and pharyngeal cancer.

Table 4 considers the association with time since diagnosis of diabetes for selected cancer sites. For cancers of the oral cavity, esophagus, colorectum, rectum, liver, and post-menopausal breast, the excess risk persisted 10 or more years since diagnosis of diabetes; for pancreatic and endometrial cancer, the association was no longer evident after 10 years since diagnosis $(\mathrm{OR}=0.73,95 \% \mathrm{Cl} 0.31-1.74$, and $1.18,95 \% \mathrm{Cl} 0.65-2.13$, respectively). 
Table 3. Distribution of cases of selected cancer sites and odds ratios (OR) and $95 \%$ confidence intervals $(\mathrm{Cl})$ according to age at diagnosis of diabetes. Italy and Switzerland, 1991-2009.

\begin{tabular}{|c|c|c|c|c|}
\hline \multirow{3}{*}{ Cancer site } & \multicolumn{4}{|c|}{ Age at diagnosis of diabetes } \\
\hline & \multicolumn{2}{|c|}{$<40$ years } & \multicolumn{2}{|c|}{$\geq 40$ years } \\
\hline & No. $^{a}$ & $\mathrm{OR}^{\mathrm{b}}(95 \% \mathrm{Cl})$ & No. $^{a}$ & $O R^{b}(95 \% \mathrm{Cl})$ \\
\hline Oral cavity and pharynx ${ }^{c}$ & 11 & $3.01(1.08-8.36)$ & 86 & $1.49(1.06-2.08)$ \\
\hline Esophagus & 5 & $2.16(0.48-9.55)$ & 45 & $2.56(1.53-4.30)$ \\
\hline Colorectum & 9 & $0.73(0.34-1.59)$ & 152 & $1.29(1.03-1.62)$ \\
\hline Colon & 4 & $0.55(0.19-1.58)$ & 88 & $1.23(0.94-1.61)$ \\
\hline Rectum & 5 & $1.05(0.39-2.82)$ & 64 & $1.43(1.05-1.94)$ \\
\hline Liver $^{c}$ & 2 & $2.28(0.31-16.70)$ & 36 & $3.48(1.86-6.53)$ \\
\hline Pancreas $^{c}$ & 2 & $0.95(0.15-6.12)$ & 54 & $3.54(2.11-5.93)$ \\
\hline Breast/post-menopause $^{d}$ & 10 & $1.26(0.53-3.01)$ & 124 & $1.82(1.37-2.43)$ \\
\hline Endometrium $^{\mathrm{e}}$ & 2 & $0.52(0.10-2.57)$ & 60 & $1.85(1.23-2.80)$ \\
\hline
\end{tabular}

${ }^{a}$ Number of cases.

${ }^{b}$ Estimates from logistic regression model adjusted for sex (when appropriate), age, study centre, year of interview, education, alcohol drinking, tobacco smoking, and body mass index. Reference category: no history of diabetes. 'The sum does not add up to the total because of some missing values. ${ }^{\mathrm{F}}$ Further adjusted for age at first birth, parity, menopausal status, age at menopause, oral contraceptives use, and hormone replacement therapy use. ${ }^{\mathrm{e}}$ Further adjusted for parity, menopausal status, age at menopause, oral contraceptives use, and hormone replacement therapy use.

Table 4. Distribution of cases of selected cancer sites and odds ratios (OR) and 95\% confidence intervals $(\mathrm{Cl})$ according to time since diagnosis of diabetes. Italy and Switzerland, 1991-2009.

\begin{tabular}{|c|c|c|c|c|c|c|}
\hline \multirow{3}{*}{ Cancer site } & \multicolumn{6}{|c|}{ Time since diagnosis of diabetes } \\
\hline & \multicolumn{2}{|r|}{$<5$ years } & \multicolumn{2}{|r|}{$5-9$ years } & \multicolumn{2}{|r|}{$\geq 10$ years } \\
\hline & $\mathrm{N}^{\mathrm{a}}$ & $\mathrm{OR}^{\mathrm{b}}(95 \% \mathrm{Cl})$ & $\mathrm{N}^{\mathrm{a}}$ & $\mathrm{OR}^{\mathrm{b}}(95 \% \mathrm{Cl})$ & $\mathrm{N}^{\mathrm{a}}{ }^{2}$ & $\mathrm{OR}^{\mathrm{b}}(95 \% \mathrm{Cl})$ \\
\hline $\begin{array}{l}\text { Oral } \\
\text { cavity/pharynx }\end{array}$ & 23 & $1.24(0.68-2.26)$ & 30 & $1.94(1.05-3.56)$ & 44 & $1.60(1.02-2.52)$ \\
\hline Esophagus & 11 & $1.96(0.79-4.87)$ & 20 & $4.16(1.75-9.85)$ & 19 & $2.02(0.95-4.31)$ \\
\hline Colorectum & 41 & $1.09(0.73-1.64)$ & 39 & $1.31(0.84-2.05)$ & 81 & $1.28(0.94-1.73)$ \\
\hline Colon & 26 & $1.11(0.69-1.78)$ & 20 & $1.16(0.67-1.99)$ & 46 & $1.19(0.83-1.71)$ \\
\hline Rectum & 15 & $1.03(0.57-1.84)$ & 19 & $1.67(0.95-2.94)$ & 35 & $1.48(0.99-2.21)$ \\
\hline Liver $^{c}$ & 14 & $3.16(1.17-8.51)$ & 11 & $8.33(2.03-34.19)$ & 13 & $2.45(1.05-5.71)$ \\
\hline Pancreas $^{c}$ & 29 & $5.51(2.54-11.94)$ & 18 & $15.45(4.06-58.53)$ & 9 & $0.73(0.31-1.74)$ \\
\hline $\begin{array}{l}\text { Breast/ } \\
\text { post-menopause }^{d}\end{array}$ & 48 & 2.63 (1.61-4.32) & 26 & $1.26(0.73-2.19)$ & 60 & $1.61(1.09-2.38)$ \\
\hline Endometrium ${ }^{\mathrm{e}}$ & 23 & $2.61(1.30-5.23)$ & 18 & $1.88(0.90-3.95)$ & 21 & $1.18(0.65-2.13)$ \\
\hline
\end{tabular}

${ }^{a}$ Number of cases. ${ }^{b}$ Estimates from logistic regression model adjusted for sex (when appropriate), age, study centre, year of interview, education, alcohol drinking, tobacco smoking, and body mass index. Reference category: no history of diabetes. ${ }^{\text {CT}}$ The sum 
does not add up to the total because of some missing values. ${ }^{d}$ Further adjusted for age at first birth, parity, menopausal status, age at menopause, oral contraceptives use, and hormone replacement therapy use. ${ }^{\mathrm{e}}$ Further adjusted for parity, menopausal status, age at menopause, oral contraceptives use, and hormone replacement therapy use.

The ORs of the selected cancer sites in relation to diabetes across strata of sex and age ( $<60$ and $\geq 60$ years) are given in Table 5 . Risk estimates were consistent in men and women; with reference to age, the associations where somewhat stronger in older subjects for esophageal, colorectal (particularly colon), and post-menopausal breast cancer, while they were similar in the two age groups for the other cancers.

Table 5. Distribution of cases of selected cancer sites and odds ratios (OR) and $95 \%$ confidence intervals $(\mathrm{Cl})$ according to history of diabetes, by sex and age at cancer diagnosis. Italy and Switzerland, 1991-2009.

\begin{tabular}{|c|c|c|c|c|c|c|c|c|}
\hline \multirow{3}{*}{ Cancer site } & \multicolumn{4}{|c|}{ Sex } & \multicolumn{4}{|c|}{ Age } \\
\hline & \multicolumn{2}{|r|}{ Men } & \multicolumn{2}{|r|}{ Women } & \multicolumn{2}{|c|}{$<60$ years } & \multicolumn{2}{|c|}{$\geq 60$ years } \\
\hline & No. $^{a}$ & $\begin{array}{c}O^{b^{b}} \\
(95 \% \mathrm{Cl})\end{array}$ & No. & $\begin{array}{c}\mathrm{OR}^{\mathrm{b}} \\
(95 \% \mathrm{Cl})\end{array}$ & No. $^{a}$ & $\begin{array}{c}O^{\mathrm{b}} \\
(95 \% \mathrm{Cl})\end{array}$ & No. $^{a}$ & $\begin{array}{c}\mathrm{OR}^{\mathrm{b}} \\
(95 \% \mathrm{Cl})\end{array}$ \\
\hline $\begin{array}{l}\text { Oral cavity/ } \\
\text { pharynx }\end{array}$ & 78 & $\begin{array}{c}1.54 \\
(1.06-2.22)\end{array}$ & 20 & $\begin{array}{c}1.70 \\
(0.89-3.27)\end{array}$ & 36 & $\begin{array}{c}1.74 \\
(1.00-3.03)\end{array}$ & 62 & $\begin{array}{c}1.49 \\
(1.01-2.21)\end{array}$ \\
\hline Esophagus & 45 & $\begin{array}{c}2.38 \\
(1.39-4.08)\end{array}$ & 5 & $\begin{array}{c}4.88 \\
(1.28-18.6)\end{array}$ & 13 & $\begin{array}{c}1.57 \\
(0.66-3.74)\end{array}$ & 37 & $\begin{array}{c}3.29 \\
(1.80-6.03)\end{array}$ \\
\hline Colorectum & 107 & $\begin{array}{c}1.23 \\
(0.94-1.62)\end{array}$ & 54 & $\begin{array}{c}1.20 \\
(0.80-1.79)\end{array}$ & 22 & $\begin{array}{c}0.83 \\
(0.50-1.36)\end{array}$ & 139 & $\begin{array}{c}1.39 \\
(1.08-1.78)\end{array}$ \\
\hline Colon & 59 & $\begin{array}{c}1.12 \\
(0.81-1.56)\end{array}$ & 33 & $\begin{array}{c}1.09 \\
(0.67-1.76)\end{array}$ & 9 & $\begin{array}{c}0.55 \\
(0.27-1.12)^{c}\end{array}$ & 83 & $\begin{array}{c}1.37 \\
(1.03-1.83)^{c}\end{array}$ \\
\hline Rectum & 48 & $\begin{array}{c}1.44 \\
(1.01-2.06)\end{array}$ & 21 & $\begin{array}{c}1.44 \\
(0.83-2.49)\end{array}$ & 13 & $\begin{array}{c}1.29 \\
(0.69-2.41)\end{array}$ & 56 & $\begin{array}{c}1.45 \\
(1.04-2.03)\end{array}$ \\
\hline Liver & 33 & $\begin{array}{c}3.46 \\
(1.76-6.81)\end{array}$ & 7 & $\begin{array}{c}4.93 \\
(1.01-24.20)\end{array}$ & 8 & $\begin{array}{c}7.96 \\
(1.65-38.38)\end{array}$ & 32 & $\begin{array}{c}3.35 \\
(1.73-6.51)\end{array}$ \\
\hline Pancreas & 37 & $\begin{array}{c}2.88 \\
(1.57-5.29)\end{array}$ & 20 & $\begin{array}{c}4.70 \\
(1.92-11.5)\end{array}$ & 15 & $\begin{array}{c}3.42 \\
(1.25-9.34)\end{array}$ & 42 & $\begin{array}{c}3.11 \\
(1.75-5.53)\end{array}$ \\
\hline $\begin{array}{l}\text { Breast/post- } \\
\text { menopause }^{d}\end{array}$ & & & 150 & $\begin{array}{c}1.76 \\
(1.36-2.27)\end{array}$ & 27 & $\begin{array}{c}1.28 \\
(0.73-2.23)\end{array}$ & 107 & $\begin{array}{c}1.89 \\
(1.38-2.60)\end{array}$ \\
\hline Endometrium $^{\mathrm{e}}$ & & & & & 18 & $\begin{array}{c}2.18 \\
(1.00-4.78)\end{array}$ & 44 & $\begin{array}{c}1.52 \\
(0.95-2.43)\end{array}$ \\
\hline
\end{tabular}

${ }^{a}$ Number of cases with diabetes. ${ }^{b}$ Estimates from logistic regression model adjusted for sex (when appropriate), age, study centre, year of interview, education, alcohol drinking, tobacco smoking, and body mass index. Reference category: no history of diabetes. ${ }^{c} p$-test for heterogeneity $<0.05$. ${ }^{d}$ Further adjusted for age at first birth, parity, menopausal status, age at menopause, oral contraceptives use, and hormone 
replacement therapy use. ${ }^{\mathrm{e}}$ Further adjusted for parity, menopausal status, age at menopause, oral contraceptives use, and hormone replacement therapy use.

\section{Discussion}

The present analysis confirms and further quantifies the increased risk of colorectal, liver, pancreatic, post-menopausal breast, and endometrial, cancer in subjects with diabetes, particularly at elderly age and hence of type $2[1-6,11]$. An excess risk of cancer was also found for cancers of the oral cavity and the esophagus, while no meaningful relation was found for gastric, ovarian, prostate, and kidney cancer. Most of the associations were not meaningfully modified by $\mathrm{BMI}$; only for endometrial cancer the association was reduced after allowance for BMI, while for oral and pharyngeal cancer it was increased. This is not surprising, since endometrial cancer is strongly positively associated to body mass measures [29, 30], while oral cavity and esophageal cancer are inversely associated [31, 32]. No differences in risk estimates were observed between men and women, while the associations were somewhat stronger in older subjects, probably on account of the longer duration of diabetes.

For all cancer sites significantly associated with diabetes (with the exception of oral and esophageal cancer) the excess risk was restricted to subjects whose first diagnosis of diabetes occurred after age 40 years, i.e., to those more likely to have had type 2 diabetes. The number of subjects with a diagnosis of diabetes before age 40 was, however, limited. Consequently, our data mainly reflect the relation with type 2 diabetes. In other datasets as well, the association was mainly related to type 2 diabetes, while data on type 1 diabetes have been limited and provided no consistent evidence of an association [1, 33, 34].

With reference to cancers of the oral cavity and esophagus, we found a 1.5 excess risk in subjects with diabetes. The relation persisted 10 or more year after diabetes was diagnosed and was somewhat stronger when diabetes was diagnosed before age 40 years, i.e., likely diabetes of type 1 . A recent pooled-analysis of 12 case-control studies did not report an overall excess of head and neck cancers (OR=1.09, 95\% $\mathrm{Cl} 0.95-1.24$ ) [35], though a significant increased risk was found (OR=1.19, 95\% Cl 1.02-1.38), when excluding the only study reporting a significant inverse association [36]. An increased risk of oral cancer in subjects with diabetes was also suggested in a pooled analysis of 97 prospective studies [7], while no excess risk was found in the large US Veteran cohort [5]. In support to a possible association between diabetes and oral and pharyngeal cancer, there are clinical observations that leukoplakia and other preneoplastic oral lesions are more frequent among diabetics [37-40].

With reference to esophageal cancer, we found a 2-fold excess risk, which - as in the case of oral cancer - persisted 10 or more year after diabetes diagnosis and was present when diabetes was diagnosed before age 40 years. A recent meta-analysis of 
six case-control and 11 cohort studies also reported a modestly increased risk in diabetics ( $R R=1.30,95 \% \mathrm{Cl} 1.12-1.50)$, the association being stronger for adenocarcinoma of the esophagus ( $R R=2.12,95 \% \mathrm{Cl} 1.01-4.46)$. [41]. Since our esophageal cancer cases were of squamous-cell subtype, the association with diabetes is unlikely to be explained by residual confounding by $\mathrm{BMI}$, since obesity is a risk factor mainly for adenocarcinoma of the esophagus [42].

We found a modest increase in risk of colorectal cancer in relation to diabetes, in line with the $30 \%$ increased risk reported in a meta-analysis of six case-control and nine cohort studies (relative risk, $\mathrm{RR}=1.30,95 \% \mathrm{Cl} 1.20-1.40$ ) [43] and in a subsequent metaanalysis of 30 cohort studies ( $R R=1.27,95 \% \mathrm{Cl} 1.21-1.34$ ) [44]. The association in our study was somewhat stronger for rectal cancer, although no meaningful differences in subsite-specific risk estimates were generally reported $[43,44]$.

The effect of diabetes on the colorectum may be mediated by insulin-related mechanisms. Insulin resistance and compensatory hyperinsulinemia (which characterize diabetes) have been reported to influence the insulin-like growth factor (IGF) system, which in turn may stimulate cellular proliferation and inhibit apoptosis $[45,46]$.

The 3-fold excess risk for cancer of the liver in diabetics is consistent with the pooled RR of 2.5 in a meta-analysis of 13 case-control $(95 \% \mathrm{Cl} 1.8-3.5)$ and 13 cohort $(95 \% \mathrm{Cl} 1.9$ 3.2) studies [47], although another meta-analysis of 25 cohort studies reported a RR of 2.01 (95\% Cl 1.61-2.51). Residual confounding by obesity - consistently associated to this neoplasm $[48,49]$ - does not seem to account for this finding, since allowance for BMI did not materially modify the strength of the association. Similarly, the association was not materially modified by alcohol and tobacco use. Diabetes may be a consequence of liver diseases which usually precede liver cancer [50]. However, in this study the association with diabetes persisted for more than 10 years after diagnosis and was not totally explained by overweight. This suggests a causal relation between diabetes and liver cancer $[19,51]$, which may be explained by changes in the hepatic activity and mitosis related to metabolic alterations or to impaired liver function in diabetics $[52,53]$.

Our data confirm the increased pancreatic cancer risk in subjects with diabetes reported in previous investigations, although our risk estimate was somewhat higher than the overall RR of $1.82(95 \% \mathrm{Cl} 1.66-1.99)$ reported in a meta-analyses of 17 casecontrol and 19 cohort studies [54] and of 1.94 (95\% Cl 1.66-2.27) from a subsequent meta-analysis of 35 cohort studies [55]. In agreement with findings from previous studies, the excess risk was stronger in subjects with a more recent diagnosis of diabetes [5, 54-57]. The risk remained elevated up to 10 years following the diagnosis of diabetes, but declines thereafter, as observed in two other recent case-control studies [56, 57]. However, persistent 30-50\% increased risks were found among individuals who had diabetes for 10 or more years in the studies included in the two 
meta-analyses [54, 55], as well as in a recent large cohort study among US veterans [5] and in other three large case-control studies from the USA [58]. Diabetes may be in part an early manifestation or a consequence of pre-clinical pancreatic cancer; early symptoms of pancreatic cancer may also favor the diagnosis of diabetes [59, 60]. However, reverse causation cannot completely account for the excess risk observed up to 10 years since diagnosis of diabetes, suggesting that it plays a real etiologic role on pancreatic cancer development. High insulin concentrations may be involved in the etiology of pancreatic cancer, as insulin acts as a growth promoter and mitogen in the pancreas [61, 62].

The increased risk of post-menopausal breast cancer in our data is consistent with the modest association reported in two meta-analyses of 20 studies ( $R R=1.15,95 \% \mathrm{Cl} 1.12$ 1.19) [8] and 26 studies ( $R R=1.20,95 \% \mathrm{Cl} 1.12-1.28)$ [9]. In agreement with the findings from these two meta-analyses $[8,9]$, we also found no relation between diabetes and breast cancer in pre-menopause. Diabetes may affect breast cancer risk by altering hormones, such as the signaling of insulin, the IGF system, and steroid sex hormones $[8,9]$. Overweight and obesity are known risk factors of post-menopausal breast cancer $[49,63,64]$ and constitute the major risk factor for type 2 diabetes, too. Thus, in the absence of a relation with pre-menopausal breast cancer, it is likely that the association between diabetes and post-menopausal breast cancer is partly due to residual confounding by obesity [65], although our risk estimate does not seem to be meaningfully influenced by allowance for BMI.

The almost 2-fold increased risk of endometrial cancer in diabetic women in our data is in line with the result of a meta-analysis of 13 case-control and three cohort studies reporting an overall RR of $2.10(95 \% \mathrm{Cl} 1.75-2.53)$ [66], as well as of a few subsequent studies $[67,68]$. The excess risk, however, declined with time since diagnosis of diabetes, being no more significant after 10 years. Hyperinsulinaemia and its influence on the IGF system $[69,70]$ and on serum levels and availability of estrogens may explain the increased endometrial cancer risk in diabetics [71-73]. However, since overweight and obesity are major risk factors for both conditions [49], the association between diabetes and endometrial cancer may be partly - though not totally accounted for by the higher BMI of endometrial cancer cases, as also indicated by the decline in our OR estimates after adjustment for BMI.

A non significant inverse relation was observed between type 2 diabetes and prostate cancer, consistent with the $\mathrm{RR}$ of 0.84 (95\% $\mathrm{Cl} 0.76-0.93)$ reported in a meta-analysis of 19 studies [74]. A subsequent large nested case-control study from the USA [75], and a prospective study within the Prostate, Lung, Colorectal and Ovarian (PLCO) Cancer Screening Trial [76] also found an approximate $20 \%$ reduction in prostate cancer in relation to diabetes. A suggested explanation for such an inverse effect is the reduced androgen levels among diabetics $[62,77,78]$, but the mechanisms underlining this association are still unclear. 
The relation between diabetes and the risk of kidney cancer is controversial, indicating, if anything, a moderately increased risk [11, 79-84]. Our results are, thus, comparable with the overall epidemiological evidence. Also for this neoplasm, it is possible that residual confounding by overweight and obesity explains part of the association.

For gastric, laryngeal and ovarian cancer, we found no meaningful association, in line with most other investigations $[2,5,11,85]$.

Cases and controls in the present studies came from comparable catchment areas, were interviewed by uniformly trained interviewers in their respective hospital settings, had an almost complete participation rate and were unaware of any particular hypothesis relating diabetes to the cancers considered, thereby reducing the likelihood of potential selection and recall bias. History of diabetes and other medical conditions was self-reported. However, reliability of information on medical history provided by hospital controls has been shown to be satisfactory in these studies, with a reproducibility coefficient $(k)$ of 0.85 for history of diabetes [86]. Moreover, the prevalence of diabetes among controls is similar across diagnostic categories, and the overall prevalence of diabetes among controls (4.8\%) is consistent with estimates from Italian population-based surveys [87]. We were also able to allow for major confounding factors for the cancers considered, including in particular careful allowance for BMI. A limitation of this study is the lack of information on the use of antidiabetic drugs, which have been both directly (insulin and insulin analogues) and inversely (metformin) related to cancer risk [4].

Thus, our data confirm the excess risk of cancer of the colorectum, liver, pancreas, breast in post-menopause, and endometrium in subjects with diabetes. Moreover, they indicate that diabetes also increases the risk of cancers of the oral cavity/pharynx and esophagus, although the epidemiological evidence on these neoplasms so far inconclusive. It remains to clarify whether the association between type 2 diabetes and the risk of various cancer sites is largely due to common risk factors (in particular overweight/obesity). Metabolic alterations correlated to obesity and diabetes (hyperglycemia, hyperinsulinemia, insulin resistance), as well as systemic inflammation secondary to (abdominal) obesity, may in fact be responsible for the increase in cancer risk $[1,4,62,88,89]$. 


\section{References}

1. Vigneri P, Frasca F, Sciacca L et al. Diabetes and cancer. Endocr Relat Cancer 2009; 16: 1103-1123.

2. Hemminki K, Li X, Sundquist J, Sundquist K. Risk of cancer following hospitalization for type 2 diabetes. Oncologist 2010; 15: 548-555.

3. Renehan A, Smith U, Kirkman MS. Linking diabetes and cancer: a consensus on complexity. Lancet 2010; 375: 2201-2202.

4. Giovannucci E, Harlan DM, Archer MC et al. Diabetes and cancer: a consensus report. Diabetes Care 2010; 33: 1674-1685.

5. Atchison EA, Gridley G, Carreon JD et al. Risk of cancer in a large cohort of U.S. veterans with diabetes. Int J Cancer 2010; 128: 635-643.

6. Lam EK, Batty GD, Huxley RR et al. Associations of diabetes mellitus with sitespecific cancer mortality in the Asia-Pacific region. Ann Oncol 2011; 22: 730738.

7. Seshasai SR, Kaptoge S, Thompson A et al. Diabetes mellitus, fasting glucose, and risk of cause-specific death. N Engl J Med 2011; 364: 829-841.

8. Larsson SC, Mantzoros CS, Wolk A. Diabetes mellitus and risk of breast cancer: a meta-analysis. Int J Cancer 2007; 121: 856-862.

9. Xue F, Michels KB. Diabetes, metabolic syndrome, and breast cancer: a review of the current evidence. Am J Clin Nutr 2007; 86: s823-835.

10. MacKenzie T, Zens MS, Ferrara A et al. Diabetes and risk of bladder cancer: evidence from a case-control study in New England. Cancer 2011; 117: 15521556.

11. La Vecchia C, Negri E, Franceschi S et al. A case-control study of diabetes mellitus and cancer risk. Br J Cancer 1994; 70: 950-953.

12. Levi $F$, Pasche $C$, La Vecchia $C$ et al. Food groups and risk of oral and pharyngeal cancer. Int J Cancer 1998; 77: 705-709.

13. Garavello W, Foschi R, Talamini R et al. Family history and the risk of oral and pharyngeal cancer. Int J Cancer 2008; 122: 1827-1831.

14. Bosetti C, La Vecchia C, Talamini R et al. Food groups and risk of squamous cell esophageal cancer in northern Italy. Int J Cancer 2000; 87: 289-294.

15. Levi $F$, Pasche $C$, Lucchini $F$ et al. Food groups and oesophageal cancer risk in Vaud, Switzerland. Eur J Cancer Prev 2000; 9: 257-263.

16. Lucenteforte $E$, Scita V, Bosetti $C$ et al. Food groups and alcoholic beverages and the risk of stomach cancer: a case-control study in Italy. Nutr Cancer 2008; 60: 577-584.

17. La Vecchia C, Negri E, Decarli A, Franceschi S. Diabetes mellitus and colorectal cancer risk. Cancer Epidemiol Biomarkers Prev 1997; 6: 1007-1010.

18. Levi F, Pasche $\mathrm{C}$, La Vecchia $\mathrm{C}$ et al. Food groups and colorectal cancer risk. Br J Cancer 1999; 79: 1283-1287. 
19. Polesel J, Zucchetto A, Montella $M$ et al. The impact of obesity and diabetes mellitus on the risk of hepatocellular carcinoma. Ann Oncol 2009; 20: 353-357.

20. Lucenteforte $E$, Talamini R, Bosetti $C$ et al. Macronutrients, fatty acids, cholesterol and pancreatic cancer. Eur J Cancer 2010; 46: 581-587.

21. Bosetti C, La Vecchia C, Talamini R et al. Food groups and laryngeal cancer risk: a case-control study from Italy and Switzerland. Int J Cancer 2002; 100: 355-360.

22. Levi F, Pasche C, Lucchini F, La Vecchia C. Dietary intake of selected micronutrients and breast-cancer risk. Int J Cancer 2001; 91: 260-263.

23. Talamini R, Franceschi S, Favero A et al. Selected medical conditions and risk of breast cancer. Br J Cancer 1997; 75: 1699-1703.

24. Lucenteforte E, Bosetti C, Talamini R et al. Diabetes and endometrial cancer: effect modification by body weight, physical activity and hypertension. $\mathrm{Br} \mathrm{J}$ Cancer 2007; 97: 995-998.

25. Bosetti C, Negri E, Franceschi S et al. Diet and ovarian cancer risk: a case-control study in Italy. Int J Cancer 2001; 93: 911-915.

26. Tavani A, Gallus S, Bertuzzi M et al. Diabetes mellitus and the risk of prostate cancer in Italy. Eur Urol 2005; 47: 313-317; discussion 317.

27. Zucchetto A, Dal Maso L, Tavani A et al. History of treated hypertension and diabetes mellitus and risk of renal cell cancer. Ann Oncol 2007; 18: 596-600.

28. Breslow NE, Day NE. Statistical methods in cancer research. Vol. I. The analysis of case-control studies. IARC Sci Publ No. 32. Lyon, France: IARC 1980.

29. La Vecchia C, Parazzini F, Negri E et al. Anthropometric indicators of endometrial cancer risk. Eur J Cancer 1991; 27: 487-490.

30. Levi F, La Vecchia C, Negri E et al. Body mass at different ages and subsequent endometrial cancer risk. Int J Cancer 1992; 50: 567-571.

31. Gallus S, La Vecchia C, Levi F et al. Leanness and squamous cell oesophageal cancer. Ann Oncol 2001; 12: 975-979.

32. Franceschi S, Dal Maso L, Levi F et al. Leanness as early marker of cancer of the oral cavity and pharynx. Ann Oncol 2001; 12: 331-336.

33. Zendehdel K, Nyren O, Ostenson CG et al. Cancer incidence in patients with type 1 diabetes mellitus: a population-based cohort study in Sweden. J Natl Cancer Inst 2003; 95: 1797-1800.

34. Stevens RJ, Roddam AW, Beral V. Pancreatic cancer in type 1 and young-onset diabetes: systematic review and meta-analysis. Br J Cancer 2007; 96: 507-509.

35. Stott-Miller M, Chen C, Chuang SC et al. History of Diabetes and risk of head and neck cancer: a pooled analysis from the International Head and Neck Cancer Epidemiology (INHANCE) Consortium. Cancer Epidemiol Biomarkers Prev 2011; 21: 294-304. 
36. Divaris $\mathrm{K}$, Olshan $\mathrm{AF}$, Smith J et al. Oral health and risk for head and neck squamous cell carcinoma: the Carolina Head and Neck Cancer Study. Cancer Causes Control 2010; 21: 567-575.

37. Dikshit RP, Ramadas K, Hashibe $\mathrm{M}$ et al. Association between diabetes mellitus and pre-malignant oral diseases: a cross sectional study in Kerala, India. Int J Cancer 2006; 118: 453-457.

38. Ujpal $M$, Matos $O$, Bibok $G$ et al. Diabetes and oral tumors in Hungary: epidemiological correlations. Diabetes Care 2004; 27: 770-774.

39. Albrecht M, Banoczy J, Dinya E, Tamas G, Jr. Occurrence of oral leukoplakia and lichen planus in diabetes mellitus. J Oral Pathol Med 1992; 21: 364-366.

40. Dietrich T, Reichart PA, Scheifele C. Clinical risk factors of oral leukoplakia in a representative sample of the US population. Oral Oncol 2004; 40: 158-163.

41. Huang $W$, Ren $H$, Ben $Q$ et al. Risk of esophageal cancer in diabetes mellitus: a meta-analysis of observational studies. Cancer Causes Control 2011.

42. Chow WH, Blot WJ, Vaughan TL et al. Body mass index and risk of adenocarcinomas of the esophagus and gastric cardia. J Natl Cancer Inst 1998; 90: 150-155.

43. Larsson SC, Orsini N, Wolk A. Diabetes mellitus and risk of colorectal cancer: a meta-analysis. J Natl Cancer Inst 2005; 97: 1679-1687.

44. Jiang $\mathrm{Y}$, Ben $\mathrm{Q}$, Shen $\mathrm{H}$ et al. Diabetes mellitus and incidence and mortality of colorectal cancer: a systematic review and meta-analysis of cohort studies. Eur J Epidemiol 2011; 26: 863-876.

45. Giovannucci E. Insulin, insulin-like growth factors and colon cancer: a review of the evidence. J Nutr 2001; 131: 3109S-3120S.

46. Jenab M, Riboli E, Cleveland RJ et al. Serum C-peptide, IGFBP-1 and IGFBP-2 and risk of colon and rectal cancers in the European Prospective Investigation into Cancer and Nutrition. Int J Cancer 2007; 121: 368-376.

47. El-Serag HB, Hampel $H$, Javadi $F$. The association between diabetes and hepatocellular carcinoma: a systematic review of epidemiologic evidence. Clin Gastroenterol Hepatol 2006; 4: 369-380.

48. Larsson SC, Wolk A. Overweight, obesity and risk of liver cancer: a meta-analysis of cohort studies. Br J Cancer 2007; 97: 1005-1008.

49. World Cancer Research Fund and American Institute for Cancer Research. Food, Nutrition, Physical Activity and the Prevention of Cancer: a Global Perspective. Washington, DC: AICR. 2007.

50. Beasley RP. Diabetes and hepatocellular carcinoma. Hepatology 2006; 44: 14081410.

51. Hassan MM, Curley SA, Li D et al. Association of diabetes duration and diabetes treatment with the risk of hepatocellular carcinoma. Cancer 2010; 116: 19381946. 
52. Tanaka S, Mohr L, Schmidt EV et al. Biological effects of human insulin receptor substrate-1 overexpression in hepatocytes. Hepatology 1997; 26: 598-604.

53. Dellon ES, Shaheen NJ. Diabetes and hepatocellular carcinoma: associations, biologic plausibility, and clinical implications. Gastroenterology 2005; 129 : 1132-1134.

54. Huxley R, Ansary-Moghaddam A, Berrington de Gonzalez A et al. Type-II diabetes and pancreatic cancer: a meta-analysis of 36 studies. $\mathrm{Br} J$ Cancer 2005; 92: 2076-2083.

55. Ben $Q, X u M, N i n g ~ X$ et al. Diabetes mellitus and risk of pancreatic cancer: $A$ meta-analysis of cohort studies. Eur J Cancer 2011; 47: 1928-1937.

56. Wang F, Gupta S, Holly EA. Diabetes mellitus and pancreatic cancer in a population-based case-control study in the San Francisco Bay Area, California. Cancer Epidemiol Biomarkers Prev 2006; 15: 1458-1463.

57. Maisonneuve $\mathrm{P}$, Lowenfels $\mathrm{AB}$, Bueno-de-Mesquita $\mathrm{HB}$ et al. Past medical history and pancreatic cancer risk: Results from a multicenter case-control study. Ann Epidemiol 2010; 20: 92-98.

58. Li D, Tang H, Hassan MM et al. Diabetes and risk of pancreatic cancer: a pooled analysis of three large case-control studies. Cancer Causes Control 2011; 22: 189-197.

59. Permert J, Ihse I, Jorfeldt $L$ et al. Pancreatic cancer is associated with impaired glucose metabolism. Eur J Surg 1993; 159: 101-107.

60. Wang F, Herrington M, Larsson J, Permert J. The relationship between diabetes and pancreatic cancer. Mol Cancer 2003; 2: 4.

61. Fisher WE, Boros LG, Schirmer WJ. Insulin promotes pancreatic cancer: evidence for endocrine influence on exocrine pancreatic tumors. J Surg Res 1996; 63: 310-313.

62. Giovannucci E, Michaud D. The role of obesity and related metabolic disturbances in cancers of the colon, prostate, and pancreas. Gastroenterology 2007; 132: 2208-2225.

63. Franceschi S, Favero A, La Vecchia $C$ et al. Body size indices and breast cancer risk before and after menopause. Int J Cancer 1996; 67: 181-186.

64. Tavani A, Gallus S, La Vecchia $C$ et al. Risk factors for breast cancer in women under 40 years. Eur J Cancer 1999; 35: 1361-1367.

65. La Vecchia C, Giordano SH, Hortobagyi GN, Chabner B. Overweight, obesity, diabetes, and risk of breast cancer: interlocking pieces of the puzzle. Oncologist 2011; 16: 726-729.

66. Friberg E, Orsini N, Mantzoros CS, Wolk A. Diabetes mellitus and risk of endometrial cancer: a meta-analysis. Diabetologia 2007; 50: 1365-1374. 
67. Lindemann K, Vatten LJ, Ellstrom-Engh M, Eskild A. Body mass, diabetes and smoking, and endometrial cancer risk: a follow-up study. Br J Cancer 2008; 98 : 1582-1585.

68. Saltzman BS, Doherty JA, Hill DA et al. Diabetes and endometrial cancer: an evaluation of the modifying effects of other known risk factors. Am J Epidemiol 2008; 167: 607-614.

69. Weiderpass E, Brismar K, Bellocco R et al. Serum levels of insulin-like growth factor-I, IGF-binding protein 1 and 3, and insulin and endometrial cancer risk. $\mathrm{Br}$ J Cancer 2003; 89: 1697-1704.

70. Augustin LS, Dal Maso L, Franceschi S et al. Association between components of the insulin-like growth factor system and endometrial cancer risk. Oncology 2004; 67: 54-59.

71. Parazzini F, La Vecchia C, Bocciolone L, Franceschi S. The epidemiology of endometrial cancer. Gynecol Oncol 1991; 41: 1-16.

72. Nestler JE, Powers LP, Matt DW et al. A direct effect of hyperinsulinemia on serum sex hormone-binding globulin levels in obese women with the polycystic ovary syndrome. J Clin Endocrinol Metab 1991; 72: 83-89.

73. Cook LS, Weiss NS, Doherty JA, Chen C. Endometrial cancer. In Schottenfeld D, Fraumeni JF, Jr. (eds): Cancer Epidemiology and Prevention. New York: Oxford University Press 2006; 1027-1043.

74. Kasper JS, Giovannucci E. A meta-analysis of diabetes mellitus and the risk of prostate cancer. Cancer Epidemiol Biomarkers Prev 2006; 15: 2056-2062.

75. Turner EL, Lane JA, Donovan JL et al. Association of diabetes mellitus with prostate cancer: nested case-control study (Prostate testing for cancer and treatment study). Int J Cancer 2011; 128: 440-446.

76. Leitzmann MF, Ahn J, Albanes D et al. Diabetes mellitus and prostate cancer risk in the Prostate, Lung, Colorectal, and Ovarian Cancer Screening Trial. Cancer Causes Control 2008; 19: 1267-1276.

77. Giovannucci E. Medical history and etiology of prostate cancer. Epidemiol Rev 2001; 23: 159-162.

78. Hsing AW. Hormones and prostate cancer: what's next? Epidemiol Rev 2001; 23: 42-58.

79. McCredie M, Stewart JH. Risk factors for kidney cancer in New South Wales, Australia. II. Urologic disease, hypertension, obesity, and hormonal factors. Cancer Causes Control 1992; 3: 323-331.

80. Kreiger N, Marrett LD, Dodds L et al. Risk factors for renal cell carcinoma: results of a population-based case-control study. Cancer Causes Control 1993; 4: 101110.

81. Schlehofer B, Pommer W, Mellemgaard A et al. International renal-cell-cancer study. VI. the role of medical and family history. Int J Cancer 1996; 66: 723-726. 
82. Lindblad $\mathrm{P}$, Chow $\mathrm{WH}, \mathrm{Chan} \mathrm{J}$ et al. The role of diabetes mellitus in the aetiology of renal cell cancer. Diabetologia 1999; 42: 107-112.

83. Larsson SC, Wolk A. Diabetes mellitus and incidence of kidney cancer: a metaanalysis of cohort studies. Diabetologia 2011; 1013-1018.

84. Washio $\mathrm{M}$, Mori $\mathrm{M}$, Khan $\mathrm{M}$ et al. Diabetes mellitus and kidney cancer risk: the results of Japan Collaborative Cohort Study for Evaluation of Cancer Risk (JACC Study). Int J Urol 2007; 14: 393-397.

85. Kuriki K, Hirose K, Tajima K. Diabetes and cancer risk for all and specific sites among Japanese men and women. Eur J Cancer Prev 2007; 16: 83-89.

86. Bosetti C, Tavani A, Negri E et al. Reliability of data on medical conditions, menstrual and reproductive history provided by hospital controls. J Clin Epidemiol 2001; 54: 902-906.

87. Istituto Nazionale di Statistica. Stili di vita e condizioni di salute. Indagine multiscopo sulle famiglie Aspetti della vita quotidiana. Anno 2003. ISTAT 2005.

88. van Kruijsdijk RC, van der Wall E, Visseren FL. Obesity and cancer: the role of dysfunctional adipose tissue. Cancer Epidemiol Biomarkers Prev 2009; 18: 25692578.

89. Khandekar MJ, Cohen P, Spiegelman BM. Molecular mechanisms of cancer development in obesity. Nat Rev Cancer 2011; 11: 886-895. 


\section{Chapter 4.2. The ROLE OF THE MediterRanean Diet ON THE RISK OF PANCReatic CANCER}

Cristina Bosetti, Federica Turati, Alessia Dal Pont, Monica Ferraroni, Jerry Polesel, Eva Negri ${ }^{1}$, Diego Serraino, Renato Talamini, Carlo La Vecchia, Maurice P. Zeegers

British Journal of Cancer 2013; 109:1360-1366. 


\section{Abstract}

The Mediterranean diet has been shown to have a beneficial role on various neoplasms, but data are scanty on pancreatic cancer. We analyzed data from two casecontrol studies conducted in Italy between 1983 and 2008, including 362 and 326 pancreatic cancer cases and 1552 and 652 hospital-controls, respectively. A Mediterranean Diet Score (MDS) summarizing major characteristics of the Mediterranean diet was used in the two studies separately and overall. Two further scores of adherence to the Mediterranean diet were applied in the second study only, the Mediterranean Dietary Pattern Adherence Index (MDP) and the Mediterranean Adequacy Index (MAI). Odds ratios (OR) for increasing levels of the scores (i.e., increasing adherence) were estimated using multiple logistic regression models. OR for a MDS score $\geq 6$ compared to $<3$ was 0.57 (95\% confidence interval, $\mathrm{Cl}, 0.34-0.95$ ) in the first study, $0.51(95 \% \mathrm{Cl} 0.29-0.92)$ in the second study, and $0.48(95 \% \mathrm{Cl} 0.35-0.67)$ overall. A trend of decreasing risk was observed also for the MDP and MAI scores, the ORs for the highest versus the lowest quintile being 0.44 (95\% $\mathrm{Cl} 0.27-0.73$ ) for MDP and 0.68 (95\% $\mathrm{Cl} 0.42-1.11)$ for MAl. The results were consistent across strata of age, sex, education, body mass index, alcohol drinking, tobacco smoking, and diabetes. Our study provides evidence that a priori defined scores measuring adherence to the Mediterranean diet are favorably associated with pancreatic cancer risk. 


\section{Introduction}

The Mediterranean diet typical of southern European countries has different variants but it is generally characterized by some common features, i.e., abundant consumption of plant foods, fresh and varied fruit, high consumption of cereals, frequent consumption of fish, olive oil as the main seasoning fat, moderate consumption of wine mainly during meals, and relatively low intake of meat and dairy products [1]. Several epidemiological studies have indicated that adherence to the Mediterranean dietary pattern has a beneficial role on cardiovascular diseases [2-5] and overall mortality [4, 6-10]. In particular, for coronary heart diseases, no particular food has been implicated as causal, but the evidence for a favorable role of the Mediterranean dietary pattern is convincing [11]. More recently, other studies suggested that the Mediterranean diet has a favorable impact on common cancers as well [12-20].

Adherence to a Mediterranean diet pattern may have a beneficial role also on pancreatic cancer, although only a few studies have evaluated such an association. The US prospective National Institutes of Health-AARP Diet and Health study, including a total of 450,416 participants and 1,057 pancreatic cancer cases, reported a relative risk (RR) of 0.92 (95\% confidence interval, $\mathrm{Cl}, 0.81-1.05$ ) for high (5-8 points) versus low (04 points) no-alcohol Mediterranean dietary score. The risk reduction comparing the most extreme categories of the dietary score (7-8 points versus $0-1)$ was $27 \%$, although it was not significant $(p=0.06)$ [21]. In a cohort study from Sweden on 77,151 participants and including 92 pancreatic cancer cases, the Mediterranean diet score was significantly inversely related to pancreatic cancer risk ( $R R=0.82,95 \% \mathrm{Cl} 0.72-0.94)$ [22]. The adherence to various aspects of the Mediterranean diet, however, is likely to be much lower in those countries than in Italy.

We have therefore evaluated the hypothesis that the Mediterranean diet has a beneficial role on the risk of pancreatic cancer using data from two Italian case-control studies [23]. To measure the adherence to the Mediterranean diet, we used three different a priori defined scores proposed in the literature to combine various foods/food groups, and adopted in various other epidemiological studies [24]. This is an alternative approach to that used in one of the Italian studies [25], where nutrientbased dietary patterns were identified using an exploratory a posteriori approach, built on the specific dietary data under consideration.

\section{Materials and methods}

We analyzed data from two hospital-based case-control studies of pancreatic cancer conducted in Italy. Briefly, the first one was conducted between 1983 and 1992 in the province of Milan on 362 incident cases of pancreatic cancer (229 men, 133 women, median age 60 years, range 18-86) and 1,552 controls (1,114 men, 411 women, 
median age 56 years, range 18-84) [26]; the second study was conducted between 1992 and 2008 in the provinces of Milan and Pordenone (northern Italy) on 326 incident cases (174 men, 152 women, median age 62 years, range 34-80) and 652 controls (348 men, 304 women, median age 62 years, range 34-80), frequencymatched to cases by age, sex, and study center (ratio 2:1) [27]. In both studies, controls were subjects admitted to the same network of hospitals as cases for a wide spectrum of acute, non-neoplastic conditions. Overall, $30 \%$ were admitted for traumas, $21 \%$ for non-traumatic orthopedic disorders, $33 \%$ for acute surgical conditions, and $16 \%$ for miscellaneous other illnesses, including eye, ear, nose, throat, skin or dental disorders. Less than $5 \%$ of cases and controls approached for interview refused to participate.

Cases and controls were personally interviewed by centrally trained interviewers using similar structured questionnaires including information on socio-demographic characteristics, anthropometric measures (including self-reported weight and height), tobacco smoking, alcohol drinking, other lifestyle habits, and personal medical history of selected diseases. In the first study, subjects' usual diet prior to cancer diagnosis or hospital admission (for controls) was investigated using a simplified dietary section, including weekly frequency of consumption of 14 selected indicator foods. Subjective scores (low, medium, high) were used to obtain information on (whole grain) cereals and seasoning fat intake (butter, margarine, olive oil). In the second study, subjects' usual diet during the two years prior to cancer diagnosis or hospital admission (for controls) was assessed through a validated and reproducible food frequency questionnaire $[28,29]$, including 78 foods and beverages, as well as a range of recipes, i.e. the most common ones in the Italian diet, grouped into 7 sections: (i) bread and cereal dishes (first courses); (ii) meat and other main dishes (second courses); (iii) vegetables (side dishes); (iv) fruit; (v) sweets, desserts and soft drinks; (vi) milk and hot beverages; (vii) alcoholic beverages. Subjects were asked to indicate the average weekly frequency of consumption of each dietary item; occasional intake (lower than once a week, but at least once a month) was coded as 0.5 per week. An Italian food composition database, integrated with other sources, was used to estimate nutrient and total energy intake in this study [30, 31].

In both studies, we defined an a priori Mediterranean Diet Score (MDS) on the basis of nine (eight for the first study) characteristics of the traditional Mediterranean diet, as suggested by Trichopoulou et al. [6] (Supplemental Table): high consumption of cereals, fruit, vegetables, legumes (for the second study only), and fish, high monounsaturated/saturated fat ratio, low consumption of milk and dairy products, and meat and meat products, and moderate alcohol intake. The cut-points for the items considered were set to study and sex-specific median values among controls. For each subject, one point was attributed for the presence of each characteristic; for alcohol, one point was attributed to moderate drinkers (consumption over 0 and 
below the median), and none to non or heavy drinkers (consumption above the median). We then summed up the points for all the nine (or eight in the first study) items to calculate the MDS, which thus ranges between 0 (no adherence) and nine (or eight) (maximum adherence).

Supplemental Table. Dietary items included in the definition of the Mediterranean dietary scores used in the two case-control studies on pancreatic cancer. Italy, 19832008.

\begin{tabular}{|c|c|}
\hline First study (1983-1992) & Second study (1992-2008) \\
\hline \multicolumn{2}{|l|}{ Mediterranean Dietary Score } \\
\hline Cereals & Cereals \\
\hline Fruit & Fruit \\
\hline Vegetables & Vegetables \\
\hline- & Legumes \\
\hline Fish & Fish \\
\hline Olive oil/butter \& margarine & Monounsaturated/saturated fat \\
\hline Milk and dairy products & Milk and dairy products \\
\hline Meat and meat products & Meat and meat products \\
\hline Alcohol intake & Alcohol intake \\
\hline \multicolumn{2}{|c|}{ Mediterranean Dietary Pattern Adherence Index } \\
\hline & Cereals \\
\hline & Fruit \\
\hline & Vegetables \\
\hline & Legumes \\
\hline & Alcohol \\
\hline & Monounsaturated/ saturated fat \\
\hline & Milk \\
\hline & Meat and meat products \\
\hline \multicolumn{2}{|l|}{ Mediterranean Adequacy Index } \\
\hline & Cereals \\
\hline & Fruit \\
\hline & Vegetables \\
\hline & Legumes \\
\hline & Potatoes \\
\hline & Fish \\
\hline & Red wine \\
\hline & Vegetable oils \\
\hline & Milk and dairy products \\
\hline & Meat and meat products \\
\hline & Eggs \\
\hline & Animal fats/margarines \\
\hline & Sweet beverages \\
\hline & Sweets \\
\hline & Sugar \\
\hline
\end{tabular}


Two further scores of adherence to the Mediterranean diet were applied in the second study only, the Mediterranean Dietary Pattern Adherence Index (MDP) and the Mediterranean Adequacy Index (MAI). The MDP was calculated by summing up the standardized residuals of the regression of cereals, fruit, vegetables, legumes, moderate alcohol, monounsaturated to saturated fat ratio on total calories, and subtracting those of milk and meat. The MDP was then expressed as a percentage of adherence using the range of the values in the sample, and assumed values between $0 \%$ (low adherence) and $100 \%$ (maximum adherence) [32]. MAI was calculated by dividing the sum of the intake of selected typical Mediterranean foods (i.e., bread, cereals, fruit, vegetables, legumes, potatoes, fish, red wine, and vegetable oils) as a percentage of total energy by the sum of the intake of non-typical Mediterranean foods (i.e., milk, cheese, meat, eggs, animal fats and margarines, sweet beverages, cakes, pies and cookies, sugar) again as the percentage of total energy [33]. In our population, this score ranged between 0.33 and 14.18. The MDP score had a high correlation with the MDS score (Pearson correlation coefficient=0.59), while the correlation coefficient was 0.29 between the MAI and the MDS score.

We estimated odds ratios (OR) and the corresponding $95 \% \mathrm{Cl}$ of pancreatic cancer for categories of the three scores by unconditional multiple logistic regression models [34], including terms for age (5-years groups), sex, centre, calendar year at diagnosis, years of education $\left(<7,7-11, \geq 12\right.$ ), body mass index (BMI, $<25,25-29.9, \geq 30 \mathrm{~kg} / \mathrm{m}^{2}$ ), tobacco consumption (never, ex-smoker, current smoker of $<15$ and $\geq 15$ cigarettes/day), history of diabetes (no, yes), and total energy intake (quintiles, available for the second study only). Overall risk estimates for the two studies combined were further adjusted by study. We also computed continuous ORs, for an increment of one unit for MDS and MAI and of 10-unit for the MDP.

To investigate whether the associations with the three dietary scores was homogeneous across strata of selected covariates, we conducted analyses stratified by sex, age, education, BMI, tobacco smoking, alcohol consumption, and history of diabetes. Heterogeneity across strata was tested by likelihood ratio tests and resulting $\chi^{2}$ statistics.

\section{Results}

Table 1 shows the distribution of pancreatic cancer cases and corresponding controls by selected covariates. As compared to controls, cases were more frequently of female sex, were somewhat older, had a lower BMI, were more frequently heavy smoker, and reported more frequently a history of diabetes. No difference was observed with reference to education and alcohol drinking. 
Table 1. Distribution of 688 pancreatic cancer cases and 2204 controls according to centre, sex, age and selected other variables. Italy, 1983-2008.

\begin{tabular}{|c|c|c|c|c|}
\hline & \multicolumn{2}{|c|}{ Cases } & \multicolumn{2}{|c|}{ Controls } \\
\hline & No. & $\%$ & No. & $\%$ \\
\hline \multicolumn{5}{|l|}{ Centre/study } \\
\hline Milan (first study) & 362 & 52.6 & 1552 & 70.4 \\
\hline Pordenone (second study) & 175 & 25.4 & 350 & 15.9 \\
\hline Milan (second study) & 151 & 22.0 & 302 & 13.7 \\
\hline \multicolumn{5}{|l|}{ Sex } \\
\hline Men & 403 & 58.6 & 1489 & 67.6 \\
\hline Women & 285 & 41.2 & 715 & 32.4 \\
\hline \multicolumn{5}{|l|}{ Age (years) } \\
\hline$<50$ & 92 & 13.4 & 519 & 23.6 \\
\hline $50-59$ & 208 & 30.2 & 678 & 30.8 \\
\hline $60-69$ & 247 & 35.9 & 686 & 31.1 \\
\hline$\geq 70$ & 141 & 20.5 & 321 & 14.6 \\
\hline \multicolumn{5}{|l|}{ Education (years) ${ }^{a}$} \\
\hline$<7$ & 358 & 52.2 & 1087 & 49.4 \\
\hline $7-11$ & 181 & 26.4 & 646 & 29.3 \\
\hline$\geq 12$ & 147 & 21.4 & 469 & 21.3 \\
\hline \multicolumn{5}{|l|}{ Body mass index $\left(\mathrm{kg} / \mathrm{m}^{2}\right)^{a}$} \\
\hline$<20$ & 90 & 13.2 & 122 & 5.6 \\
\hline $20-24.9$ & 316 & 46.2 & 952 & 43.4 \\
\hline $25-29.9$ & 212 & 31.0 & 884 & 40.3 \\
\hline$\geq 30$ & 66 & 9.7 & 234 & 10.7 \\
\hline \multicolumn{5}{|l|}{ Tobacco smoking $^{\text {a }}$} \\
\hline Never smoker & 274 & 39.9 & 913 & 41.5 \\
\hline Ex smoker & 173 & 25.2 & 521 & 23.7 \\
\hline \multicolumn{5}{|l|}{ Current smoker } \\
\hline 1-19 cigarettes/day & 89 & 13.0 & 357 & 16.2 \\
\hline$\geq 20$ cigarettes/day & 150 & 21.9 & 410 & 18.6 \\
\hline \multicolumn{5}{|l|}{ Alcohol drinking (drinks/day) $)^{a}$} \\
\hline$<8$ & 257 & 37.4 & 804 & 36.6 \\
\hline $8-14$ & 123 & 17.9 & 403 & 18.3 \\
\hline $15-21$ & 63 & 9.2 & 240 & 10.9 \\
\hline$\geq 22$ & 244 & 35.5 & 752 & 34.2 \\
\hline \multicolumn{5}{|l|}{ Diabetes } \\
\hline No & 585 & 85.0 & 2078 & 94.3 \\
\hline Yes & 103 & 15.0 & 126 & 5.7 \\
\hline
\end{tabular}

${ }^{\mathrm{a}}$ The sum does not add up to the total because of some missing values.

The distribution of pancreatic cancer cases and controls, and the corresponding ORs according to the MDS (separately for the two studies and overall) are given in Table 2. A significant reduced risk of pancreatic cancer was found for increasing levels of the MDS: the ORs for subjects with 6 or more Mediterranean characteristics, compared to those with less than 3 characteristics were 0.57 (95\% Cl 0.34-0.95) in the first study, 
0.51 (95\% $\mathrm{Cl} 0.29-0.92)$ in the second study, and 0.48 (95\% $\mathrm{Cl} 0.35-0.67)$ overall. The continuous ORs for a unit increment of the MDS were $0.88(95 \% \mathrm{Cl} 0.81-0.95)$ in the first study, 0.89 (95\% Cl 0.81-0.99) in the second study, and 0.85 (95\% Cl 0.80-0.91) overall. In sensitivity analyses, the overall continuous OR was 0.84 (95\% Cl 0.79-0.90) after excluding milk from the MDS score, 0.83 (95\% Cl 0.78-0.88) after excluding cereals, $0.86(95 \% \mathrm{Cl} 0.81-0.92)$ after excluding fruit, 0.84 (95\% Cl 0.79-0.90) after excluding vegetables, $0.87(95 \% \mathrm{Cl} 0.82-0.93)$ after excluding meat, 0.85 (95\% Cl 0.79 $0.90)$ after excluding fish, $0.85(95 \% \mathrm{Cl}$ 0.80-0.91) after excluding alcohol, and 0.83 (95\% $\mathrm{Cl} 0.78-0.89)$ after excluding monounsaturated to saturated fat ratio.

Table 2. Odds ratios ${ }^{a}(O R)$ and $95 \%$ confidence intervals $(\mathrm{Cl})$ for pancreatic cancer according to the Mediterranean Diet Score (MDS) among 688 pancreatic cancer cases and 2204 controls. Italy, 1983-2008.

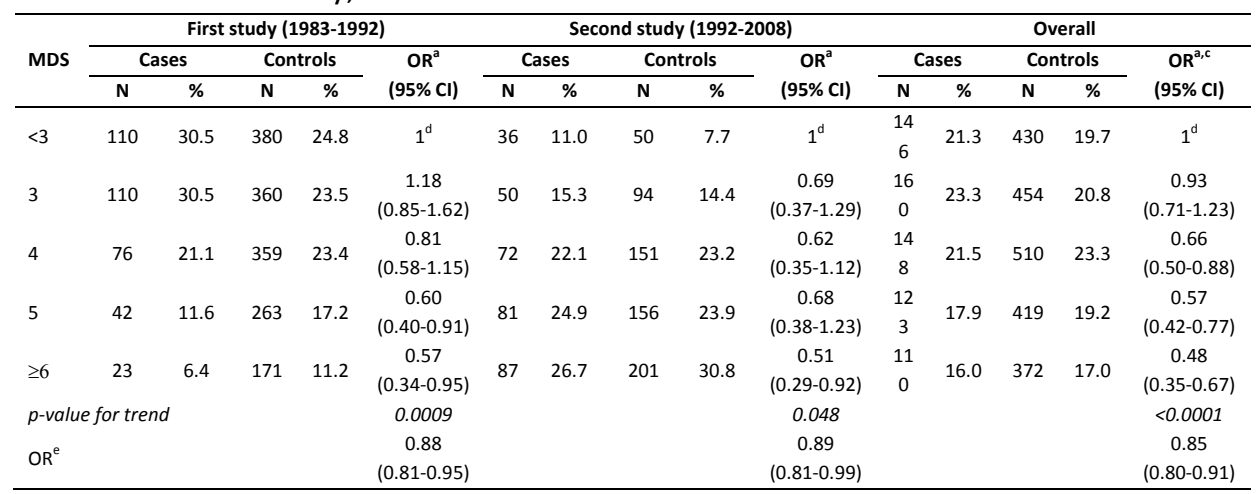

${ }^{\mathrm{a}}$ Estimates from unconditional logistic regression adjusted for center, age, sex, year of interview, education, body mass index, tobacco smoking, alcohol consumption, history of diabetes, and total energy intake (second study only). ${ }^{\text {b}}$ The sum does not add up to the total because of some missing values. 'Estimates further adjusted for study. ${ }^{d}$ Reference category. ${ }^{e}$ Estimate for an increment of one unit.

The association for a continuous increment of the MDS was consistent in strata of age, BMI, alcohol drinking, and tobacco smoking (Table 3). The inverse relation with pancreatic cancer was stronger in subjects with a lower level of education as compared to those with a higher level $(\mathrm{OR}=0.79$ and 0.91 , respectively, $\mathrm{p}$ for heterogeneity between strata $=0.0095$ ) and in those with no history of diabetes as compared with those with a history of diabetes $(\mathrm{OR}=0.84$ and 0.99 , respectively, $\mathrm{p}$ for heterogeneity between strata=0.01). 
Table 3. Odds ratios $(\mathrm{OR})$ and $95 \%$ confidence intervals $(\mathrm{Cl})$ for pancreatic cancer according to the Mediterranean diet score in strata of selected covariates among 688 pancreatic cancer cases and 2204 controls. Italy, 1983-2008.

\begin{tabular}{lcc}
\hline & Cases/controls & OR $^{\mathrm{a}}(\mathbf{9 5} \% \mathrm{Cl})$ \\
\hline Age (years) & & \\
$\quad<60$ & $300 / 1197$ & $0.85(0.77-0.93)$ \\
$\quad 260$ & $388 / 1007$ & $0.86(0.79-0.93)$ \\
Sex & & \\
$\quad$ Men & $403 / 1489$ & $0.84(0.78-0.91)$ \\
$\quad$ Women & $285 / 715$ & $0.87(0.79-0.97)$ \\
Education (years) & & \\
$\quad<7$ & $358 / 1087$ & $0.79(0.72-0.87)^{\mathrm{b}}$ \\
$\quad \geq 7$ & $328 / 1115$ & $0.91(0.84-0.99)^{\mathrm{b}}$ \\
Body mass index (kg/m ${ }^{2}$ ) & & \\
$\quad<25$ & $406 / 1074$ & $0.89(0.82-0.96)$ \\
$\quad \geq 25$ & $278 / 1118$ & $0.82(0.75-0.91)$ \\
Alcohol drinking (drinks/week) & & \\
$1-14$ & $380 / 1207$ & $0.82(0.75-0.89)$ \\
$\quad \geq 15$ & $307 / 992$ & $0.89(0.81-0.98)$ \\
Tobacco smoking & & \\
$\quad$ Never smoker & $274 / 913$ & $0.86(0.78-0.95)$ \\
$\quad$ Ex smoker & $173 / 521$ & $0.83(0.73-0.94)$ \\
$\quad$ Current smoker & $239 / 767$ & $0.86(0.77-0.95)$ \\
History of diabetes & & \\
$\quad$ No & $585 / 2078$ & $0.84(0.79-0.89)^{\mathrm{b}}$ \\
$\quad$ Yes & $103 / 126$ & $0.99(0.81-1.23)^{\mathrm{b}}$ \\
\hline
\end{tabular}

${ }^{a}$ Estimates from unconditional logistic regression adjusted for center, age, sex, year of interview, education, body mass index, tobacco smoking, alcohol consumption, history of diabetes, total energy intake (second study only) and study. OR for an increment of one unit. ${ }^{b} p$-value for heterogeneity across strata $<0.05$.

Table 4 shows the distribution of pancreatic cancer cases and controls and corresponding ORs according to the MDP and MAI scores. A trend of decreasing risk was observed for both scores, with ORs comparing the highest versus the lowest quintile of 0.44 (95\% $\mathrm{Cl} 0.27-0.72$ ) for MDP and of 0.68 (95\% $\mathrm{Cl} 0.42-1.11$ ) for MAl. The ORs were 0.79 (95\% $\mathrm{Cl} 0.69-0.90)$ for a 10-unit increment of the MDP and $0.82(95 \% \mathrm{Cl}$ 0.69-0.98) for a one unit increment of the MAI. The results for MDP and MAI were consistent across strata of age, sex, education, BMI, alcohol drinking, tobacco smoking and diabetes (data not shown). 
Table 4. Odds ratios (OR) and $95 \%$ confidence intervals $(\mathrm{Cl})$ for pancreatic cancer according to the Mediterranean Dietary Pattern Adherence Index (MDP) and Mediterranean Adequacy Index (MAI) among 326 pancreatic cancer cases and 652 controls. Italy, 1992-2008.

\begin{tabular}{|c|c|c|c|c|c|}
\hline & \multicolumn{2}{|c|}{ Cases } & \multicolumn{2}{|c|}{ Controls } & \multirow{2}{*}{$\mathrm{OR}^{\mathrm{a}}(95 \% \mathrm{Cl})$} \\
\hline & $\mathrm{N}$ & $\%$ & $\mathbf{N}$ & $\%$ & \\
\hline \multicolumn{6}{|l|}{ MDP } \\
\hline$<48.7$ & 85 & 26.1 & 111 & 17.0 & $1^{b}$ \\
\hline $48.7-54.1$ & 67 & 20.6 & 129 & 19.8 & $0.71(0.45-1.12)$ \\
\hline $54.2-59.1$ & 67 & 20.6 & 127 & 19.5 & $0.71(0.44-1.13)$ \\
\hline $59.2-65.4$ & 59 & 18.1 & 138 & 21.2 & $0.68(0.42-1.08)$ \\
\hline$\geq 65.5$ & 48 & 14.7 & 147 & 22.5 & $0.44(0.27-0.73)$ \\
\hline$p$-value for trend & & & & & 0.003 \\
\hline$O R^{c}$ & & & & & $0.79(0.69-0.90)$ \\
\hline \multicolumn{6}{|l|}{ MAI } \\
\hline$<1.23$ & 76 & 23.5 & 119 & 18.3 & $1^{\mathrm{b}}$ \\
\hline $1.23-1.60$ & 73 & 23.5 & 122 & 18.7 & $1.04(0.65-1.64)$ \\
\hline $1.61-2.95$ & 54 & 16.7 & 141 & 21.7 & $0.60(0.37-0.97)$ \\
\hline $1.96-2.47$ & 66 & 20.4 & 129 & 19.8 & $0.83(0.52-1.33)$ \\
\hline$\geq 2.48$ & 55 & 17.0 & 140 & 21.5 & $0.68(0.42-1.11)$ \\
\hline$p$-value for trend & & & & & 0.073 \\
\hline$O R^{d}$ & & & & & $0.82(0.69-0.98)$ \\
\hline
\end{tabular}

${ }^{\mathrm{a}}$ Estimates from unconditional logistic regression adjusted for center, age, sex, year of interview, education, body mass index, tobacco smoking, alcohol consumption, history of diabetes and total energy intake. ${ }^{b}$ Reference category. ${ }^{c}$ Estimate for an increment of 10 units. ${ }^{d}$ Estimate for an increment of one unit.

\section{Discussion}

Our study provides evidence that a priori defined scores which include several aspects of the Mediterranean diet are favorably associated with pancreatic cancer risk. Such beneficial role is not meaningfully modified by allowance for known risk factors for this neoplasm, such as BMI, tobacco, alcohol, and diabetes. Moreover, as reported in two other studies that analyzed pancreatic cancer risk in relation to Mediterranean diet scores [21, 22], the inverse association was consistent in the two sexes.

Among specific components of the Mediterranean diet, vegetables and fruits have been reported to reduce the risk of pancreatic cancer in a few studies, possibly on account of their high content in vitamin C, folate and phenolic compounds [35-40]. However, the evidence is not consistent and a recent report of the World Cancer Research Association has judged the evidence for fruit and vegetables and pancreatic cancer "limited - not conclusive" [41, 42]. 
Olive oil, the most used seasoning fat and the main source of monounsaturated fatty acid in Mediterranean countries, has also been reported to be a favorable indicator of various common cancers [43], although data on pancreatic cancer are scanty [44]. A possible beneficial role of olive oil on cancer has been explained in terms of its strong antioxidant properties, due to the specific fatty acid composition, as well as to the presence of various nutrients, such as vitamin $E$ and polyphenols [43, 45]. However, olive oil may simply be an indicator of a healthier diet, richer in vegetables and other plant foods.

Refined cereals (such as bread, pasta or rice) frequently consumed in Italy have been hypothesized to increase pancreatic cancer risk, through mechanisms involving insulin, insulin resistance and insulin-like growth factors (IGFs), and this is reflected in the estimates above unity for cereals in the present study [27, 46]. However, most epidemiological data do not indicate that a high intake of carbohydrates has a detrimental role on pancreatic cancer [36, 38, 47, 48].

A direct association between pancreatic cancer and meat, particularly red meat, has been reported in several epidemiological studies [27, 36, 49-52]. Thus, the limited intake of (red) meat is another characteristic of the Mediterranean diet which favorably influences pancreatic cancer risk. The association with red meat has been attributed to heterocyclic amines, polycyclic aromatic hydrocarbons, and nitrosamines produced in meat cooking, thought the interpretation remains open to discussion [5355].

The limited intake of animal foods and fats from animal sources, which characterizes the Mediterranean diet, may also contribute to its favorable role on pancreatic cancer, although the evidence of the role of animal foods other than meat, including milk and dairy products, eggs and fish, and of (saturated) fats on pancreatic cancer is limited and inconsistent [36, 38].

Finally, heavy - but not low/moderate - alcohol intake has been associated with an increased pancreatic cancer risk [56-58]. Thus, the regular but moderate consumption of wine mainly during meals characteristic of the Mediterranean diet, is not an unfavorable indicator of pancreatic cancer.

More than on single dietary aspects, however, the interest of this study has to be related to the strong inverse relation between pancreatic cancer and the combination of various food items into a priori defined scores that take into consideration the synergistic effects or interactions of foods and nutrients characteristic of the Mediterranean diet. Thus, the combination of the favorable fatty acid profile, high fiber content, antioxidants and phytochemicals typical of the Mediterranean diet, and their synergistic effect appear to have a beneficial role on pancreatic, as on other cancers [12-19].

With reference to possible sources of bias inherent to case-control studies, in order to reduce any potential information bias, the questionnaires were administered to both 
cases and controls by the same interviewers, under similar condition. Dietary habits of hospital controls may be different from those of the general population, but we paid attention to exclude from the control group all diagnoses associated with long-term dietary modifications. Potential recall bias should be limited, given the limited appreciation by the Italian population of a link between diet and pancreatic cancer risk at the time of interview. To reduce any possible dietary modification bias due to the recent cancer diagnosis, we asked for habitual dietary habits before cancer diagnosis, although diet could have changed before due to subclinical disease. Among the limitations of the study is the short dietary questionnaire of the first study. However, the consistency of the results in the two studies, conducted in different calendar periods and using different questionnaires to assess dietary habits, gives further support to the finding of a beneficial role of the Mediterranean diet on pancreatic cancer. Among the strengths of the study are the relatively large sample size, the almost complete participation of cases and controls, the comparable catchment areas of study subjects, and the accurate control for major recognized risk factors for pancreatic cancer. Since other healthy behaviors may be associated with a better diet, unaccounted confounding could partly explain the observed inverse association. The major strength of the study is the application of a priori and independently developed Mediterranean scores to a population with a considerable variability with respect to these scores, while other studies on the issue were conducted in non-Mediterranean populations. The comparability of the results obtained from a simple intuitive score (MDS) adopted in various previous epidemiological studies and from two other more complex a priori scores (MDP and MAI) proposed to evaluate the adherence to the Mediterranean diet also supports our findings of a beneficial role of the Mediterranean diet on pancreatic cancer. 


\section{References}

1. Trichopoulou A, Lagiou P. Healthy traditional Mediterranean diet: an expression of culture, history, and lifestyle. Nutr Rev 1997; 55: 383-389.

2. Panagiotakos DB, Pitsavos C, Chrysohoou C et al. Risk stratification of coronary heart disease in Greece: final results from the CARDIO2000 Epidemiological Study. Prev Med 2002; 35: 548-556.

3. Dilis V, Katsoulis $M$, Lagiou $P$ et al. Mediterranean diet and CHD: the Greek European Prospective Investigation into Cancer and Nutrition cohort. Br J Nutr 2012; 108: 699-709.

4. Sofi F, Abbate R, Gensini GF, Casini A. Accruing evidence on benefits of adherence to the Mediterranean diet on health: an updated systematic review and meta-analysis. Am J Clin Nutr 2010; 92: 1189-1196.

5. Misirli G, Benetou V, Lagiou P et al. Relation of the Traditional Mediterranean Diet to Cerebrovascular Disease in a Mediterranean Population. Am J Epidemiol 2012.

6. Trichopoulou A, Kouris-Blazos A, Wahlqvist ML et al. Diet and overall survival in elderly people. BMJ 1995; 311: 1457-1460.

7. Trichopoulou A, Costacou T, Bamia C, Trichopoulos D. Adherence to a Mediterranean diet and survival in a Greek population. N Engl J Med 2003; 348: 2599-2608.

8. Trichopoulou A, Orfanos P, Norat T et al. Modified Mediterranean diet and survival: EPIC-elderly prospective cohort study. BMJ 2005; 330: 991.

9. Knoops KT, de Groot LC, Kromhout D et al. Mediterranean diet, lifestyle factors, and 10-year mortality in elderly European men and women: the HALE project. JAMA 2004; 292: 1433-1439.

10. Mitrou PN, Kipnis V, Thiebaut AC et al. Mediterranean dietary pattern and prediction of all-cause mortality in a US population: results from the NIH-AARP Diet and Health Study. Arch Intern Med 2007; 167: 2461-2468.

11. Mente A, de Koning L, Shannon HS, Anand SS. A systematic review of the evidence supporting a causal link between dietary factors and coronary heart disease. Arch Intern Med 2009; 169: 659-669.

12. Trichopoulou A, Lagiou P, Kuper H, Trichopoulos D. Cancer and Mediterranean dietary traditions. Cancer Epidemiol Biomarkers Prev 2000; 9: 869-873.

13. Bosetti C, Gallus S, Trichopoulou A et al. Influence of the Mediterranean diet on the risk of cancers of the upper aerodigestive tract. Cancer Epidemiol Biomarkers Prev 2003; 12: 1091-1094.

14. Verberne L, Bach-Faig A, Buckland G, Serra-Majem L. Association between the Mediterranean diet and cancer risk: a review of observational studies. Nutr Cancer 2010; 62: 860-870. 
15. Pelucchi C, Bosetti C, Rossi M et al. Selected aspects of Mediterranean diet and cancer risk. Nutr Cancer 2009; 61: 756-766.

16. Buckland G, Agudo A, Lujan L et al. Adherence to a Mediterranean diet and risk of gastric adenocarcinoma within the European Prospective Investigation into Cancer and Nutrition (EPIC) cohort study. Am J Clin Nutr 2010; 91: 381-390.

17. Buckland G, Travier N, Cottet $\mathrm{V}$ et al. Adherence to the Mediterranean diet and risk of breast cancer in the EPIC cohort study. Int J Cancer 2013; 132: 29182927.

18. Couto E, Boffetta $\mathrm{P}$, Lagiou $\mathrm{P}$ et al. Mediterranean dietary pattern and cancer risk in the EPIC cohort. Br J Cancer 2011; 104: 1493-1499.

19. Giacosa A, Barale $R$, Bavaresco $L$ et al. Cancer prevention in Europe: the Mediterranean diet as a protective choice. Eur J Cancer Prev 2013; 22: 90-95.

20. Bamia C, Lagiou P, Buckland $G$ et al. Mediterranean diet and colorectal cancer risk: results from a European cohort. Eur J Epidemiol 2013; 28: 317-328.

21. Jiao L, Mitrou PN, Reedy J et al. A combined healthy lifestyle score and risk of pancreatic cancer in a large cohort study. Arch Intern Med 2009; 169: 764-770.

22. Tognon $G$, Nilsson LM, Lissner $L$ et al. The Mediterranean diet score and mortality are inversely associated in adults living in the subarctic region. J Nutr 2012; 142: 1547-1553.

23. Turati F, Galeone C, Talamini R et al. Coffee, decaffeinated coffee, tea, and pancreatic cancer risk: a pooled-analysis of two Italian case-control studies. Eur J Cancer Prev 2011; 20: 287-292.

24. Bach A, Serra-Majem L, Carrasco JL et al. The use of indexes evaluating the adherence to the Mediterranean diet in epidemiological studies: a review. Public Health Nutr 2006; 9: 132-146.

25. Bosetti C, Bravi F, Turati F et al. Nutrient-based dietary patterns and pancreatic cancer risk. Ann Epidemiol 2013; 23: 124-128.

26. La Vecchia C, Negri E, D'Avanzo B et al. Medical history, diet and pancreatic cancer. Oncology 1990; 47: 463-466.

27. Polesel J, Talamini R, Negri E et al. Dietary habits and risk of pancreatic cancer: an Italian case-control study. Cancer Causes Control 2010; 21: 493-500.

28. Franceschi S, Negri E, Salvini S et al. Reproducibility of an Italian food frequency questionnaire for cancer studies: results for specific food items. Eur J Cancer 1993; 29A: 2298-2305.

29. Decarli A, Franceschi S, Ferraroni $M$ et al. Validation of a food-frequency questionnaire to assess dietary intakes in cancer studies in Italy. Results for specific nutrients. Ann Epidemiol 1996; 6: 110-118.

30. Gnagnarella $P$, Parpinel $M$, Salvini $S$ et al. The update of the Italian food composition database. J Food Comp Analysis 2004; 17: 509-522. 
31. Salvini S, Parpinel M, Gnagnarella $P$ et al. Banca di composizione degli alimenti per studi epidemiologici in Italia. Milan, Italy: Istituto Europeo di Oncologia 1998.

32. Sanchez-Villegas A, Martinez JA, De Irala J, Martinez-Gonzalez MA. Determinants of the adherence to an "a priori" defined Mediterranean dietary pattern. Eur J Nutr 2002; 41: 249-257.

33. Alberti-Fidanza A, Fidanza F. Mediterranean Adequacy Index of Italian diets. Public Health Nutr 2004; 7: 937-941.

34. Breslow NE, Day NE. Statistical methods in cancer research. Vol. I. The analysis of case-control studies. IARC Sci Publ No. 32. Lyon, France: IARC 1980.

35. Larsson SC, Giovannucci E, Wolk A. Folate intake, MTHFR polymorphisms, and risk of esophageal, gastric, and pancreatic cancer: a meta-analysis. Gastroenterology 2006; 131: 1271-1283.

36. World Cancer Research Fund and American Institute for Cancer Research. Food, Nutrition, Physical Activity and the Prevention of Cancer: a Global Perspective. Washington DC: AICR 2007.

37. Nothlings $U$, Murphy SP, Wilkens LR et al. Flavonols and pancreatic cancer risk: the multiethnic cohort study. Am J Epidemiol 2007; 166: 924-931.

38. Hart AR, Kennedy $\mathrm{H}$, Harvey I. Pancreatic cancer: a review of the evidence on causation. Clin Gastroenterol Hepatol 2008; 6: 275-282.

39. Bae JM, Lee EJ, Guyatt G. Citrus fruit intake and pancreatic cancer risk: a quantitative systematic review. Pancreas 2009; 38: 168-174.

40. Rossi $M$, Lugo $A$, Lagiou $P$ et al. Proanthocyanidins and other flavonoids in relation to pancreatic cancer: a case-control study in Italy. Ann Oncol 2012; 23: 1488-1493.

41. World Cancer Research Fund and American Institute for Cancer Research. Food, Nutrition, Physical Activity and Pancreatic Cancer. Washington DC: AICR 2012.

42. Koushik A, Spiegelman D, Albanes $D$ et al. Intake of fruits and vegetables and risk of pancreatic cancer in a pooled analysis of 14 cohort studies. Am J Epidemiol 2012; 176: 373-386.

43. Pelucchi C, Bosetti C, Negri E et al. Olive oil and cancer risk: an update of epidemiological findings through 2010. Curr Pharm Des 2011; 17: 805-812.

44. La Vecchia C, Negri E. Fats in seasoning and the relationship to pancreatic cancer. Eur J Cancer Prev 1997; 6: 370-373.

45. Owen RW, Giacosa A, Hull WE et al. Olive-oil consumption and health: the possible role of antioxidants. Lancet Oncol 2000; 1: 107-112.

46. Rossi M, Lipworth L, Polesel J et al. Dietary glycemic index and glycemic load and risk of pancreatic cancer: a case-control study. Ann Epidemiol 2010; 20: 460-465. 
47. Nothlings U, Murphy SP, Wilkens LR et al. Dietary glycemic load, added sugars, and carbohydrates as risk factors for pancreatic cancer: the Multiethnic Cohort Study. Am J Clin Nutr 2007; 86: 1495-1501.

48. Aune D, Chan DS, Vieira AR et al. Dietary fructose, carbohydrates, glycemic indices and pancreatic cancer risk: a systematic review and meta-analysis of cohort studies. Ann Oncol 2012; 23: 2536-2546.

49. Stolzenberg-Solomon RZ, Cross AJ, Silverman DT et al. Meat and meat-mutagen intake and pancreatic cancer risk in the NIH-AARP cohort. Cancer Epidemiol Biomarkers Prev 2007; 16: 2664-2675.

50. Zheng W, Lee SA. Well-done meat intake, heterocyclic amine exposure, and cancer risk. Nutr Cancer 2009; 61: 437-446.

51. Larsson SC, Wolk A. Red and processed meat consumption and risk of pancreatic cancer: meta-analysis of prospective studies. Br J Cancer 2012; 106: 603-607.

52. Anderson KE, Mongin SJ, Sinha R et al. Pancreatic cancer risk: associations with meat-derived carcinogen intake in the Prostate, Lung, Colorectal, and Ovarian Cancer Screening Trial (PLCO) cohort. Mol Carcinog 2012; 51: 128-137.

53. Tavani A, La Vecchia C, Gallus $S$ et al. Red meat intake and cancer risk: a study in Italy. Int J Cancer 2000; 86: 425-428.

54. Risch HA. Etiology of pancreatic cancer, with a hypothesis concerning the role of $\mathrm{N}$-nitroso compounds and excess gastric acidity. J Natl Cancer Inst 2003; 95: 948-960.

55. Anderson KE, Kadlubar FF, Kulldorff $M$ et al. Dietary intake of heterocyclic amines and benzo(a)pyrene: associations with pancreatic cancer. Cancer Epidemiol Biomarkers Prev 2005; 14: 2261-2265.

56. Tramacere I, Scotti $\mathrm{L}$, Jenab $\mathrm{M}$ et al. Alcohol drinking and pancreatic cancer risk: a meta-analysis of the dose-risk relation. Int J Cancer 2010; 126: 1474-1486.

57. Genkinger JM, Spiegelman D, Anderson KE et al. A pooled analysis of 14 cohort studies of anthropometric factors and pancreatic cancer risk. Int J Cancer 2011; 129: 1708-1717.

58. Lucenteforte E, La Vecchia C, Silverman D et al. Alcohol consumption and pancreatic cancer: a pooled analysis in the International Pancreatic Cancer Case-Control Consortium (PanC4). Ann Oncol 2012; 23: 374-382. 


\title{
Chapter 4.3. Nutrient-Based Dietary Patterns and Pancreatic Cancer Risk
}

\author{
Cristina Bosetti, Francesca Bravi, Federica Turati, Valeria Edefonti, \\ Jerry Polesel, Adriano Decarli, Eva Negr, Renato Talamini, Silvia Franceschi, Carlo La \\ Vecchia, Maurice P. Zeegers
}

Annals of Epidemiology 2013;23:124-8 


\begin{abstract}
Scanty data are available on the role of combinations of foods and/or nutrients pancreatic cancer risk. In order to add further information on dietary patterns potentially associated to pancreatic cancer, we applied an exploratory principal component factor analysis on $\mathbf{2 8}$ major nutrients derived from an Italian case-control study. Cases were 326 incident pancreatic cancer cases and controls 652 frequencymatched controls admitted to hospital for non neoplastic diseases. Dietary information was collected through a validated and reproducible food-frequency questionnaire. Multivariate logistic regression models - adjusted for socio-demographic variables and major recognized risk factors for pancreatic cancer - were used to estimate odds ratios (OR) of pancreatic cancer for each dietary pattern. We identified four dietary patterns - named "Animal Products", "Unsaturated Fats", "Vitamins and Fiber" and "Starch-rich - which explain $75 \%$ of the total variance in nutrient intake in this population. After allowing for all the four patterns, positive associations were found for the "Animal Products" and the "Starch-rich" patterns, the ORs for the highest vs the lowest quartiles being 2.03 (95\% confidence interval, $\mathrm{Cl}$ : 1.29-3.19) and 1.69 (95\% Cl: $1.02-$ 2.79), respectively; an inverse association emerged for the "Vitamins and Fiber" pattern (OR=0.55, 95\% Cl: 0.35-0.86), while no significant association was observed for the "Unsaturated Fats" pattern (OR=1.13, 95\% Cl: 0.71-1.78). A diet characterized by a high consumption of meat and other animal products, as well as of (refined) cereals and sugars has a detrimental role on pancreatic cancer, while a diet rich in fruit and vegetables have a favorable role.
\end{abstract}




\section{Introduction}

Cancer of the pancreas is the $5^{\text {th }}$ most common cause of cancer death in men and the $4^{\text {th }}$ in women from Europe [1]. It has a very poor prognosis and it is one of the few neoplasms for which mortality trends have not changed over the past 40 years in developed countries [2-4]. Although the etiology of pancreatic cancer is still largely unknown, recognized risk factors are tobacco smoking, heavy alcohol drinking, overweight/obesity, history of diabetes and chronic pancreatitis, and family history of the disease $[5,6]$.

With reference to dietary habits, several epidemiological studies reported an excess pancreatic cancer risk for high consumption of (red) meat and starchy foods/sweets, and a decreased risk for high consumption of fruit, vegetables, and folate-rich foods [713], although the evidence remains inconsistent [8, 14]. Only a limited number of studies have considered the role of combinations of foods and/or nutrients - identified through a priori scores or a posteriori derived dietary patterns. In the US prospective National Institutes of Health-AARP Diet and Health study, a non significant $8 \%$ reduced risk of pancreatic cancer was found for high versus low no-alcohol Mediterranean dietary score, which became $27 \%$ comparing the most extreme categories of the dietary score [15]. A Canadian case-control study on 585 pancreatic cancer cases reported a $49 \%$ reduced risk for the "Fruit and Vegetables" pattern (characterized by high intake of fresh fruit and cruciferous vegetables) in men but not in women, and found no significant associations for the "Western" pattern (characterized by high intake of processed meat, sweets/desserts, refined grains and potatoes) and the "Drinker" pattern, characterized by elevated consumption of liquor, wine and beer [16]. In a combined analysis of the Health Professionals Follow-up Study and the Nurses' Health Study, including a total of 366 pancreatic cancer cases, no overall associations were reported with either the "Prudent" pattern (characterized by high consumption of vegetables, legumes, fruit, whole grains, fish and poultry) and the "Western" one (characterized by high consumption of red and processed meat, refined grains, French fries, high-fat dairy products, sweets, desserts, and high-sugar drinks) [17]. A pattern characterized by high flavonol intake from tea, fruit, cabbage and wine was found to be inversely related to the risk of pancreatic cancer in smokers only in the Multiethnic Cohort including 610 pancreatic cancers, but not in the European Prospective Investigation into Cancer and Nutrition (EPIC) cohort including 517 cases [18]. In the lowa Women's Health Study (IWHS), including 256 postmenopausal women with pancreatic cancer, no significant associations were found with any of the four dietary patterns identified, i.e., the "Mediterranean", the "High Fiber", the "High Fruit" and the "High Sweet" [19].

In order to add further information on dietary patterns potentially associated to pancreatic cancer, we applied an exploratory principal component factor analysis (PCFA) on selected major nutrients derived from an Italian case-control study. 


\section{Methods}

Between 1991 and 2008 we conducted a multicentre case-control study on pancreatic cancer in the province of Pordenone and in the greater Milan area, northern Italy [12]. Cases were 326 patients (174 men and 152 women, median age 63 years) with incident, confirmed pancreatic cancer, admitted to major teaching and general hospitals. Controls were 652 patients (348 men, 304 women, median age 62 years), frequency matched to cases by study center, sex, and age (with a control to case ratio of 2:1), admitted to the same hospitals as cases for a wide spectrum of acute conditions other than neoplastic or digestive tract diseases. They were hospitalized for traumas (31\%), other orthopedic disorders (31\%), acute surgical conditions (28\%), and miscellaneous other illnesses (10\%). Over $95 \%$ of cases and controls approached to be interviewed agreed to participate.

Trained interviewers administered a structured questionnaire to both cases and controls during their hospital stay. The questionnaire included information on sociodemographic and anthropometric characteristics, selected lifestyle habits, physical activity, personal medical history, and family history of cancer. Usual diet during the two years before cancer diagnosis (for cases) or hospital admission (for controls) was assessed through a validated [20] and reproducible [21] food-frequency questionnaire (FFQ). Study participants were asked to indicate their average weekly frequency of consumption of 78 specific foods, food groups and Italian recipes, as well as lifetime consumption of alcoholic beverages. Several questions were also included to assess seasoning fat intake patterns. Foods consumed less than once a week but at least once a month were coded as 0.5 per week. Total energy intake and intake of nutrient and fiber were computed using an Italian food composition database, integrated with other sources when needed [22, 23].

\section{Data analysis}

We carried out an exploratory PCFA on the correlation matrix of 28 selected major macro- and micro-nutrients to derive a smaller set of uncorrelated underlying factors, known as dietary patterns [24]. Analyses were performed on the overall group of cases and controls. The PCFA-derived dietary patterns were labeled quantitatively according to those nutrients that loaded $\geq 0.63$ on the respective factors [25]. To assess reliability and refine the identified patterns, we calculated standardized Cronbach's coefficient alphas for each factor and coefficient alpha when item deleted (i.e., calculated excluding each nutrient, one at a time) for each factor and for each nutrient loading $\geq 0.40$. Spearman rank correlation coefficients between the continuous factor scores derived from PCFA and the weekly number of portions of 29 selected food groups were calculated to improve interpretability of the identified dietary patterns.

For each dietary pattern, study subjects were grouped into four categories according to quartiles of factor scores among controls. Logistic regression models conditioned on 
age (5-years groups), sex and center, and adjusted for year of interview (continuous), education ( $<7,7-11, \geq 12$ years), and major recognized risk factors for pancreatic cancer, i.e., body mass index (BMI, $\left(<25.0,25.0-29.9, \geq 30.0 \mathrm{~kg} / \mathrm{m}^{2}\right.$ ), tobacco smoking (never smoker, ex-smoker, current smoker $<15$ cigarettes/day, current smoker $\geq 15$ cigarettes/day), alcohol drinking (0,1-2, $\geq 3$ drinks/day), and diabetes (yes/no), where used to estimate odds ratios (OR) of pancreatic cancer and the corresponding $95 \%$ confidence intervals $(\mathrm{Cl})$ for each quartile category of the dietary patterns, as compared to the lowest one. Further allowance for other risk factors as family history did not meaningfully modified our risk estimates. Separate models including one dietary pattern at a time, and a composite model including all the patterns simultaneously, were fitted. Tests for trend were based on the difference of the likelihood ratio test between models with and without a linear term for the variable considered. All the analyses were performed using the SAS software, version 9.1 (SAS Institute, Inc., Cary, NY).

\section{Results}

The correlation matrix of the original nutrients was suitable for the factor analysis. Each nutrient showed at least 10 correlation coefficients $>0.30$ in absolute value (data not shown), thus allowing to perform the analyses on the entire set of selected nutrients. Results of Bartlett's test of sphericity ( $p$-value $<0.001$ ) allowed to rejecting the null hypothesis that the correlation matrix is an identity matrix (Appendix Table).

Appendix Table. Factorability of the correlation matrix of the original nutrients: individual and overall measures of sampling adequacy, and Bartlett's test of sphericity.

\begin{tabular}{ll}
\hline Bartelett's test of sphericity: $p$-value $<0.0001$ \\
\hline Kaiser-Meyer-Olkin statistic - overall measure of sampling adequacy: 0.85 \\
\hline Individual measures of sampling adequacy: \\
\hline Mediocre: $<0.60$ & - \\
Acceptable: $0.60-0.69$ & linoleic acid, monounsaturated fatty acids \\
Middling: $0.70-0.79$ & lycopene, retinol, total fiber, vitamin E \\
Meritorious: $0.80-0.89$ & animal protein, vegetable protein, saturated fatty acids, other \\
& polyunsaturated fatty acids, soluble carbohydrates, calcium, \\
& phosphorus, iron, thiamine, riboflavin, total folate, vitamin C, vitamin \\
& cholesterol, linolenic acid, sodium, potassium, zinc, vitamin B6, niacin, \\
Marvellous: $\geq 0.90$ & beta-carotene equivalents
\end{tabular}

The Kaiser-Meyer-Olkin statistic was 0.85 , indicating that the sample size for the factor analysis was adequate. The individual measures of sampling adequacy were generally 
very high, with 26 nutrients having measures $\geq 0.70$, and the remaining nutrients (i.e., linoleic acid and monounsaturated fatty acids) showing an "acceptable" value of the statistic. Overall, the correlations among individual nutrients were strong enough to suggest that the correlation matrix was factorable.

Table 1 gives the factor loading matrix for the four retained dietary patterns, which together accounted for about $75 \%$ of the variance of the 28 original nutrients.

Table 1. Factor loading matrix ${ }^{a}$ and explained variances (VAR) for the four major dietary patterns identified by factor analysis. Italy 1991-2008.

\begin{tabular}{|c|c|c|c|c|}
\hline & \multicolumn{4}{|c|}{ Dietary patterns } \\
\hline & $\begin{array}{l}\text { Animal } \\
\text { Products }\end{array}$ & $\begin{array}{l}\text { Unsaturated } \\
\text { Fats }\end{array}$ & $\begin{array}{l}\text { Vitamins and } \\
\text { Fiber }\end{array}$ & Starch-rich \\
\hline Animal protein & 0.84 & 0.39 & - & 0.22 \\
\hline Vegetable protein & 0.25 & 0.23 & 0.36 & 0.84 \\
\hline Cholesterol & 0.71 & 0.46 & - & 0.31 \\
\hline Saturated fatty acids & 0.72 & 0.42 & 0.20 & 0.24 \\
\hline Monounsaturated fatty acids & 0.28 & 0.60 & 0.29 & 0.29 \\
\hline Linoleic acid & 0.20 & 0.80 & 0.12 & - \\
\hline Linolenic acid & 0.34 & 0.76 & 0.15 & 0.13 \\
\hline Other PUFAs & 0.29 & 0.69 & - & 0.31 \\
\hline Soluble carbohydrates & 0.44 & - & 0.67 & 0.10 \\
\hline Starch & 0.28 & 0.16 & 0.12 & 0.88 \\
\hline Sodium & 0.62 & 0.12 & - & 0.64 \\
\hline Calcium & 0.87 & - & 0.27 & - \\
\hline Potassium & 0.52 & 0.31 & 0.64 & 0.35 \\
\hline Phosphorus & 0.83 & 0.30 & 0.26 & 0.33 \\
\hline Iron & 0.44 & 0.44 & 0.35 & 0.46 \\
\hline Zinc & 0.71 & 0.42 & 0.23 & 0.45 \\
\hline Thiamin (vitamin B1) & 0.60 & 0.29 & 0.47 & 0.43 \\
\hline Riboflavin (vitamin B2) & 0.83 & 0.24 & 0.37 & 0.11 \\
\hline Vitamin B6 & 0.55 & 0.42 & 0.50 & 0.41 \\
\hline Total folate & 0.43 & 0.29 & 0.67 & 0.35 \\
\hline Niacin & 0.46 & 0.48 & 0.32 & 0.48 \\
\hline Vitamin C & 0.11 & - & 0.85 & - \\
\hline Retinol & 0.37 & 0.29 & 0.12 & - \\
\hline Beta-carotene equivalents & - & 0.22 & 0.71 & - \\
\hline Lycopene & - & 0.34 & 0.23 & 0.53 \\
\hline Vitamin D & 0.37 & 0.47 & - & 0.26 \\
\hline Vitamin $\mathrm{E}$ & 0.15 & 0.78 & 0.47 & 0.19 \\
\hline Total fiber & 0.16 & 0.13 & 0.82 & 0.34 \\
\hline Proportion of explained VAR & 25.86 & 17.77 & 17.31 & 14.90 \\
\hline Cumulative explained VAR & 25.86 & 43.63 & 60.94 & 75.84 \\
\hline
\end{tabular}

PUFAs: polyunsaturated fatty acids. ${ }^{\mathrm{a}}$ Estimated from a principal component factor analysis performed on 28 nutrients. The magnitude of each loading indicates the importance of the corresponding nutrient to the factor. Loadings greater or equal to 0.63 were shown in bold typeface; loadings smaller than 0.10 were suppressed. 
The greater the loading of a given nutrient to a factor, the higher the contribution of that nutrient was on that factor. Thus, the first pattern, labeled "Animal Products", had the greatest loadings on calcium, animal protein, phosphorus, riboflavin, saturated fatty acids, cholesterol, and zinc. The second pattern, named "Unsaturated Fats", had the greatest loadings on linoleic acid, vitamin E, linolenic acid, and other polyunsaturated fatty acids. The third pattern, labeled "Vitamins and Fiber", had the greatest loadings on vitamin $\mathrm{C}$, total fiber, beta-carotene equivalents, soluble carbohydrates, total folate, and potassium. The fourth pattern, named "Starch-rich", had the greatest loadings on starch, vegetable protein, and sodium. All the examined nutrients showed at least one loading greater than 0.30 on any factor, thus confirming a role of each nutrient in the original list.

The baseline characteristics of participants according to quartiles of the four identified dietary patterns are given in Table 2.

Table 2. Baseline characteristics of the study participants according to quartiles of dietary patterns. Italy 1991-2008.

\begin{tabular}{|c|c|c|c|c|c|c|c|}
\hline $\begin{array}{l}\text { Dietary pattern, } \\
\text { quartile }\end{array}$ & $\begin{array}{l}\text { Cases/ } \\
\text { controls }\end{array}$ & $\mathrm{Age}^{\mathrm{a}, \mathrm{b}}$ (years) & $\begin{array}{l}\text { Education }^{\mathrm{a}, \mathrm{b}} \\
\text { (years) }\end{array}$ & Smoking $^{\mathrm{b}, \mathrm{c}}$ & $\begin{array}{l}\text { Physical } \\
\text { activity }^{\text {b,d }}\end{array}$ & $\begin{array}{c}\text { Body mass } \\
\text { index } \\
\left(\mathrm{kg} / \mathrm{m}^{\mathrm{a}, \mathrm{b}}\right)\end{array}$ & $\begin{array}{c}\text { Energy } \\
\text { intake }^{\mathrm{a}, \mathrm{b}} \\
\text { (kcal/day) }\end{array}$ \\
\hline \multicolumn{8}{|l|}{ Animal Products } \\
\hline 1 (low) & $56 / 163$ & 63 & 5.0 & 21.9 & 30.1 & 25.4 & 1901.8 \\
\hline 2 & $68 / 163$ & 64 & 5.0 & 20.8 & 27.7 & 25.4 & 1995.7 \\
\hline 3 & $96 / 163$ & 63 & 5.0 & 20.9 & 26.7 & 26.0 & 2348.7 \\
\hline 4 (high) & $107 / 163$ & 62 & 6.0 & 28.9 & 39.3 & 26.0 & 2834.8 \\
\hline$p$-value & & 0.65 & 0.7191 & 0.0667 & 0.0329 & 0.0033 & $<0.0001$ \\
\hline \multicolumn{8}{|l|}{ Unsaturated Fats } \\
\hline 1 (low) & $76 / 163$ & 64 & 5.0 & 24.3 & 26.8 & 24.8 & 2038.6 \\
\hline 2 & $82 / 163$ & 63 & 5.0 & 22.0 & 29.0 & 25.9 & 2296.4 \\
\hline 3 & $91 / 163$ & 63 & 6.0 & 25.2 & 32.7 & 25.9 & 2296.4 \\
\hline 4 (high) & $77 / 163$ & 62 & 5.0 & 21.7 & 36.3 & 26.9 & 2843.1 \\
\hline$p$-value & & 0.022 & 0.15 & 0.7127 & 0.0162 & 0.0001 & $<0.0001$ \\
\hline \multicolumn{8}{|l|}{ Vitamins and Fiber } \\
\hline 1 (low) & $105 / 163$ & 64 & 5.0 & 29.1 & 32.1 & 25.7 & 1922.7 \\
\hline 2 & $96 / 163$ & 64 & 5.0 & 24.7 & 34.0 & 26.0 & 2263.2 \\
\hline 3 & $68 / 163$ & 62 & 8.0 & 21.7 & 26.4 & 25.8 & 2362.2 \\
\hline 4 (high) & $57 / 163$ & 61 & 7.0 & 16.4 & 31.8 & 25.6 & 2610.1 \\
\hline$p$-value & & 0.0008 & 0.23 & 0.0007 & 0.5080 & 0.3154 & $<0.0001$ \\
\hline \multicolumn{8}{|l|}{ Starch-rich } \\
\hline 1 (low) & $50 / 163$ & 64 & 5.0 & 15.5 & 27.2 & 26.0 & 1753.5 \\
\hline 2 & $80 / 163$ & 64 & 5.0 & 23.9 & 30.0 & 25.4 & 2036.3 \\
\hline 3 & $105 / 163$ & 63 & 7.0 & 24.3 & 27.6 & 25.7 & 2322.2 \\
\hline 4 (high) & $91 / 163$ & 61 & 7.5 & 28.4 & 39.4 & 26.0 & 2848.6 \\
\hline$p$-value & & 0.0002 & 0.0001 & 0.0020 & 0.0108 & 0.0712 & $<0.0001$ \\
\hline
\end{tabular}

${ }^{a}$ Median. ${ }^{b}$ Trend across quartiles according to Cochran-Armitage test. ${ }^{\circ}$ Percentage of

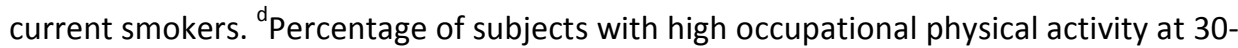
39 years.

Age was inversely associated with the "Unsaturated Fats", "Vitamins and Fiber" the "Starch-rich" patterns; and education was directly associated with the "Starch-rich" 
pattern; smoking was directly associated with the "Animal Products", and "Starch-rich" patterns and inversely associated with the "Vitamins and Fiber" pattern; physical activity was directly associated to the "Animal Products", "Unsaturated Fats", and "Starch-rich" patterns; BMI was directly associated to the "Animal Products" and "Unsaturated Fats" pattern; total energy intake was positively associated with all dietary patterns identified.

Table 3. Spearman rank correlation coefficients ${ }^{a}$ between continuous factor scores derived from factor analysis on nutrient intakes and weekly number of portions of 29 selected food groups. Italy 1991-2008.

\begin{tabular}{|c|c|c|c|c|}
\hline & \multicolumn{4}{|c|}{ Dietary patterns } \\
\hline & $\begin{array}{c}\text { Animal } \\
\text { Products }\end{array}$ & $\begin{array}{l}\text { Unsaturated } \\
\text { Fats }\end{array}$ & $\begin{array}{l}\text { Vitamins and } \\
\text { Fiber }\end{array}$ & Starch-rich \\
\hline Milk & 0.55 & - & 0.24 & - \\
\hline Coffee & 0.16 & - & - & - \\
\hline Tea and decaffeinated coffee & - & - & 0.11 & - \\
\hline Bread & 0.25 & - & - & 0.69 \\
\hline Pasta and rice & - & - & 0.14 & 0.45 \\
\hline Soups & 0.11 & - & - & - \\
\hline Eggs & 0.28 & 0.29 & - & - \\
\hline White meat & 0.17 & 0.15 & - & - \\
\hline Red meat & 0.31 & 0.44 & - & 0.30 \\
\hline Liver & 0.25 & 0.29 & - & - \\
\hline Processed meat & 0.23 & - & - & 0.22 \\
\hline Fish & 0.14 & 0.27 & - & 0.11 \\
\hline Cheese & 0.54 & - & - & - \\
\hline Potatoes & 0.22 & 0.17 & - & 0.14 \\
\hline Pulses & 0.12 & 0.12 & 0.26 & 0.17 \\
\hline Leafy vegetables & - & 0.21 & 0.27 & - \\
\hline Fruiting vegetables & - & 0.20 & 0.29 & - \\
\hline Root vegetables & - & 0.13 & 0.39 & - \\
\hline Cruciferous vegetables & 0.11 & 0.18 & 0.27 & - \\
\hline Other vegetables & 0.14 & 0.30 & 0.40 & - \\
\hline Citrus fruit & - & - & 0.54 & - \\
\hline Other fruit & 0.11 & - & 0.68 & - \\
\hline Soft drinks and fruit juice & 0.19 & - & 0.11 & - \\
\hline Desserts & 0.32 & - & 0.18 & 0.20 \\
\hline Sugar and candies & 0.27 & - & - & 0.18 \\
\hline Butter and margarine & 0.13 & 0.20 & - & - \\
\hline Specified seed oils & - & 0.20 & - & - \\
\hline Unspecified seed oils & - & 0.52 & - & - \\
\hline Olive oil & - & 0.30 & 0.30 & 0.31 \\
\hline
\end{tabular}

${ }^{a}$ Correlation coefficients $\geq 0.25$ were shown in bold typeface; correlation coefficients $<0.1$ were suppressed. 
The dietary patterns labeling based on factor scores is consistent with what emerged from the Spearman rank correlation coefficients between the continuous factor scores and the 29 selected food groups (Table 3).

Table 4 shows the ORs and corresponding $\mathrm{Cls}$ for pancreatic cancer according to quartiles of factor scores for the four retained dietary patterns.

Table 4. Odds ratios $(\mathrm{ORs})^{\mathrm{a}}$ and corresponding $95 \%$ confidence intervals (Cls) for quartiles of factor scores among 326 pancreatic cancer cases and 652 controls. Italy 1991-2008.

\begin{tabular}{lcccc}
\hline \multirow{2}{*}{ Dietary pattern } & $\mathbf{2}$ & $\mathbf{3}$ & Quartile category, OR (95\% Cl) & \multirow{2}{*}{ for trend $^{\mathrm{b}}$} \\
\cline { 2 - 5 } & $1.02(0.64-1.63)$ & $1.23(0.78-1.94)$ & $2.03(1.29-3.19)$ & 0.0008 \\
\hline Animal Products & $1.17(0.76-1.80)$ & $1.18(0.76-1.82)$ & $1.13(0.71-1.78)$ & 0.6767 \\
Unsaturated Fats & $0.93(0.63-1.39)$ & $0.68(0.44-1.04)$ & $0.55(0.35-0.86)$ & 0.0035 \\
Vitamins and Fiber & $1.54(0.96-2.49)$ & $1.85(1.15-2.98)$ & $1.69(1.02-2.79)$ & 0.0592 \\
Starch-rich & &
\end{tabular}

${ }^{a}$ Estimated from conditional logistic regression models conditioned on age, sex and study center and adjusted for year of interview, education, body mass index, tobacco smoking, alcohol drinking, and diabetes. Results refer to the composite model including all the four factors simultaneously. ${ }^{b}$ Reference category: first quartile.

After allowing for all the four patterns and major confounding factors, an increased risk of pancreatic cancer was found for the "Animal Products" and the "Starch-rich" patterns, the ORs for the highest vs the lowest quartiles being 2.03 (95\% Cl: 1.29-3.19, $\mathrm{p}$ for trend=0.0008) and $1.96(95 \% \mathrm{Cl}: 1.02-2.79, \mathrm{p}$ for trend=0.0592), respectively. An inverse association emerged for the "Vitamins and Fiber" pattern $(\mathrm{OR}=0.55,95 \% \mathrm{Cl}$ : 0.35-0.86, $p$ for trend=0.0035), while no significant association was observed for the "Unsaturated Fats" pattern (OR=1.13, 95\% Cl: 0.71-1.78, p for trend=0.6767). Similar results were obtained from models including each factor separately (data not shown). Moreover, analyses by strata of selected covariates (including sex, age, tobacco smoking and $\mathrm{BMI}$ ), did not show any significant differences in the associations between men and women, subjects with age $<65$ and age $\geq 65$ years, never/ex smokers and current smokers, and normal-weight $\left(\mathrm{BMI}<25 \mathrm{~kg} / \mathrm{m}^{2}\right)$ and overweight (BMI $\geq 25$ $\mathrm{kg} / \mathrm{m}^{2}$ ) subjects (data not shown).

\section{Discussion}

In the present analysis we identified four dietary patterns, which explain $75 \%$ of the total variance in nutrient intake in this Italian population. The "Animal Products" pattern, highly correlated with meat, cheese, and milk, and the "Starch-rich" pattern, 
with a high correlation with bread, pasta and rice, were significantly associated to an increased pancreatic cancer risk, while the "Vitamins and Fiber" pattern, correlated with various vegetables, pulses and fruit, was associated with a reduced risk. No relation was found with the "Unsaturated Fats" pattern, correlated with seasoning oils, but also meat and eggs.

The identified associations with dietary patterns are consistent with findings from several previous studies on foods or nutrients, though the evidence of the role of dietary items on pancreatic cancer is not consistent. An inverse association of pancreatic cancer with vegetables and fruit has been reported in our [12] as several in other studies, although other investigations (mainly cohort ones) have not supported such an association $[8,9,11,12,14,26]$. A more consistent beneficial role has been reported for folate and folate-rich foods $[8,27]$. Conversely, a detrimental role of (red and processed) meat on pancreatic cancer risk has been reported in many, though not all, studies [8, 9, 12, 28-31]. An increased risk of pancreatic cancer in relation to high exposure to heterocyclic amines, polycyclic aromatic hydrocarbons, and nitrosamines meat has also been reported [32, 33]. The evidence of an association with other foods of animal origin (as dairy products or eggs) or with fats has been, however, less consistent $[8,9,34]$. The relation between starchy foods and pancreatic cancer is still unclear $[8,9]$, while there is some evidence of a possible increased risk, particularly for sugars $[8,9,35,36]$. Any such relation is possibly mediated by hyperinsulinemia, insulin resistance and insulin-like growth factors (IGF) [37], as also indicated by the excess pancreatic cancer risk in diabetic subjects [38].

Another study which investigated dietary pattern in relation to pancreatic cancer using a similar method reported an inverse relation with a "Fruit and Vegetable" pattern, the association being however limited to men [16]. No association was found in the IWHS with the "High Fruit" or "High Fiber" patterns [19], while in a US study no overall relation was found with the "Prudent" pattern - which included whole grain, fish and poultry besides fruit and vegetables - while a direct association was found in men [17]. Similarly, no association was found with other dietary patterns, as the "Western" pattern (rich in meat, animal foods, as well as cereals and sugars) $[16,17]$ nor with the "High Sweet" and "Mediterranean" patterns [19].

The inconsistencies in the results from various studies may be due to different study populations, methods of analysis, as well as to different definitions of dietary patterns, even in case similar labels. Labels indeed integrate both the statistical output and the subjective views of the investigators. In particular, our study included a Mediterranean population whose dietary habits differ substantially from those of northern American and European populations. Moreover, in our study dietary patterns were defined on the basis of nutrients, instead of using foods as in previous investigations. This allows to explain a higher proportion of the variance in dietary intake; moreover, from a 
statistical point of view PCFA is more properly performed on continuous variables (such as nutrients) than on discrete ones (such as foods/food groups).

Analyses of dietary patterns through PCFA, as compared to analyses on single foods or nutrients, provide more comprehensive information on the overall effect of dietary behaviors, also accounting for complex interactions between them. Among the limitations of such methods, however, there is the fact that PCFA is data driven and requires some arbitrary decisions, including the selection of dietary items to enter in the analysis, the number of factors to retain, the rotation method, the interpretation and labeling of the factors. However, sensitivity analyses confirmed the stability and robustness of our methods. Moreover, the factors identified in our analysis are consistent with those identified in similar analyses on other study populations $[39,40]$. Potential selection and recall bias of hospital-based case-control studies should also be considered. Dietary habits of hospital controls may be different from those of the general population, but we paid attention to exclude from the control group all diagnoses which could be associated to long-term dietary modifications. The similar catchment areas and the almost complete participation of cases and controls are reassuring against selection bias. A recent diagnosis of cancer may have influenced recall of diet for cases, although we asked for dietary habits 2 years before cancer diagnosis, and awareness of a role of diet in pancreatic cancer was unknown to the general population. The similar interview setting for cases and controls has reduced potential information bias. Among the strengths of the study there are the use of a validated [20] and reproducible [21] FFQ, which allowed for a comprehensive assessment of major nutrient sources in the Italian diet, although some measurement error inherent to the FFQ may be present. Moreover, we had detailed information on major recognized risk factors for pancreatic cancer.

In conclusion, our data indicate that a diet characterized by a high consumption of meat and other animal products, as well as of (refined) cereals and sugars has a detrimental role on pancreatic cancer, while a diet rich in fruit and vegetables have a favorable role. 


\section{References}

1. La Vecchia C, Bosetti C, Lucchini F et al. Cancer mortality in Europe, 2000-2004, and an overview of trends since 1975. Ann Oncol 2010; 21: 1323-1360.

2. Hidalgo M. Pancreatic cancer. N Engl J Med 2010; 362: 1605-1617.

3. Greer JB, Brand RE. New developments in pancreatic cancer. Curr Gastroenterol Rep 2011; 13: 131-139.

4. Bosetti C, Bertuccio P, Negri E et al. Pancreatic cancer: overview of descriptive epidemiology. Mol Carcinog 2012; 51: 3-13.

5. Anderson KE, Mack TM, Silverman DT. Cancer of the pancreas. In Schottenfeld D, Fraumeni JFJr (eds): Cancer Epidemiology and Prevention. New York: Oxford University Press 2006; 721-762.

6. Maisonneuve $P$, Lowenfels $A B$. Epidemiology of pancreatic cancer: an update. Dig Dis 2010; 28: 645-656.

7. Soler M, Chatenoud L, La Vecchia C et al. Diet, alcohol, coffee and pancreatic cancer: final results from an Italian study. Eur J Cancer Prev 1998; 7: 455-460.

8. World Cancer Research Fund and American Institute for Cancer Research. Food, Nutrition, Physical Activity and the Prevention of Cancer: a Global Perspective. Washington, DC: AICR. 2007.

9. Hart AR, Kennedy $H$, Harvey I. Pancreatic cancer: a review of the evidence on causation. Clin Gastroenterol Hepatol 2008; 6: 275-282.

10. Zheng $W$, Lee SA. Well-done meat intake, heterocyclic amine exposure, and cancer risk. Nutr Cancer 2009; 61: 437-446.

11. Bae JM, Lee EJ, Guyatt G. Citrus fruit intake and pancreatic cancer risk: a quantitative systematic review. Pancreas 2009; 38: 168-174.

12. Polesel J, Talamini R, Negri E et al. Dietary habits and risk of pancreatic cancer: an Italian case-control study. Cancer Causes Control 2010; 21: 493-500.

13. Bravi F, Polesel J, Bosetti $C$ et al. Dietary intake of selected micronutrients and the risk of pancreatic cancer: an Italian case-control study. Ann Oncol 2011; 22: 202206.

14. Vrieling A, Verhage BA, van Duijnhoven FJ et al. Fruit and vegetable consumption and pancreatic cancer risk in the European Prospective Investigation into Cancer and Nutrition. Int J Cancer 2009; 124: 1926-1934.

15. Jiao L, Mitrou PN, Reedy J et al. A combined healthy lifestyle score and risk of pancreatic cancer in a large cohort study. Arch Intern Med 2009; 169: 764-770.

16. Nkondjock A, Krewski D, Johnson KC, Ghadirian P. Dietary patterns and risk of pancreatic cancer. Int J Cancer 2005; 114: 817-823.

17. Michaud DS, Skinner HG, Wu K et al. Dietary patterns and pancreatic cancer risk in men and women. J Natl Cancer Inst 2005; 97: 518-524.

18. Nothlings $U$, Murphy SP, Wilkens LR et al. A food pattern that is predictive of flavonol intake and risk of pancreatic cancer. Am J Clin Nutr 2008; 88: 1653-1662. 
19. Inoue-Choi M, Flood A, Robien K, Anderson K. Nutrients, food groups, dietary patterns, and risk of pancreatic cancer in postmenopausal women. Cancer Epidemiol Biomarkers Prev 2011; 20: 711-714.

20. Decarli A, Franceschi S, Ferraroni $M$ et al. Validation of a food-frequency questionnaire to assess dietary intakes in cancer studies in Italy. Results for specific nutrients. Ann Epidemiol 1996; 6: 110-118.

21. Franceschi S, Negri E, Salvini S et al. Reproducibility of an Italian food frequency questionnaire for cancer studies: results for specific food items. Eur J Cancer 1993; 29A: 2298-2305.

22. Salvini S, Parpinel M, Gnagnarella P et al. Banca di composizione degli alimenti per studi epidemiologici in Italia. Milano, Italia: Istituto Europeo di Oncologia 1998.

23. Gnagnarella $P$, Parpinel $M$, Salvini $S$ et al. The update of the Italian food composition database. J Food Comp Analysis 2004; 17: 509-522.

24. Bravi F, Edefonti V, Bosetti $C$ et al. Nutrient dietary patterns and the risk of colorectal cancer: a case-control study from Italy. Cancer Causes Control 2010; 21: 1911-1918.

25. Comrey A, Lee HB. A first course in factor analysis. Hillsdale, New Jersey: Lawrence Erlbaum Associates. 1992.

26. Heinen MM, Verhage BA, Goldbohm RA, van den Brandt PA. Intake of vegetables, fruits, carotenoids and vitamins $C$ and $E$ and pancreatic cancer risk in The Netherlands Cohort Study. Int J Cancer 2012; 130: 147-158.

27. Larsson SC, Hakansson N, Naslund I et al. Fruit and vegetable consumption in relation to pancreatic cancer risk: a prospective study. Cancer Epidemiol Biomarkers Prev 2006; 15: 301-305.

28. Stolzenberg-Solomon RZ, Cross AJ, Silverman DT et al. Meat and meat-mutagen intake and pancreatic cancer risk in the NIH-AARP cohort. Cancer Epidemiol Biomarkers Prev 2007; 16: 2664-2675.

29. Heinen MM, Verhage BA, Goldbohm RA, van den Brandt PA. Meat and fat intake and pancreatic cancer risk in the Netherlands Cohort Study. Int J Cancer 2009; 125: 1118-1126.

30. Larsson SC, Wolk A. Red and processed meat consumption and risk of pancreatic cancer: meta-analysis of prospective studies. Br J Cancer 2012; 106: 603-607.

31. Anderson KE, Mongin SJ, Sinha R et al. Pancreatic cancer risk: associations with meat-derived carcinogen intake in the Prostate, Lung, Colorectal, and Ovarian Cancer Screening Trial (PLCO) cohort. Mol Carcinog 2012; 51: 128-137.

32. Risch HA. Etiology of pancreatic cancer, with a hypothesis concerning the role of $\mathrm{N}$-nitroso compounds and excess gastric acidity. J Natl Cancer Inst 2003; 95: 948960. 
33. Anderson KE, Kadlubar FF, Kulldorff $\mathrm{M}$ et al. Dietary intake of heterocyclic amines and benzo(a)pyrene: associations with pancreatic cancer. Cancer Epidemiol Biomarkers Prev 2005; 14: 2261-2265.

34. Lucenteforte $E$, Talamini R, Bosetti $C$ et al. Macronutrients, fatty acids, cholesterol and pancreatic cancer. Eur J Cancer 2010; 46: 581-587.

35. Larsson SC, Bergkvist L, Wolk A. Consumption of sugar and sugar-sweetened foods and the risk of pancreatic cancer in a prospective study. Am J Clin Nutr 2006; 84: 1171-1176.

36. Nothlings U, Murphy SP, Wilkens LR et al. Dietary glycemic load, added sugars, and carbohydrates as risk factors for pancreatic cancer: the Multiethnic Cohort Study. Am J Clin Nutr 2007; 86: 1495-1501.

37. Stolzenberg-Solomon RZ, Graubard BI, Chari S et al. Insulin, glucose, insulin resistance, and pancreatic cancer in male smokers. JAMA 2005; 294: 2872-2878.

38. Bosetti C, Rosato V, Polesel J et al. Diabetes Mellitus and Cancer Risk in a Network of Case-Control Studies. Nutr Cancer 2012; 64: 643-651.

39. Edefonti V, Hashibe M, Ambrogi $F$ et al. Nutrient-based dietary patterns and the risk of head and neck cancer: a pooled analysis in the International Head and Neck Cancer Epidemiology consortium. Ann Oncol 2012; 23:1869-1880.

40. Bravi F, Edefonti V, Randi G et al. Dietary patterns and the risk of esophageal cancer. Ann Oncol 2012; 23: 765-770. 
ChAPTER 5. Discussion 
In the present dissertation, I considered various epidemiological aspects of pancreatic cancer. First, I conducted an updated analysis of the mortality from pancreatic mortality in Europe and other selected areas of the world. Secondly, I provided further quantifications of the risk of pancreatic cancer in relation to tobacco smoking and type 2 diabetes, two of the major recognized risk factors for this neoplasm. Thirdly, I provided further information on the association between ulcer and its treatment on the risk of pancreatic cancer, and issue which has been investigated in various epidemiological studies, providing, however, inconsistent results. Finally, I evaluated the role of diet on pancreatic cancer, through the investigation of a priori and $a$ posteriori dietary patterns which combined different food items and nutrients. The results of each epidemiological aspect considered in the present dissertation were presented and discussed in the single publications and corresponding chapters. I will provide here a final summary of these results, their discussion, and their interpretation on the basis of biological mechanisms, as well as a brief discussion of methodological aspects related to the studies considered in the present work.

\section{Review and interpretation of main findings}

\section{Mortality trends}

As an indicator of the burden of pancreatic cancer, I considered mortality, since official data on mortality are available at a national level for many countries and for long time periods, thus allowing comparisons across countries and calendar periods. Incidence data are generally not available at a national level, but estimates are available only from local cancer registries. Moreover, incidence - more than mortality - can be influenced by improved accuracy in the diagnosis and certification of the disease, following the introduction of various modern imaging techniques [1, 2]. Moreover, for pancreatic cancer, which is a highly lethal neoplasm, mortality data are likely to strongly reflect incidence ones.

The updated analysis of pancreatic cancer mortality shows that, in the early 2000's, rates have been approximately stable in many European countries, as in the USA, Japan and Australia. In Japan, mortality from pancreatic cancer is relatively high, although overall mortality from cancer is $10 \%$ lower than in the USA and $20 \%$ lower than in the EU [3]. In Nordic countries and the UK, where declines in pancreatic mortality rates have been observed since the 1980's, mortality seems to have reached a plateau or even to rise over most recent calendar years. Some persisting rises are still found in a few countries of southern and central/eastern Europe (with low rates in the past), in the EU overall, and in women from European and Asian countries. Recent trends are generally more favorable in young adults (30-49 years), suggesting that overall trends in pancreatic mortality are likely to improve in the next future [4]. 
Although this overview of mortality from pancreatic cancer has mainly a descriptive aim, such trends can be interpreted in terms of changes in exposure to main risk factors for pancreatic cancer (namely tobacco smoking, obesity, type 2 diabetes, alcohol drinking, and dietary exposures) as well as to changes in diagnosis and treatment for the diseases, and consequently in survival, over time. Trends in pancreatic cancer mortality at least in part reflect the different patterns in tobacco consumption - the major known risk factor for pancreatic cancer [5-9] - in subsequent generations of men and women in various countries worldwide. Thus, pancreatic mortality rates started to decrease earlier in countries where smoking control has been earlier (i.e., the UK, USA, Japan and Australia) [10-12], while upwards trends are still observed in men from various central/eastern European countries, as well as in women, for whom smoking has been increasing up to more recent generations. However, the modest increases in pancreatic mortality in various European countries, as well as in the EU overall, are in contrast with the persisting declines in mortality from cancers of the lung, upper digestive tract, and bladder [13, 14], suggesting that other factors, besides smoking, may have had some role. Overweight/obesity [15-19], as well as diabetes [20-22], may have adversely affected pancreatic cancer mortality trends, due to an increase in their prevalence in several areas of the world over the last few decades $[23,24]$. Other recognized risk factors for pancreatic cancer, i.e., pancreatitis $[25,26]$, heavy alcohol drinking $[27,28]$, as well as selected dietary factors [19], cause a small proportion of pancreatic cancers on a population level, and consequently are likely to have had a negligible effect on national mortality trends.

The diagnosis of pancreatic cancer poses some difficulties and less than $50 \%$ of cases worldwide has been histologically confirmed [6]. At least part of the earlier trends in pancreatic cancer mortality, as well as the rises in some countries of southern and central/eastern Europe, may have been due to improvement in the diagnosis and certification for the disease, following the introduction of ultrasound, computerized tomography, endoscopic retrograde cholangio-pancreatography, and imaging-guided fine needle aspiration [1, 2]. It is unlikely, however, that changes in diagnosis accuracy have played a major role over more recent calendar periods in most high-income countries of Europe and North America, as well as in Japan, also given the consistency of trends in these countries.

Improvements in the treatment and management for pancreatic cancer are unlikely to have meaningfully affected mortality rates over the last decades in many countries, since progress in the treatment of pancreatic cancer has been very limited and 5-year relative survival from this neoplasm has remained extremely low [29].

This analysis thus confirms a leveling off in pancreatic cancer mortality in various areas of the world after decades of steady rises, although modest increases are still observed in countries of southern and central/eastern Europe, as well as in women. Pancreatic 
cancer remains, therefore, one of the few cancer sites for which mortality has not declined over the last two decades in Europe, as in North America and Japan.

\section{Cigarette smoking}

The uniquely large collaborative analysis conducted within the PanC4 consortium allowed to provide more accurate estimates of the association between cigarette smoking and pancreatic cancer risk, with particular reference to the dose and duration-risk relationships. Results from this analysis confirm that current cigarette smoking is associated with a 2-fold increased risk of pancreatic cancer and that the risk rises with increasing number of cigarettes smoked and duration of smoking. A $20 \%$ excess risk of pancreatic cancer is still found among former smokers; this excess risk declines with time since quitting smoking and reaches the level of never cigarette smokers 20 years after stopping the habit.

The increased pancreatic cancer risk in current cigarette smokers reported in our data is consistent with the results of a meta-analysis of 82 epidemiological studies (42 casecontrol studies, 40 cohort studies) published between 1950 and 2007 [7] and with those of a pooled-analysis of eight cohort studies with almost 1500 incident cases of pancreatic cancer [8]. However, the estimate for current cigarette smokers from our data was slightly higher that that reported in previous investigations $[7,8,30]$. This can be due to the better distinction between current and former smokers that was possible in our analysis, but not in the studies included in the meta-analysis by lodice et al. [7], as well as in prospective studies [8, 30]. In cohort studies, smoking habits are generally assessed at baseline and misclassification of smoking exposure is likely to underestimate the associated risks. The significant dose-risk relationship with increasing number of cigarettes smoked is consistent with that reported in the pooledanalysis of cohort studies [8]. However, case-control studies data allowed us to assess this association specifically among current smokers, something that was not possible in cohort studies where the effect pertained to ever smokers. With reference to duration of smoking, we observed that risk of pancreatic cancer increased in relation to years of smoking, up to 40 years of smoking, confirming the long-term effect of cigarette smoking on pancreatic carcinogenesis $[8,31]$. The results of our study also confirm the decline in risk of pancreatic cancer with increasing time since quitting cigarette smoking $[7,8]$, thus underlining the importance of stopping cigarette smoking to reduce the risk of developing pancreatic cancer.

There is no a clear mechanistic explanation for the carcinogenicity of cigarette smoking on the pancreas. There are over 70 carcinogens in tobacco smoke that have been classified by the IARC as having sufficient evidence for carcinogenicity in either laboratory animals or humans $[9,31]$. However, only a few pancreatic carcinogens have been identified in tobacco smoke, i.e., benzo[a]pyrene (BaP), 4(methylnitrosamino)-1-(3-pyridyl)-1-butanone (NNK) and its metabolite 4- 
(methylnitrosamino)-1-(3-pyridyl)-1-butanol (NNAL). Significantly higher levels of NNK were detected in the pancreatic juice of smokers as compared to non-smokers; NNAL and NNN were also detected in some samples [32]. DNA adducts of NNK and NNAL have been identified in pancreatic tissues of rats treated with these nitrosamines (Zhang et al., 2009b), although they were not detected in most human pancreatic tissue samples [33]. It is also unclear when smoking exerts its effect on pancreatic cancer development, although the declining risk following smoking cessation suggests that tobacco smoking is a late-stage carcinogen for pancreatic cancer.

\section{Type 2 diabetes mellitus}

Our data shows that type 2 diabetes is significantly associated to an increased risk of pancreatic cancer, the excess risk being stronger in subjects with a more recent diagnosis of diabetes, persisting up to 10 years following the diagnosis of diabetes, and declining thereafter.

We thus confirm the evidence from previous studies indicating a 1.8-1.9 excess risk in diabetic subjects $[20,21]$. The stronger excess risk we found in subjects with a more recent diagnosis of diabetes is in agreement with findings from previous studies [20, 21, 34-36].

With reference to the duration-risk relationship between diabetes and pancreatic cancer, inconsistent results have been reported. As in our study, a few previous investigations indicated that the risk leveled off after 10 years since diabetes diagnosis $[34,35]$, while in other studies persistent $30-50 \%$ increased risks were found among subjects who had diabetes for 10 or more years [20-22, 36, 37].

The stronger excess risk of pancreatic cancer for a diagnosis of diabetes in close proximity to that of cancer suggests that diabetes is an early manifestation or a consequence of pre-clinical pancreatic cancer. In vitro studies suggested that pancreatic cancer induce insulin resistance, with consequent blockage of insulin receptors and impaired insulin action and glucose transport [21]. Moreover, early symptoms of pancreatic cancer may also favor the diagnosis of diabetes. However, reverse causation cannot completely account for the excess risk observed up to 10 years since diagnosis of diabetes, indicating that diabetes is likely to play a real etiologic role on pancreatic carcinogenesis. Type 2 diabetes is associated with insulin resistance, hyperinsulinemia and increased levels of insulin-like growth factor (IGF)-1. High insulin concentrations may be involved in the etiology of pancreatic cancer, as insulin acts as a growth promoter and mitogen in the pancreas [38, 39]. IGF-1 and IGF1 receptor have been found to be highly expressed in pancreatic cell lines, this leading to decreased apoptosis, increased cell proliferation, and angiogenesis promotion. It remains to clarify whether at least part of the association between type 2 diabetes and the risk of pancreatic cancer is due to common risk factors (in particular overweight/obesity). 


\section{Dietary patterns}

I have evaluated the role of role of combinations of foods and nutrients on pancreatic cancer risk using both a priori defined scores proposed in the literature and adopted in various other epidemiological studies to measure the adherence to the Mediterranean diet and a posteriori dietary patterns built on the specific dietary data under consideration.

Our study provides evidence that a priori defined scores which include several aspects of the Mediterranean diet are favorably associated with pancreatic cancer risk in the Italian population. Thus, the combination of the favorable fatty acid profile and the high content of fiber, antioxidants and phytochemicals typical of the Mediterranean diet appear to have a beneficial role on pancreatic, as on other neoplasms [40-42]. In the analysis of a posteriori dietary patterns defined on the Italian population, we also found that an "Animal Products" pattern (highly correlated with meat, cheese, and milk) and a "Starch-rich" pattern (highly correlated with bread, pasta and rice) are significantly associated to an increased pancreatic cancer risk, while a "Vitamins and Fiber" pattern (highly correlated with various vegetables, pulses and fruit) is associated with a reduced risk.

The association observed with the dietary patterns identified can be interpreted in terms of major food items included in such dietary patterns. An inverse association between pancreatic cancer and vegetables and fruit has been reported in several studies, possibly on account of their high content in vitamins and phenolic compounds, with antioxidant, antimutagenic, and anticarcinogenic activity [19, 43-47]. Conversely, a detrimental role of (red and processed) meat has been reported in many, though not all, studies [19, 45, 48-52]. Such an association has been attributed to N-nitroso compounds, heterocyclic amines, and polycyclic aromatic hydrocarbons produced in meat cooking, thought its interpretation remains open to discussion $[53,54]$. The relation between starchy foods (such as bread, pasta or rice) and pancreatic cancer is still unclear $[45,55]$, but there is some evidence of a possible increased risk, particularly for sugars $[19,45,55-58]$. Any such relation is possibly mediated by hyperinsulinemia, insulin resistance, and IGFs [59]. There is also some evidence that saturated fatty acids are associated to an increased risk of pancreatic cancer [19]. Dietary fat have been shown to promote pancreatic carcinogenesis in animal models through various proposed mechanisms $[60,61]$. Conversely olive oil - the main source of monounsaturated fatty acid in Mediterranean countries - has been reported to be a favorable indicator of various common cancers [62]; this is possibly due to its specific fatty acid composition and to the presence of various nutrients, such as vitamin $E$ and polyphenols, with strong antioxidant properties [62, 63]. Finally, heavy - but not low/moderate - alcohol intake has been associated with an increased pancreatic cancer risk [27, 28]. Alcohol (ethanol) has been classified by the IARC as a Group 1 carcinogen and ethanol metabolites, such as acetaldehyde, have been identified as the 
most important carcinogens [64]. Heavy alcohol consumption may increase pancreatic cancer risk via mechanisms that promote the effects of other risk factors such as tobacco smoking; heavy alcohol consumption may also alter metabolic pathways involved in inflammatory response $[65,66]$.

Most previous studies analyzed single foods or nutrients on pancreatic cancer, while only a few investigations considered the role of diet in the complex [67-73]. Thus, the interest of this study has to be related to the strong inverse relation between pancreatic cancer and the combination of various food items/nutrients into a priori or a posteriori scores that take into consideration their synergistic effects.

Our data indicate that a diet characterized by a high consumption of meat and other animal products, as well as of (refined) cereals and sugars, has a detrimental role on pancreatic cancer, while a diet rich in fruit and vegetables have a favorable role. In particular the Mediterranean diet, characteristic of Italy, may favorably affect pancreatic cancer risk.

\section{Ulcer and treatments for ulcer}

Our analysis based on a uniquely large dataset provides strong evidence that subjects with a history of gastric or duodenal ulcer have no excess risk of pancreatic cancer, although a diagnosis of peptic ulcer two years before pancreatic cancer diagnosis was associated with an increased risk. Study participants who underwent gastrectomy for treatment of ulcer or other benign conditions had a 50\% excess risk, but this was again limited to those who had surgery within two years before cancer diagnosis.

The results of this study confirm the evidence from several previous investigations that reported no association between peptic ulcer and subsequent pancreatic cancer risk [26]. The positive association observed in participants with a diagnosis of ulcer within two years prior to cancer diagnosis and the absence of risk for a longer time prior to diagnosis may be due to enhanced surveillance of people with newly diagnosed peptic ulcer, increasing the probability of being diagnosed with pancreatic cancer. Moreover, it is possible that peptic ulcer is an early symptom or a consequence of pancreatic cancer.

The $50 \%$ increased risk of pancreatic cancer in relation to a history of gastrectomy is consistent with the evidence from previous investigations [26] and with the results of a meta-analysis [74]. Although a few small previous studies suggested that the increase in risk persisted more than 20 years after surgery [75-78], we found that the excess risk of pancreatic cancer was evident only for participants who had undergone gastrectomy within two years prior to cancer diagnosis. Thus, as for peptic ulcer, this would indicate a likely role of detection bias, following the increased medical surveillance of participants undergoing gastrectomy. 
Our data do not support a role of any ulcer medications (including antacids, H2antagonists and PPIs) in pancreatic carcinogenesis, in agreement with the evidence from a few other studies [79-81].

In conclusion, our study provides definitive evidence that ulcer and its treatment have no causal role in pancreatic cancer development.

\section{Methodological issues}

In this section, I will discuss major weaknesses and strengths of the studies considered and the analyses conducted in the current dissertation. Moreover, I will discuss methodological aspects of nutritional patterns measuring.

\section{Limitation and strengths of the studies analyzed}

The studies analyzed within the network of Italian studies had a case-control design and are thus susceptible of possible bias, including recall bias, selection bias, and confounding [82]. In order to reduce any potential information or selection bias, cases and controls came from comparable catchment areas and were interviewed by the same interviewers, in their respective hospital settings. Cases and controls had an almost complete participation rate, this reassuring against a potential selection bias. Dietary habits of hospital controls may be different from those of the general population, but we paid attention to exclude from the control group all diagnoses associated with long-term dietary modifications. In particular, the controls enrolled in our studies were selected among patients admitted to the same hospitals as cases for acute, non neoplastic conditions, including traumas, non-traumatic orthopedic conditions, acute surgical conditions, and miscellaneous other illnesses (including dental, ear, eye, nose, throat or skins diseases). To reduce any possible dietary modification due to the recent cancer diagnosis, we asked for dietary habits two years before cancer diagnosis (or hospital admission for controls), although diet could have changed due to subclinical disease. For history of diabetes, we considered all diagnoses occurring prior to cancer diagnosis (or hospital admission for controls) and we are aware that this may have lead to an overestimation of pancreatic cancer risk, since diabetes diagnosis in close proximity to cancer diagnosis may be a consequence rather than a cause of pancreatic cancer. In any case, we also analyzed time since diabetes history, in order to better assess the causal role of diabetes on pancreatic cancer. Potential recall bias should be limited, also given the limited appreciation by the Italian population of a link between diet and medical conditions as diabetes and pancreatic cancer risk at the time of interview. Although some measurement error inherent to the FFQ used to asses dietary habits may be present, we used a validated [83] and reproducible [84] FFQ, which allowed for a comprehensive assessment of major nutrient sources in the Italian diet. History of diabetes and other medical conditions 
was self-reported, but reliability of information on medical history provided by hospital controls has been shown to be satisfactory [85]. Moreover, we were able to carefully allow for major recognized risk factors for pancreatic cancer, including in particular tobacco smoking and BMI.

With specific reference to the Panc4 consortium, it also included (hospital-based or population-based) case-control studies, which can have the inherent bias of this study design. As the Italian case-control studies, however, most studies paid careful attention to minimize any possible sources of bias. Among the strengths of the PanC4 data are the uniquely large dataset, the availability of original and detailed information on the factors investigated, the possibility to uniformly and carefully account for study design variables and potential confounding factors for pancreatic cancer, including education, tobacco smoking, BMI, history of diabetes and pancreatitis, and heavy alcohol consumption, and to conduct stratified analyses by selected covariates. Given the retrospective design of the case-control studies included in the pooled analysis, it is possible that self-reported information on tobacco smoking, medical conditions as well as other factors were reported more accurately in cases than controls. However, the similar results in hospital and population-based studies and the consistency with those from cohort studies argue against a major role of recall bias and misclassification.

\section{Measuring nutritional patterns}

Analyses of dietary patterns, as compared to those of single foods or nutrients, may provide more comprehensive information on the overall effect of diet on cancer risk, accounting for the complex interactions between various dietary components [86-90]. By characterizing a healthy diet in a defined population, dietary patterns are also intuitively practical tools for disseminating dietary recommendations.

Various approaches have been proposed in the literature to define dietary patterns, including the hypothesis-oriented/a priori approach and the exploratory/a posteriori approach used in this dissertation. In the a priori approach, dietary patterns are defined as indexes or scores built upon scientific evidence or knowledge for a specific disease and, generally, include foods or nutrients supported by dietary guidelines, recommendations, and/or specific dietary compositions (such as the Mediterranean diet) that are considered healthful $[86,87,89,91,92]$. The major limitation of this approach is that the a priori dietary patterns are highly subjective, the subjectivity being introduced in the selection and interpretation of the guidelines and in the construction of the scores (i.e., choice of foods selected for inclusion). Indexes also heavily dependent on the questionnaires used for data collection and are generally adapted to the specific questionnaire. Moreover, a priori dietary patterns vary across studies and include different dietary components, different weightings of components 
and cutoff-points, resulting in indexes that potentially measure different definitions of the healthful behavior.

In the a posteriori approach, dietary patterns are defined empirically, applying multivariate statistical methods (such as principal component analyses, PCA, exploratory factor analysis, FA, or cluster analysis) directly to the data under consideration $[86,89,90,93]$. The aim of PCA and FA is to reduce the dimensionality of the data by transforming an original larger set of correlated foods or nutrients into a smaller and more easily interpretable set of uncorrelated variables, called principal components or factors (dietary patterns). The principal component factor analysis (PCFA) used in the present work is a FA where the PCA is adopted for parameter estimation. Such technique allows an easier interpretation of the identified factors as compared to normal PCA.

For each subject and for each (retained) factor, a continuous summary score is then derived from PCA, FA or PCFA indicating the degree of adherence of a subject's diet to each of the identified dietary patterns. Such factor scores are used for further cancer risk assessment.

Among the limitations of such methods, however, there is the fact that PCA, FA or PCFA are data driven and requires some arbitrary decisions, including the selection of dietary items to enter in the analysis (foods or nutrients), the data matrix to work on (e.g., covariance or correlation matrix), the number of factors to retain, the rotation method, the interpretation and labeling of the factors. Sensitivity analyses can be used (as in our analyses) to confirm the stability and robustness of the method. The consistency of the factors identified in the analysis with those found in similar analyses on other study populations are another method to confirm the reproducibility of the dietary patterns identified.

\section{Conclusion}

Pancreatic cancer is the single major neoplasm showing unfavorable trends in most populations over the last decades. Thus, the burden of pancreatic cancer may become larger in the future [94]. Given the lack of effective screening and the modest improvement in therapies over the last decades, primary prevention is the only way to reduce pancreatic cancer. Control of tobacco smoking is one of the key measures, since it could avoid $15-25 \%$ of pancreatic cancers in various populations $[8,95]$. Many efforts have been made in this regards, although further improvements are possible, particularly in countries were tobacco prevalence is still high and in female population. Control of overweight/obesity, and consequent type 2 diabetes, is another key measure for the prevention of pancreatic cancer. Obesity is increasing in most areas of the world, thought there are a few exeptions (i.e., France and Italy) [24]. Thus, a joined effort, involving the medical community, public health officials, and governments, 
should be made to fight against overweight/obesity, through adequate campaigns and policies aimed at improving dietary habits and increasing physical activity. Although the evidence of the role of single foods and nutrients on pancreatic cancer is inconsistent, a more healthy diet, rich in plant foods and poor in meat, other animal products, (refined) cereals, and sugars, may favorably affect pancreatic cancer both directly and indirectly, by helping maintaining normal body weight and controlling type 2 diabetes onset. 


\section{References}

1. Hidalgo M. Pancreatic cancer. N Engl J Med 2010; 362: 1605-1617.

2. Sharma C, Eltawil KM, Renfrew PD et al. Advances in diagnosis, treatment and palliation of pancreatic carcinoma: 1990-2010. World J Gastroenterol 2011; 17 : 867-897.

3. Ferlay J, Shin HR, Bray F et al. Estimates of worldwide burden of cancer in 2008: GLOBOCAN 2008. Int J Cancer 2010; 127: 2893-2917.

4. Muir CS, Fraumeni JF, Jr., Doll R. The interpretation of time trends. Cancer Surv 1994; 19-20: 5-21.

5. IARC. IARC Monographs on the evaluation of carcinogenic risks to humans. Vol. 83. Tobacco smoke and involuntary smoking. Lyon: International Agency for Research on Cancer 2004.

6. Anderson KE, Mack TM, Silverman DT. Cancer of the pancreas. In Schottenfeld D, Fraumeni JFJr (eds): Cancer Epidemiology and Prevention, Edition 3th. New York: Oxford University Press 2006; 721-762.

7. Iodice S, Gandini S, Maisonneuve P, Lowenfels AB. Tobacco and the risk of pancreatic cancer: a review and meta-analysis. Langenbecks Arch Surg 2008; 393: 535-545.

8. Lynch SM, Vrieling A, Lubin JH et al. Cigarette smoking and pancreatic cancer: a pooled analysis from the pancreatic cancer cohort consortium. Am J Epidemiol 2009; 170: 403-413.

9. IARC. IARC Monographs on the evaluation of carcinogenic risks to humans. Vol. 100E. Personal Habits and Indoor Combustions. Lyon: International Agency for Research on Cancer 2012.

10. Tyczynski JE, Bray F, Aareleid T et al. Lung cancer mortality patterns in selected Central, Eastern and Southern European countries. Int J Cancer 2004; 109: 598610.

11. Marugame T, Kamo K, Sobue $\mathrm{T}$ et al. Trends in smoking by birth cohorts born between 1900 and 1977 in Japan. Prev Med 2006; 42: 120-127.

12. World Health Organization Regional Office for Europe. Health for all database (HFA-DB). Available at: http://data.euro.who.int/hfadb/ Last accessed 2010.

13. La Vecchia C, Bosetti C, Lucchini F et al. Cancer mortality in Europe, 2000-2004, and an overview of trends since 1975. Ann Oncol 2010; 21: 1323-1360.

14. Edwards BK, Ward E, Kohler BA et al. Annual report to the nation on the status of cancer, 1975-2006, featuring colorectal cancer trends and impact of interventions (risk factors, screening, and treatment) to reduce future rates. Cancer 2010; 116: 544-573.

15. Calle EE, Rodriguez C, Walker-Thurmond K, Thun MJ. Overweight, obesity, and mortality from cancer in a prospectively studied cohort of U.S. adults. N Engl J Med 2003; 348: 1625-1638. 
16. Larsson SC, Orsini N, Wolk A. Body mass index and pancreatic cancer risk: A metaanalysis of prospective studies. Int J Cancer 2007; 120: 1993-1998.

17. Renehan $A G$, Tyson $M$, Egger $M$ et al. Body-mass index and incidence of cancer: a systematic review and meta-analysis of prospective observational studies. Lancet 2008; 371: 569-578.

18. Arslan AA, Helzlsouer KJ, Kooperberg C et al. Anthropometric measures, body mass index, and pancreatic cancer: a pooled analysis from the Pancreatic Cancer Cohort Consortium (PanScan). Arch Intern Med 2010; 170: 791-802.

19. World Cancer Research Fund and American Institute for Cancer Research. Food, Nutrition, Physical Activity and Pancreatic Cancer. Washington DC: American Institute for Cancer Research 2012.

20. Huxley R, Ansary-Moghaddam A, Berrington de Gonzalez A et al. Type-Il diabetes and pancreatic cancer: a meta-analysis of 36 studies. Br J Cancer 2005; 92: 20762083.

21. Ben $\mathrm{Q}, \mathrm{Xu} \mathrm{M}$, Ning $\mathrm{X}$ et al. Diabetes mellitus and risk of pancreatic cancer: A metaanalysis of cohort studies. Eur J Cancer 2011; 47: 1928-1937.

22. Eijgenraam $P$, Heinen $M M$, Verhage $B A$ et al. Diabetes type II, other medical conditions and pancreatic cancer risk: a prospective study in The Netherlands. $\mathrm{Br}$ J Cancer 2013; 109: 2924-2932.

23. King $H$, Aubert RE, Herman WH. Global burden of diabetes, 1995-2025: prevalence, numerical estimates, and projections. Diabetes Care 1998; 21: 14141431.

24. Finucane MM, Stevens GA, Cowan MJ et al. National, regional, and global trends in body-mass index since 1980: systematic analysis of health examination surveys and epidemiological studies with 960 country-years and 9.1 million participants. Lancet 2011; 377: 557-567.

25. Duell EJ, Lucenteforte E, Olson SH et al. Pancreatitis and pancreatic cancer risk: a pooled analysis in the International Pancreatic Cancer Case-Control Consortium (PanC4). Ann Oncol 2012; 23: 2964-2970.

26. Olson SH. Selected medical conditions and risk of pancreatic cancer. Mol Carcinog 2012; 51: 75-97.

27. Tramacere I, Scotti L, Jenab $M$ et al. Alcohol drinking and pancreatic cancer risk: a meta-analysis of the dose-risk relation. Int J Cancer 2010; 126: 1474-1486.

28. Lucenteforte E, La Vecchia C, Silverman D et al. Alcohol consumption and pancreatic cancer: a pooled analysis in the International Pancreatic Cancer CaseControl Consortium (PanC4). Ann Oncol 2012; 23: 374-382.

29. Karim-Kos HE, de Vries E, Soerjomataram I et al. Recent trends of cancer in Europe: a combined approach of incidence, survival and mortality for 17 cancer sites since the 1990s. Eur J Cancer 2008; 44: 1345-1389. 
30. Vrieling A, Bueno-de-Mesquita HB, Boshuizen $\mathrm{HC}$ et al. Cigarette smoking, environmental tobacco smoke exposure and pancreatic cancer risk in the European Prospective Investigation into Cancer and Nutrition. Int J Cancer 2010; 126: 2394-2403.

31. IARC. IARC Monographs on the Evaluation of the Carcinogenic Risks to Humans. Vol. 83. Tobacco smoke and involuntary smoking. IARC, Lyon 2004.

32. Prokopczyk B, Hoffmann D, Bologna $M$ et al. Identification of tobacco-derived compounds in human pancreatic juice. Chem Res Toxicol 2002; 15: 677-685.

33. Prokopczyk B, Leder G, Trushin N et al. 4-Hydroxy-1-(3-pyridyl)-1-butanone, an indicator for 4-(methylnitrosamino)-1-(3-pyridyl)-1-butanone-induced DNA damage, is not detected in human pancreatic tissue. Cancer Epidemiol Biomarkers Prev 2005; 14: 540-541.

34. Wang F, Gupta S, Holly EA. Diabetes mellitus and pancreatic cancer in a population-based case-control study in the San Francisco Bay Area, California. Cancer Epidemiol Biomarkers Prev 2006; 15: 1458-1463.

35. Maisonneuve $\mathrm{P}$, Lowenfels $\mathrm{AB}$, Bueno-de-Mesquita $\mathrm{HB}$ et al. Past medical history and pancreatic cancer risk: Results from a multicenter case-control study. Ann Epidemiol 2010; 20: 92-98.

36. Atchison EA, Gridley G, Carreon JD et al. Risk of cancer in a large cohort of U.S. veterans with diabetes. Int J Cancer 2010; 128: 635-643.

37. Li D, Tang $H$, Hassan MM et al. Diabetes and risk of pancreatic cancer: a pooled analysis of three large case-control studies. Cancer Causes Control 2011; 22: 189197.

38. Fisher WE, Boros LG, Schirmer WJ. Insulin promotes pancreatic cancer: evidence for endocrine influence on exocrine pancreatic tumors. J Surg Res 1996; 63: 310313.

39. Giovannucci E, Michaud D. The role of obesity and related metabolic disturbances in cancers of the colon, prostate, and pancreas. Gastroenterology 2007; 132: 2208-2225.

40. Verberne L, Bach-Faig A, Buckland G, Serra-Majem L. Association between the Mediterranean diet and cancer risk: a review of observational studies. Nutr Cancer 2010; 62: 860-870.

41. Pelucchi C, Bosetti C, Rossi M et al. Selected aspects of Mediterranean diet and cancer risk. Nutr Cancer 2009; 61: 756-766.

42. Couto $E$, Boffetta $P$, Lagiou $P$ et al. Mediterranean dietary pattern and cancer risk in the EPIC cohort. Br J Cancer 2011; 104: 1493-1499.

43. Larsson SC, Giovannucci E, Wolk A. Folate intake, MTHFR polymorphisms, and risk of esophageal, gastric, and pancreatic cancer: a meta-analysis. Gastroenterology 2006; 131: 1271-1283. 
44. Nothlings U, Murphy SP, Wilkens LR et al. Flavonols and pancreatic cancer risk: the multiethnic cohort study. Am J Epidemiol 2007; 166: 924-931.

45. Hart AR, Kennedy $\mathrm{H}$, Harvey I. Pancreatic cancer: a review of the evidence on causation. Clin Gastroenterol Hepatol 2008; 6: 275-282.

46. Bae JM, Lee EJ, Guyatt G. Citrus fruit intake and pancreatic cancer risk: a quantitative systematic review. Pancreas 2009; 38: 168-174.

47. Rossi $M$, Lugo $A$, Lagiou $P$ et al. Proanthocyanidins and other flavonoids in relation to pancreatic cancer: a case-control study in Italy. Ann Oncol 2012; 23: 1488-1493.

48. Stolzenberg-Solomon RZ, Cross AJ, Silverman DT et al. Meat and meat-mutagen intake and pancreatic cancer risk in the NIH-AARP cohort. Cancer Epidemiol Biomarkers Prev 2007; 16: 2664-2675.

49. Heinen MM, Verhage BA, Goldbohm RA, van den Brandt PA. Meat and fat intake and pancreatic cancer risk in the Netherlands Cohort Study. Int J Cancer 2009; 125: 1118-1126.

50. Polesel J, Talamini R, Negri E et al. Dietary habits and risk of pancreatic cancer: an Italian case-control study. Cancer Causes Control 2010; 21: 493-500.

51. Larsson SC, Wolk A. Red and processed meat consumption and risk of pancreatic cancer: meta-analysis of prospective studies. Br J Cancer 2012; 106: 603-607.

52. Anderson KE, Mongin SJ, Sinha R et al. Pancreatic cancer risk: associations with meat-derived carcinogen intake in the Prostate, Lung, Colorectal, and Ovarian Cancer Screening Trial (PLCO) cohort. Mol Carcinog 2012; 51: 128-137.

53. Risch HA. Etiology of pancreatic cancer, with a hypothesis concerning the role of $\mathrm{N}$-nitroso compounds and excess gastric acidity. J Natl Cancer Inst 2003; 95: 948960.

54. Anderson KE, Kadlubar FF, Kulldorff $M$ et al. Dietary intake of heterocyclic amines and benzo(a)pyrene: associations with pancreatic cancer. Cancer Epidemiol Biomarkers Prev 2005; 14: 2261-2265.

55. World Cancer Research Fund and American Institute for Cancer Research. Food, Nutrition, Physical Activity and the Prevention of Cancer: a Global Perspective. Washington DC: American Institute for Cancer Research 2007.

56. Larsson SC, Bergkvist L, Wolk A. Consumption of sugar and sugar-sweetened foods and the risk of pancreatic cancer in a prospective study. Am J Clin Nutr 2006; 84: 1171-1176.

57. Nothlings U, Murphy SP, Wilkens LR et al. Dietary glycemic load, added sugars, and carbohydrates as risk factors for pancreatic cancer: the Multiethnic Cohort Study. Am J Clin Nutr 2007; 86: 1495-1501.

58. Aune D, Chan DS, Vieira AR et al. Dietary fructose, carbohydrates, glycemic indices and pancreatic cancer risk: a systematic review and meta-analysis of cohort studies. Ann Oncol 2012; 23: 2536-2546. 
59. Stolzenberg-Solomon RZ, Graubard BI, Chari S et al. Insulin, glucose, insulin resistance, and pancreatic cancer in male smokers. JAMA 2005; 294: 2872-2878.

60. Tucker ON, Dannenberg AJ, Yang EK, Fahey TJ, 3rd. Bile acids induce cyclooxygenase-2 expression in human pancreatic cancer cell lines. Carcinogenesis 2004; 25: 419-423.

61. Sanchez GV, Weinstein SJ, Stolzenberg-Solomon RZ. Is dietary fat, vitamin D, or folate associated with pancreatic cancer? Mol Carcinog 2012; 51: 119-127.

62. Pelucchi C, Bosetti C, Negri E et al. Olive oil and cancer risk: an update of epidemiological findings through 2010. Curr Pharm Des 2011; 17: 805-812.

63. Owen RW, Giacosa A, Hull WE et al. Olive-oil consumption and health: the possible role of antioxidants. Lancet Oncol 2000; 1: 107-112.

64. IARC. IARC Monographs on the evaluation of carcinogenic risks to humans. Vol. 96. Alcohol consumption and ethylcarbamate. Lyon: International Agency for Research on Cancer 2010.

65. Go VL, Gukovskaya A, Pandol SJ. Alcohol and pancreatic cancer. Alcohol 2005; 35: 205-211.

66. Duell EJ. Epidemiology and potential mechanisms of tobacco smoking and heavy alcohol consumption in pancreatic cancer. Mol Carcinog 2012; 51: 40-52.

67. Michaud DS, Skinner HG, Wu K et al. Dietary patterns and pancreatic cancer risk in men and women. J Natl Cancer Inst 2005; 97: 518-524.

68. Nkondjock A, Krewski D, Johnson KC, Ghadirian P. Dietary patterns and risk of pancreatic cancer. Int J Cancer 2005; 114: 817-823.

69. Nothlings $U$, Murphy SP, Wilkens LR et al. A food pattern that is predictive of flavonol intake and risk of pancreatic cancer. Am J Clin Nutr 2008; 88: 1653-1662.

70. Jiao L, Mitrou PN, Reedy J et al. A combined healthy lifestyle score and risk of pancreatic cancer in a large cohort study. Arch Intern Med 2009; 169: 764-770.

71. Inoue-Choi M, Flood A, Robien K, Anderson K. Nutrients, food groups, dietary patterns, and risk of pancreatic cancer in postmenopausal women. Cancer Epidemiol Biomarkers Prev 2011; 20: 711-714.

72. Tognon G, Nilsson LM, Lissner L et al. The Mediterranean diet score and mortality are inversely associated in adults living in the subarctic region. J Nutr 2012; 142: 1547-1553.

73. Chan JM, Gong Z, Holly EA, Bracci PM. Dietary patterns and risk of pancreatic cancer in a large population-based case-control study in the San Francisco Bay Area. Nutr Cancer 2013; 65: 157-164.

74. Gong $Y$, Zhou Q, Zhou $Y$ et al. Gastrectomy and risk of pancreatic cancer: systematic review and meta-analysis of observational studies. Cancer Causes Control 2012; 23: 1279-1288.

75. Caygill CP, Hill MJ, Hall CN et al. Increased risk of cancer at multiple sites after gastric surgery for peptic ulcer. Gut 1987; 28: 924-928. 
76. Stael von Holstein C, Anderson H, Ahsberg K, Huldt B. The significance of ulcer disease on late mortality after partial gastric resection. Eur J Gastroenterol Hepatol 1997; 9: 33-40.

77. Tascilar M, van Rees BP, Sturm PD et al. Pancreatic cancer after remote peptic ulcer surgery. J Clin Pathol 2002; 55: 340-345.

78. Luo J, Nordenvall C, Nyren $\mathrm{O}$ et al. The risk of pancreatic cancer in patients with gastric or duodenal ulcer disease. Int J Cancer 2007; 120: 368-372.

79. Mack TM, Yu MC, Hanisch R, Henderson BE. Pancreas cancer and smoking, beverage consumption, and past medical history. J Natl Cancer Inst 1986; 76: 4960.

80. Kalapothaki V, Tzonou A, Hsieh CC et al. Tobacco, ethanol, coffee, pancreatitis, diabetes mellitus, and cholelithiasis as risk factors for pancreatic carcinoma. Cancer Causes Control 1993; 4: 375-382.

81. Bradley MC, Murray L, Cantwell MM, Hughes CM. Proton pump inhibitors and histamine-2-receptor antagonists and pancreatic cancer risk: a nested casecontrol study. Br J Cancer 2012; 106: 233-239.

82. Breslow NE, Day NE. Statistical methods in cancer research. Vol. II. The design and analysis of cohort studies. IARC Sci Publ No. 82. Lyon, France: IARC 1987.

83. Decarli A, Franceschi S, Ferraroni $M$ et al. Validation of a food-frequency questionnaire to assess dietary intakes in cancer studies in Italy. Results for specific nutrients. Ann Epidemiol 1996; 6: 110-118.

84. Franceschi S, Negri E, Salvini S et al. Reproducibility of an Italian food frequency questionnaire for cancer studies: results for specific food items. Eur J Cancer 1993; 29A: 2298-2305.

85. Bosetti C, Tavani A, Negri E et al. Reliability of data on medical conditions, menstrual and reproductive history provided by hospital controls. J Clin Epidemiol 2001; 54: 902-906.

86. Hu FB. Dietary pattern analysis: a new direction in nutritional epidemiology. Curr Opin Lipidol 2002; 13: 3-9.

87. Kant AK. Dietary patterns and health outcomes. J Am Diet Assoc 2004; 104: 615635.

88. Moeller SM, Reedy J, Millen AE et al. Dietary patterns: challenges and opportunities in dietary patterns research an Experimental Biology workshop, April 1, 2006. J Am Diet Assoc 2007; 107: 1233-1239.

89. Edefonti V, Randi G, La Vecchia $C$ et al. Dietary patterns and breast cancer: a review with focus on methodological issues. Nutr Rev 2009; 67: 297-314.

90. Bravi F, Edefonti V, Bosetti $C$ et al. Nutrient dietary patterns and the risk of colorectal cancer: a case-control study from Italy. Cancer Causes Control 2010; 21: 1911-1918. 
91. Trichopoulou A, Kouris-Blazos A, Wahlqvist ML et al. Diet and overall survival in elderly people. BMJ 1995; 311: 1457-1460.

92. Bach A, Serra-Majem L, Carrasco JL et al. The use of indexes evaluating the adherence to the Mediterranean diet in epidemiological studies: a review. Public Health Nutr 2006; 9: 132-146.

93. Comrey A, Lee HB. A first course in factor analysis. Hillsdale, New Jersey: Lawrence Erlbaum Associates. 1992.

94. Rahib L, Smith BD, Aizenberg $R$ et al. Projecting cancer incidence and deaths to 2030: the unexpected burden of thyroid, liver, and pancreas cancers in the United States. Cancer Res 2014; 74: 2913-2921.

95. Maisonneuve $P$, Lowenfels $A B$. Epidemiology of pancreatic cancer: an update. Dig Dis 2010; 28: 645-656. 
SUMMARY 
Pancreatic cancer is a highly aggressive neoplasm and represents the 7th most frequent cause of cancer death worldwide with an approximate 265000 deaths, out 280000 new cases in 2008. Cigarette smoking is its major established risk factor but explains only a limited proportion of pancreatic cancers. Among other recognized risk factors are overweight/obesity, diabetes, chronic pancreatitis, and family history of the disease. No consistent association has been found with diet, except for a possible increased risk for low intake of fruit and vegetables and high intake of meat.

In order to further address some open issues in the etiology of this neoplasm, I considered various epidemiological aspects of pancreatic cancer, including a global overview of mortality trends in Europe and other selected areas of the world over the last few decades, the evaluation of tobacco smoking and history of ulcer and its treatments using original data from a large international consortium of case-controls (the International Pancreatic Cancer Case-Control Consortium, PanC4), and the analysis of history of diabetes and dietary correlates of pancreatic cancer using data from two Italian case-control studies.

\section{Mortality trends}

I analyzed official death certification data derived from the WHO for 35 European countries and 19 other selected countries over the period 1980-2007. In 2007, the highest mortality rates (age-standardized, world standard) from pancreatic cancer were in the Baltic countries, and some central/eastern and northern European countries (over 9.5/100,000 men and 6/100,000 women), while the lowest ones were in Latin America and Hong Kong (below 5/100,000 men and 3/100,000 women). Japan, the USA, Russia, the European Union (EU), as well as the largest countries in the EU, had rates between 7 and 9/100,000 men and between 5 and 6/100,000 women. Since the early 2000's, rates have been approximately stable in many European countries, as in the USA, Japan, and Australia. In Nordic countries and the UK - where declines in rates have been observed since the 1980's - mortality from pancreatic cancer seems to have reached a plateau, and have tended to rise, over most recent calendar years. Some persisting rises were still found in men from a few countries of southern Europe (with low rates in the past) and of central/eastern Europe, in the EU overall, and in women from European and Asian countries. Recent trends were generally more favorable in young adults, suggesting that overall trends are likely to improve in the next future.

The International Pancreatic Cancer Case-Control Consortium (PanC4): cigarette smoking and ulcer

To further evaluate and quantify dose- and duration-risk relationships between cigarette smoking and pancreatic cancer, I analyzed original data from 12 case-control studies within the PanC4, including 6507 pancreatic cases and corresponding 12,890 
controls. This uniquely large pooled analysis confirmed that current cigarette smoking is associated with an over 2 -fold increased risk of pancreatic cancer and the risk increases with number of cigarettes smoked (odds ratio, OR, 3.4 for $\geq 35$ cigarettes/day) and with duration of smoking (OR 2.4 up to 40 years of smoking). The risk of pancreatic cancer decreased with increasing time since smoking cessation, reaching the level of never smokers 20 years after quitting.

Peptic ulcer and gastrectomy have been suggested to increase pancreatic cancer risk, although the evidence is inconsistent. In order to further clarify this issue, I analyzed the pooled data from 10 case-control studies within the PanC4, including 4717 pancreatic cancer cases and 9374 corresponding controls. No relation between pancreatic cancer and history of ulcer was found overall, though an association was observed for a diagnosis of ulcer within two years prior to cancer diagnosis (OR=2.43). A significant increased risk was found for history of gastrectomy (OR 1.53), but the excess risk was limited to a gastrectomy within two years prior to cancer diagnosis (OR 6.18), while no significant increased risk was observed for a longer history of gastrectomy. Thus, this uniquely large collaborative study does not support the hypothesis that peptic ulcer and its treatment materially affect pancreatic cancer risk. The increased risk for short-term history of ulcer and gastrectomy suggests that any such associations may be due to increased surveillance.

\section{The Italian case-control studies: diabetes and dietary patterns}

Diabetes has been associated to the risk of pancreatic cancer, though the quantification of this association in various populations remains open to discussion. I analyzed the relation between diabetes and the risk of pancreatic cancer in a casecontrol study conducted in Italy between 1992 and 2008, including 326 cases and 652 hospital controls. An over 3-fold excess risk of pancreatic cancer was observed for history of diabetes. The excess risk was stronger in subjects with a more recent diagnosis of diabetes and remained elevated up to 10 years following the diagnosis of diabetes, to decline thereafter. Although diabetes may be in part an early manifestation or a consequence of pre-clinical pancreatic cancer, reverse causation cannot completely account for the excess risk observed up to 10 years since diagnosis of diabetes, suggesting that diabetes plays a real role on pancreatic cancer risk.

The Mediterranean diet has been shown to have a beneficial role on various neoplasms, but data are scanty on pancreatic cancer. I analyzed data from the Italian case-control study conducted in 1992-2008 and an earlier Italian case-control study conducted between 1983 and 1992, on 362 pancreatic cancer cases and 1552 hospital controls. A Mediterranean Diet Score (MDS) summarizing major characteristics of the Mediterranean diet was used in the two studies separately and overall. Two further scores of adherence to the Mediterranean diet - Mediterranean Dietary Pattern Adherence Index (MDP) and Mediterranean Adequacy Index (MAI) - were applied in 
the second study only. The OR for MDS $\geq 6$ compared to $<3$ was 0.48 in the two studies combined. A significant trend of decreasing risk was observed also for high MDP $(O R=0.44)$ and $M A I(O R=0.68)$. The study thus provides evidence that adherence to the Mediterranean diet - measured using various a priori defined scores - is favorably associated with pancreatic cancer risk.

In order to add further information on dietary patterns associated to pancreatic cancer, I applied an exploratory principal component factor analysis on 28 major nutrients derived from the Italian case-control study conducted in 1992-2008. Four dietary patterns were identified, explaining $75 \%$ of the total variance in nutrient intake in this population. Direct associations were found between pancreatic cancer and the "Animal Products" (OR=2.03 for the highest vs the lowest quartiles) and the "Starchrich" (OR=1.69) patterns; a significant inverse association emerged for the "Vitamins and Fiber" pattern (OR=0.55), while no significant association was observed for the "Unsaturated Fats" pattern. Thus a diet rich in fruit and vegetables have a favorable role on pancreatic cancer, while a diet characterized by a high consumption of meat and other animal products, as well as of (refined) cereals and sugars has a detrimental role.

\section{Conclusion}

Pancreatic cancer is the single major neoplasm showing unfavorable trends in most populations over the last decades. The lack of effective screening and the modest improvement in therapies over the last decades, prevention is the only way to reduce pancreatic cancer. Control of tobacco smoking is one of the key measures, since it could avoid $15-25 \%$ of pancreatic cancers in various populations. Many efforts have been made in this regards, although further improvements are possible, particularly in countries were tobacco prevalence is still high and in female populations. Control of overweight/obesity, and consequent type 2 diabetes, is another key measure for the prevention of pancreatic cancer. Obesity is increasing in most areas of the world, thought there are a few exeptions (i.e., France and Italy). Thus, a joined effort, involving the medical community, public health officials, and governments, should be made to fight against overweight/obesity, through adequate campaigns and policies aimed at improving dietary habits and increasing physical activity. Although the evidence of the role of single foods and nutrients on pancreatic cancer is inconsistent, a more healthy diet, rich in plant foods and poor in meat, other animal products, (refined) cereals, and sugars, may favorably affect pancreatic cancer both directly and indirectly, by helping maintaining normal body weight and controlling type 2 diabetes onset. 
AdDendum-Valorization 
Given the unfavorable trends in pancreatic cancer incidence and mortality in most countries over the world over the last decades, in contrast to most other cancer sites, pancreatic cancer is likely to acquire a greater social and economic relevance in the near future.

The findings of this work may have important implications on public health and cancer prevention at a population level. Understanding the etiology of pancreatic cancer provides the best means to develop strategies for prevention, early detection and treatment. Pancreatic cancer remains one of the most lethal neoplasms. Given the lack of effective screening and the modest improvement in therapies over the last decades, prognosis of pancreatic cancer has not dramatically changed for decades, and its 5yeasr relative survival is still less than $5 \%$. Improvement in clinical management could contribute to better survival, but primary prevention and early diagnosis are the only way to reduce the burden of this disease.

Our analysis of recent trends in pancreatic cancer mortality worldwide provides an upto-date picture of the epidemic of pancreatic cancer, indicating priority areas of intervention. These include several central/eastern European countries, which have now the highest rates on a world scale for both sexes.

Several of the analytic epidemiologic results included in the preset work are also of clear relevance on a social and economic level. Thus, the global analysis of the Panc4 on cigarette smoking provides the most accurate estimates of the association between tobacco and pancreatic cancer, with relative risk (RR) consistently above 2 in moderate to heavy smokers. It also quantifies more precisely than previously available the falls in risk after stopping smoking, with an overall leveling of the RR close to the level of never smokers 15 or more years after stopping. It provides therefore additional compelling evidence on the importance of stopping smoking, not only for cardiovascular disease and lung cancer, but also for another major tobacco-related cancer.

Our findings on diabetes and pancreatic cancer also have clear social and economic relevance. The overall 3 -fold excess risk in diabetics indicates that pancreatic cancer is one of the major (neoplastic) health consequences of diabetes. The excess risk is anything larger for diabetes diagnosis at age 40 or more, i.e., most likely type 2 diabetes, which is essentially related to overweight/obesity. Thus, the control of overweight/obesity is an additional instrument to reduce the burden of pancreatic cancer on a population level.

Apart from overweight/obesity, in this work there are indications that selected dietary patterns may favorably influence pancreatic cancer risk. Thus, the use of simple Mediterranean diet scores leads to an over $50 \%$ reduction in the overall pancreatic cancer risk for subjects with the highest adherence to the Mediterranean diet. The Mediterranean countries appear to have relatively low pancreatic cancer rates, indirectly confirming the findings of our investigation. Along this line, we also included 
an analysis of a posteriori defined dietary patterns which confirmed that a diet including animal products and starch is associated to an increased pancreatic cancer risk, while a diet rich in fruit and vegetables can have a beneficial effect on pancreatic cancer. The issue of diet and pancreatic cancer is still open to discussion, but the effect that selected dietary patterns appear to be associated to a substantial change in pancreatic cancer risk indicates the scope for further focusing our attention on dietary factors. If confirmed, our findings on diet and pancreatic cancer have not only a scientific interest, but also practical implications on a population level.

Consequently, as for most epidemiological research, the results of this work have interest not only for the scientific and academic community, but also for the medical environment in terms of providing indication for prevention and for the population at large. The information provided by this work can be translated into important prevention recommendations, thus giving a real contribution to the control of this neoplasm in the population. Indeed, our results have been widely quoted in web sites for the general public, such as those of the Cancer Research UK (http://www.cancerresearchuk.org/cancer-info/cancerstats/) and the American Cancer Society (http://www.cancer.org/research/cancerfactsstatistics/).

In addition, our findings are of interest for politicians, who can find additional reasons to strengthen the policies for tobacco control, as well as measures to limit overweight/obesity on a population level.

The food industry is another potential target of our research, since it may derive indications for supporting the distribution and consumption of favorable foods, while restricting those unfavorable. This potential indication for the food industry may well also have implications on productive and commercial activities.

While several of our results (e.g., those on tobacco) are essentially confirmative although provide more accurate information than previously available on the tobaccopancreatic cancer relationship - other findings are more innovative. These include essentially our results on nutrition and diet. This issue is still open to discussion in terms of confirmation of our results, but suggests innovative approach towards the control of at least part of pancreatic cancer cases on a population level.

Established findings from epidemiologic studies, such as the tobacco and diabetes pancreatic cancer association, call for prompt valorization and urgent implementation of measures for the control of such devastating disease on a population scale. It is simply regrettable that tobacco control has been so slow in all countries and population worldwide and our results on pancreatic cancer constitute an additional reason for urgent implication for effective measure for further control.

Epidemiological results have relevant economic implications but often less obvious market opportunities. Still, some of our findings on diet can provide useful indications towards modifying the food market in a favorable way for pancreatic cancer control. Given the foods and nutrients apparently favorable on pancreatic cancer this should 
not involve additional relevant costs and may well contribute towards the definition of a more convenient and - economically and environmental - sustainable diet. 


\section{ACKNOWLEDGEMENTS}

I would like to thank all the colleagues and friends who participated, directly or indirectly, to my PhD work and have offered their help and support in the preparation of this dissertation.

In particular, many thanks to:

Maurice Zeegers, my supervisor, the person who gave me the great opportunity to do the PhD at the Maastricht University, supervised all my work, and provided me precious suggestions and help.

Carlo La Vecchia, my second supervisor, but, most of all, my mentor and master.

The collaborators of the International Pancreatic Cancer Case-Control Consortium (PanC4) who shared their data and gave me helpful comments for the finalization of the manuscripts for publication: Peter Baghurst, William Bamlet, Paige Bracci, Hendrik Bueno-de-Mesquita, Michelle Cotterchio, Eric Duell, Elizabeth Fontham, Steven Gallinger, Parviz Ghadirian, Yu-Tang Gao, M Hassan, Elizabeth Holly, BT Ji, D Li, Robert Kurtz, Patrick Maisonneuve, Anthony Miller, Rachel Neale, Sara Olson, G Petersen, Harvey Risch, Debra Silverman, J Su, Herbert Yu, Witold Zatonski. A particular thank to Ersilia Lucenteforte (Lella) and Paolo Boffetta.

The the case-control studies network's collaborators: Adriano Decarli, Valeria Edefonti, Monica Ferraroni, Silvia Franceschi, Fabio Levi, Jerry Polesel, Maurizio Montella, Diego Serraino, Renato Talamini, and Antonella Zucchetto.

My Italian colleagues from the Mario Negri Institute who participated at various levels in this work: Paola Bertuccio, Francesca Bravi, Eva Negri, Valentina Rosato, Alessandra Tavani, and Federica Turati.

Hanneke Trines, from Maastrich University, who gave me her kind and efficient help in all the administrative and formal issues related to my $\mathrm{PhD}$.

And, last but not least, Liliane Chatenoud (Lil), Silvano Gallus (Silvo), and Marta Rossi (Martita). My best colleagues and friends! 



\section{About the Author}

Cristina Bosetti was born in Milan, Italy on December, 8 1968. After receiving her Diploma at the high school, she attended the School of Mathematics af the University of Milan, Italy and, in July 1994, she got her Master Degree in Mathematics. In 1999, she received the Post-Graduate Diploma in Pharmacological Research at the Istituto di Ricerche Farmacologiche Mario Negri, Milan, Italy. In March 2011, she started her PhD project on pancreatic cancer risk factors at the School for Nutrition, Toxicology and Metabolism (NUTRIM), at Maastricht University, Maastricht, The Netherlands. She worked as a research fellow at the Laboratory of Mother and Child Health of the Mario Negri Institute during 1996-1997 and at the Laboratory of General Epidemiology during 1998-2005. Since 2005, she is Head of the Unit of Cancer Epidemiology, at the Department of Epidemiology, Mario Negri Institute. Her main fields of interest include the epidemiology of cancer, including the monitoring of cancer mortality in Europe and other selected areas of the world; the conduction and analysis of case-control studies on various common neoplasms and their relationships with diet, nutrition, alcohol, tobacco, reproductive and hormonal factors, diabetes, occupational and environmental exposures; and the conduction of meta- and pooled-analyses on the risk of cancer in relation to various lifestyle and environmental factors. She has been a visiting scientist at the Department of Epidemiology, Harvard School of Public Health, Boston, MA, USA; the Field and Intervention Studies and Lifestyle and Cancer Units, International Agency for Research on Cancer (IARC), Lyon, France; the International Epidemiology Institute (IEI), Rockville, MD, USA; and the Center for Research in Environmental Epidemiology (CREAL), Barcelona, Spain. She participated as PI or collaborators in various research projects supported by the Italian association for Research on Cancer (AIRC), the Italian League Against Cancer (LILT), and the European Commission (EC). Moreover, she is member of the following international consortia: Bladder Cancer Consortium (BLADDER); International Head and Neck Cancer Epidemiology (INHANCE); Pancreatic Cancer Case-Control Consortium (PANC4); and Stomach Cancer Poling Project (STOP).

She authored/co-authored about 300 papers published on peer-reviewed scientific Journals cited in PubMed/MEDLINE (h-index: 45, ISI-Web of Knowledge). 
